\title{
Molecular epidemiology of African swine fever in East Africa
}

\author{
By
}

\section{Baratang Alison Lubisi}

Submitted in partial fulfilment of the requirements for the degree of Master of Science in the Faculty of Natural and Agricultural Sciences

University of Pretoria 


\section{Acknowledgements}

I wish to express my gratitude and appreciation to:

Dr. Armanda Duarte Slager-Bastos for initiating the project, guidance and support

Dr. Rahana Mohan Dwarka for guidance, patience and support

Dr. Otlotleng Comfort Phiri for sharing valuable project related information

The staff of Block G at ARC - OVI - EDD, the memory of Billy Phologane in particular, for laboratory orientation, friendship and support; the late Simon Mokuwe for technical assistance and Erika Kirkbride for assistance with computer graphics

Veterinary officials from Malawi, Zambia, Tanzania, Mozambique and Uganda for providing samples from which some viruses were isolated

My family, friends and colleagues for their encouragement and support

My gratitude extends to the following institutions for financial support:

The Agricultural Research Council (ARC)

The Red Meat Research and Development Trust (RMRDT) 


\title{
Molecular epidemiology of African swine fever in East Africa
}

\author{
By
}

\section{Baratang Alison Lubisi}

\author{
Supervisor Dr. A.D.S Bastos \\ Mammal Research Institute \\ Department of Zoology \& Entomology \\ University of Pretoria \\ Co-supervisor \\ Dr. R.M Dwarka \\ ARC-Onderstepoort Veterinary Institute \\ Degree \\ MSc
}

\section{Summary}

African swine fever (ASF), a hemorrhagic disease of domestic pigs, is caused by a large enveloped icosahedral arbovirus of the Asfivirus genus in the family Asfarviridae. It has a linear, covalently close-ended, double stranded DNA (dsDNA) genome, 170 - $190 \mathrm{kbp}$ in size. Warthogs (Phaecochoerus aethiopicus), bushpigs (Potamochoerus porcus) and soft ticks of the Ornithodoros genus are natural reservoirs of ASF virus (ASFV) in Africa. Serological differentiation between field strains is not possible and as no vaccine is available, control relies on stamping out and strict zoosanitary practices. In order to identify possible sources of virus and prevent further introductions, ASFVs need to be differentiated on genotype basis. Genotyping of East African ASFV isolates was achieved in this study by characterization of the C-terminal region of the major capsid protein gene, $p 72$. Thirteen genotypes were identified among East African sylvatic and domestic hosts. Of significance was the recovery of an apparently geographically restricted homogenous domestic pig cycle in the region, as well as the presence of viruses of the ESACWA genotype, formerly believed to be confined to Europe, South America, the 
Caribbean Islands and West Africa. Due to the conserved nature of the $p 72$ gene, intra-genotypic relationships of viruses recovered from a homogeneous domestic pigassociated lineage, genotype VIII, could not be resolved. In an attempt to address this short-coming, genetic characterization of the Central Variable Region (CVR) within the 9-RL open reading frame (ORF) of the central conserved region of ASFV genome was conducted. Eight groups were resolved, some of which confirmed prolonged periods of circulation of a particular virus type, whilst others confirmed transboundary transmission of the disease. The complexity of ASF epidemiology in East Africa exemplified by the presence of a sylvatic and domestic pig cycle, multiple genotypes within countries and identical genotypes shared by multiple countries, was revealed. The East African ASFV molecular epidemiological database created in this study will be of great assistance to veterinary officials implementing prevention and outbreak control strategies.

Scientific publications emanating directly from this dissertation

LUBISI, B.A., BASTOS, A.D.S., DWARKA, R.M. \& VOSLOO, W., 2005. Molecular Epidemiology of African Swine Fever in East Africa. Archives of Virology (in press).

Scientific publications citing data from this dissertation

1. BASTOS, A.D., PENRITH, M.L., MACOME, F., PINTO, F. \& THOMSON, G.R., 2004. Co-circulation of two genetically distinct viruses in an outbreak of African swine fever in Mozambique: no evidence for individual co-infection. Veterinary Microbiology, 103, 169 - 182.

2. PHOLOGANE, S.B., BASTOS, A.D.S. \& PENRITH, M.-L., 2005. Intra- and inter-genotypic size variation in the central variable region of the $9 R L$ open reading frame of diverse African swine fever viruses. Virus Genes (in press) 
Publication of results in conference proceedings / abstracts

1. LUBISI, B.A., BASTOS, A.D.S., DWARKA, R.M. \& VOSLOO, W., 2003. Genotyping African Swine Fever virus strains from East Africa. Proceedings of the $3^{\text {rd }}$ annual congress of the Southern African Society for veterinary Epidemiology and Preventive Medicine, Pretoria, pp 10 - 14 (Paper).

2. LUBISI, B.A., BASTOS, A.D.S., DWARKA, R.M. \& VOSLOO, W., 2004. Molecular epidemiology of African Swine Fever in East Africa. Proceedings of the $13^{\text {th }}$ biennial congress of the Southern African Society for Microbiolgy, Stellenbosch, Poster 


\section{TABLE OF CONTENTS}

\section{Acknowledgements}

Summary

Scientific presentation of results

TABLE OF CONTENTS

LIST OF FIGURES

LIST OF TABLES

CHAPTER 1: Literature Review

\subsection{INTRODUCTION}

1.2 Etiological agent

1.2.1 Nucleic acid

\subsubsection{Proteins}

1.2.3 Lipids and carbohydrates

\subsubsection{Replication}

$\begin{array}{lll}1.3 & \text { Physico-chemical properties of ASFV } & 6\end{array}$

$\begin{array}{lll}1.4 & \text { Pathogenesis } & 6\end{array}$

$\begin{array}{lll}1.5 & \text { Pig immune response to ASFV infection } & 7\end{array}$

$\begin{array}{lll}\text { 1.5.1 ASFV interactions with porcine macrophages } & 7\end{array}$

1.5.2 Functional integrity of pig lymphocytes and ASFV infection 8

1.5.3 Humoral immunity 9

$\begin{array}{lll}\text { 1.5.4 Cellular response } & 10\end{array}$

$\begin{array}{lll}1.6 & \text { Laboratory diagnosis of ASF } & 11\end{array}$

$\begin{array}{lll}\text { 1.6.1 Virus isolation } & 11\end{array}$

1.6.2 Fluorescent Antibody Test (FAT) 11

1.6.3 Polymerase Chain Reaction (PCR) 12

1.6.4 Enzyme Linked Immunosorbent Assay (ELISA) 12

$\begin{array}{lll}\text { 1.6.5 Immunoblotting } & 12\end{array}$

1.6.6 Indirect Fluorescent Antibody (IFA) test 13

1.6.7 Counter immunoelectrophoresis (immunoelectro - osmophoresis) test 13 
$\begin{array}{lll}1.7 & \text { Socio-economic impact of ASF } & 13\end{array}$

$\begin{array}{lll}1.8 & \text { Control and eradication } & 15\end{array}$

$\begin{array}{lll}1.9 & \text { Epidemiology } & 15\end{array}$

$\begin{array}{lll}1.9 .1 & \text { Sylvatic cycle } & 15\end{array}$

$\begin{array}{lll}1.9 .2 & \text { Pig/Tick cycle } & 16\end{array}$

$\begin{array}{lll}\text { 1.9.3 Domestic pig cycle } & 16\end{array}$

$\begin{array}{lll}\text { 1.9.4 Historical trans-continental spread of ASF } & 17\end{array}$

$\begin{array}{ll}\text { 1.9.5 Current situation in Sub-Saharan Africa } & 17\end{array}$

$\begin{array}{ll}\text { 1.9.5.1 Epidemiology of ASF in West Africa } & 17\end{array}$

$\begin{array}{ll}\text { 1.9.5.2 Epidemiolgy of ASF in East Africa } & 18\end{array}$

$\begin{array}{lll}\text { 1.9.5.2.1 Malawi } & 19\end{array}$

$\begin{array}{lll}\text { 1.9.5.2.2 Zambia } & 20\end{array}$

$\begin{array}{lll}\text { 1.9.5.2.3 Regional considerations } & 21\end{array}$

1.9.6 Molecular characterization of East African ASF viruses 22

1.9.7 Phylogenetic tools and considerations in ASF molecular epidemiology 24

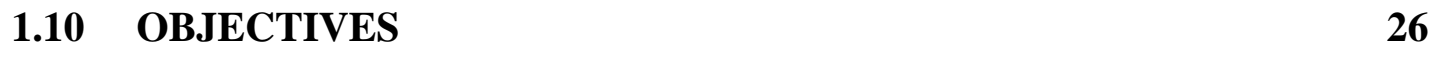

CHAPTER 2: p72 genotyping of African swine fever viruses from

$\begin{array}{ll}\text { East Africa } & 27\end{array}$

$\begin{array}{lll}2.1 & \text { INTRODUCTION } & 28\end{array}$

$\begin{array}{lll}2.2 & \text { MATERIALS AND METHODS } & 30\end{array}$

$\begin{array}{lll}2.2 .1 & \text { Study area and samples } & 30\end{array}$

2.2.2 Pig primary cell culture preparation $\quad 30$

2.2.2.1 Peripheral blood leukocyte culture $\quad 30$

2.2.2.2 Bone marrow cultures 31

2.2.3 Virus isolation $\quad 32$

2.2.4 Extraction of viral DNA 39

2.2.5 Genomic amplification of viral DNA 39

$\begin{array}{lll}\text { 2.2.6 Agarose gel electrophoresis } & 40\end{array}$

2.2.7 Purification of PCR products 40

2.2.8 Nucleotide sequencing and alignment 40

2.2.9 Phylogenetic analysis of the $p 72$ gene 41

2.2.9.1 Neighbor - Joining (NJ) 41

2.2.9.2 Minimum Evolution (ME) 41 


\subsection{RESULTS}

2.3.1 Data statistics

2.3.2 Model test and data statistics

2.3.3 Phylogenetic analysis

2.3.3.1 Minimum Evolution

2.3.3.2 Maximum Likelihood

2.3.3.3 Maximum Parsimony

2.3.3.4 Interpretation of phylogenetic analysis

\subsection{DISCUSSION}

CHAPTER 3: Intra - genotypic resolution of $p 72$ genotype VIII virus relationships by means of central variable region characterization

3.1 INTRODUCTION

\subsection{MATERIALS AND METHODS}

3.2.1 Viruses

3.2.2 DNA extraction and CVR - PCR

3.2.3 Agarose gel electrophoresis and molecular weight estimation

3.2.4 PCR product purification and nucleotide sequencing

3.2.5 Sequence alignment

3.2.6 Phylogenetic analysis of the CVR 66

3.2.6.1 Neighbor - Joining (NJ) 66

3.2.6.2 Maximum Parsimony analysis 66

\subsection{RESULTS}

3.3.1 CVR size and sequence differentiation $\quad 67$

$\begin{array}{lll}\text { 3.3.2 Data statistics from MEGA } & 67\end{array}$

$\begin{array}{lll}\text { 3.3.3 Data and tree analysis in PAUP } & 67\end{array}$

$\begin{array}{lll}\text { 3.3.4 Maximum parsimony tree } & 67\end{array}$

$\begin{array}{lll}\text { 3.3.5 Neighbor - Joining tree } & 73\end{array}$

$\begin{array}{lll}\text { 3.3.6 Interpretation of results } & 74\end{array}$

$\begin{array}{lll}3.4 & \text { DISCUSSION } & 78\end{array}$ 
REFERENCES 


\section{LIST OF FIGURES}

Fig. 1.1 Structure of the ASFV genome. (A) ASFV DNA (BA71V strain). HPL, hairpin loop; TIR, terminal inverted repetition. (B) Predicted secondary structure of the 37 nucleotide-long fast and slow components in the HPLs. (C) Structure of the TIR. The TIR is 2134 nucleotides long and consists of unique Sequences (in white) interspersed with two types of direct repeats (DR) and three sets of direct repeats in tandem (DRT). Copyright (C 1999 Academic Press (Salas, 1999).

Fig. 2.1 Nucleotide sequence alignment showing the variable sites of the 49 unique sequences identified in this study and in previous studies. Dots indicate nucleotide sites identical to that of the master sequence, IC3/96.

Superscript numbers 1 to 4 indicate those viruses included in the studies of Yu et al., 1996, Odemuyiwa et al., 2000, Bastos et al., 2003 and Bastos et al., 2004, respectively.

Fig. 2.2 Minimum evolution tree depicting the 16 ASFV $p 72$ genotypes (labeled I$\mathrm{XVI}$ ) and three main evolutionary lineages (labeled A - C). Bootstrap values $>50 \%$ and obtained by ME method are indicated next to the relevant node, whilst those obtained by $\mathrm{NJ}$ technique are indicated in brackets. All bootstrap values were obtained following 10000

Fig. 2.3 MP tree obtained with successive weighting with the RC showing p72 phylogenetic relationships of the 102 OTU used in this study. Bootstrap support of $>50 \%$ are indicated next to the relevant nodes.

Fig. 2.4 Geographical distribution of the 16 major African Swine Fever virus genotypes identified by partial $p 72$ genotyping.

Fig. 3.1 CVR amino acid sequence alignment of genotype VIII viruses discerned in this study and that of Bastos et al., 2004. Eight unique CVR sequences were recovered, each of which is indicated in a different background color.

Fig. 3.2 Coded CVR amino acid dataset of genotype VIII viruses, used to determine mean character distances in order to infer a NJ tree that takes gap information into account. 
Fig. 3.3 Parsimony tree depicting 6 genotype VIII ASFV sub groups (denoted A - F) discerned by Central Variable Region sequencing. Phylogeny was supported by 249 bootstrap replications.

Fig. 3.4 Neighbor joining tree depicting phylogenetic relationships recovered when using uncoded CVR sequences of genotype VIII viruses from this and previous studies (Bastos et al., 2003 and 2004). Nodal support is based on 10000 bootstrap replications.

Fig 3.5 Neighbor joining tree depicting phylogenetic relationships of $p 72$ genotype VIII viruses using the coded CVR dataset. 1000 bootstrap replications were conducted. 


\section{LIST OF TABLES}

Table 1.1 Summary of ASF disease situation in East African countries

for the past 10 years according to the O.I.E and

Promed - mail records.

Table 2.1 Summary of the African swine fever viruses characterized in this study and those sourced from other studies and included for comparative and phylogenetic purposes.

Table 2.2 ASFV isolates characterized and grouped by Sumption (1992) using Bam HI RFLP.

Table 2.3 Distribution, field presence and intra-genotypic variation of the major African swine fever virus $p 72$ genotypes using data of 141 virus sequences from this study and that from previous studies (Lopez-Otin et al., 1990; Yu et al. 1996; Odemuyiwa et al., 2000; Bastos et al., 2003, 2004).

Table 2.4 Average p-distance (in \%) between ASFV genotypes discerned by $p 72$ nucleotide sequencing.

Table 3.1 ASFV genotypes from Malawi and Zambia discerned by BamHI restriction fragment pattern analysis (Sumption, 1992).

Table 3.2 Classes of ASFV genotypes from Malawi and Zambia obtained by Comparison of restriction fragment lengths (A) and deletion characteristics in the left terminus of the genome

(B) (Sumption, 1992).

Table 3.3 Genotype sets resolved by differences in the mobility of single BamHI restriction fragments (I), and in the mobility of two or less fragments (II) (Sumption, 1992).

Table 3.4 ASFV genotypes and subgenotypes from Malawi and Zambia discerned by RFLP (Sumption 1992).

Table 3.5 CVR product size estimates and amino acid sequence composition of $p 72$ genotype VIII viruses identified in this study and Bastos et al. (2004). The tetrameric repeats reflect tetrameric content only and do not represent the order in which the repeats occur within the CVR of each 
virus isolate

Table 3.6 Results of lengths and fit measures of all parsimony trees in memory (PAUP) deduced from CVR sequences with gaps down weighted by a factor of 0.25 and treated as a $21^{\text {st }}$ amino acid state.

Table 3.7 Comparison of groups/subgroups of isolates common to this study and that of Sumption (1992) resolved by $p 72$ and CVR sequence, and BamHI a and $b / a ' b$ restriction fragment analysis. 


\section{LIST OF ABBREVIATIONS}

aa

Amino Acid

ASF African swine Fever

ASFV African Swine Fever Virus

BP Base Pair

CI Consistency Index

$\mathrm{CO}_{2} \quad$ Carbon Dioxide

ConA Concanavalin A

CSF Classical Swine Fever

CVR Central Variable Region

DR Direct Repeat

DR2 Dominican Republic

DRC Democratic Republic of Congo

DsDNA Double Stranded DNA

E East

EDD Exotic Diseases Division

ELISA Enzyme Linked Immunosorbent Assay

ESACWA Europe South America Caribbean and West Africa

FAO Food and Agriculture Organization

FITC Fluorescein Isothiocyanate

G Gamma Shape Distribution Parameter

HI Homoplasy Index

HPL Hairpin Loop

HTLV Human T Cell Leukemia Virus

I Invariable Sites

IAH Institute for Animal Health

IFA Indirect Fluorescent Antibody

INF Interferon

IP Infected Premises

LTR Long Terminal Repeat

MDV Mareks Disease Virus 
ME Minimum Evolution

MGF Multigene Family

ML Maximum Likelihood

MP Maximum Parsimony

NA Not Applicable

ND Not Done

NJ Neighbor-Joining

NK Not Known

OIE Office International des Epizootis

ORF Open Reading Frame

OTU Operational Taxonomic Unit

OVI Onderstepoort Veterinary Institute

PBMC Pig Bone Marrow Culture

PBS Phosphate Buffered Saline

PCR Polymerase Chain Reaction

PHA Phytohemeagglutinin

RC Rescaled Consistency Index

RFLP Restriction Fragment Length Polymorphism

RI Retention Index

RPM Rotations Per Minute

SLA Swine Lymphocyte Antigen

STR Short Terminal Repeat

SW South West

TBR Tree Bisection Reconnection

TIR Terminal Inverted Repetition

UGA Uganda

VP Virus Protein

VR Variable Region

VSV Vesicular Stomatitis Virus

WRL World Reference Laboratory

ZK Zambian Kwacha 


\section{Chapter 1}

\section{Literature review}

\subsection{INTRODUCTION}

African swine fever (ASF) is a viral disease of domestic pigs responsible for a wide variety of clinical symptoms. In the typical and acute form, the lymphoreticular endothelial cells are affected resulting in widespread hemorrhages. Morbidity and mortality classically approach $100 \%$. In sub-acute cases pigs lose condition and die of pneumonia. Chronically, survivors are characterized by emaciation, stunted growth, hemorrhagic necrosis of the skin overlying bony protuberances, followed by abscessation and deep ulceration (Plowright et al., 1994).

\subsection{Etiological agent}

The etiological agent, African swine fever virus (ASFV), presently constitutes the only member of the genus Asfivirus within the family Asfarviridae (Dixon et al., 2000). The mature virion consists of a nucleoprotein core structure, $70-100 \mathrm{~nm}$ in diameter, surrounded by an icosahedral capsid, 172 - $191 \mathrm{~nm}$ in diameter, and a lipid containing envelope (Dixon et al., 2000).

\subsubsection{Nucleic acid}

ASFV genome is a linear, covalently close-ended, double-stranded DNA (dsDNA) molecule, 170 - $190 \mathrm{kbp}$ in size (Blasco et al., 1989). The genome has a central conserved region approximately $125 \mathrm{~kb}$ long, and highly variable left and right end sequences, characterized by inverted complementary tandem repeats, of about $35 \mathrm{~kb}$ and 
15 kb respectively (Wesley and Tuthill, 1984; Gonzalez et al., 1986; Blasco et al., 1989 a, b). Genes are encoded on both DNA strands and are generally closely spaced. Short tandem repeat arrays are observed at several intergenic locations (Fig.1.1). This nucleic acid molecule can encode 150 to 200 proteins (Salas, 1999). The complete nucleotide analysis of the Spanish isolate BA71V, whose genome structure is depicted in Fig.1.1, has a genome 170,101 nucleotides in length and contains a G-C content of $38.95 \%$ (Yanez et al., 1995).

\subsubsection{Proteins}

Sequence analysis of the entire genome of the Spanish isolate, BA71V (Yáñez et al., $1995)$ revealed that this isolate contains 151 major open reading frames (ORF). There are many genes that code for proteins that are required for virus replication in cells, and these proteins are suspected to be at least 90 in quantity (Salas, 1999). More than 100 virusinduced proteins have been detected in infected Vero cells (Salas, 1999). The complex virus particle is formed by proteins in excess of 50, including those with structural functions and enzymes packaged for use early in infection. Genes encoding 15 of the structural proteins have been characterized, with two of these encoding polyproteins that are processed into four and two virion proteins each (Simon-Mateo et al., 1993,1997; Andres et al., 2001).

Approximately 54 structural proteins of molecular weights ranging from 10000 to 150 000 have been resolved by two-dimensional gel electrophoresis analysis (Salas, 1999). Virus attachment proteins p12 and p24 have been identified in the external region of the extra-cellular virions, and proteins p150, p37, p34 and p14, products of polyprotein pp220, are located in the core shell (Salas, 1999). The capsid protein, p72, is located on the surface of unenveloped intracellular virions. 

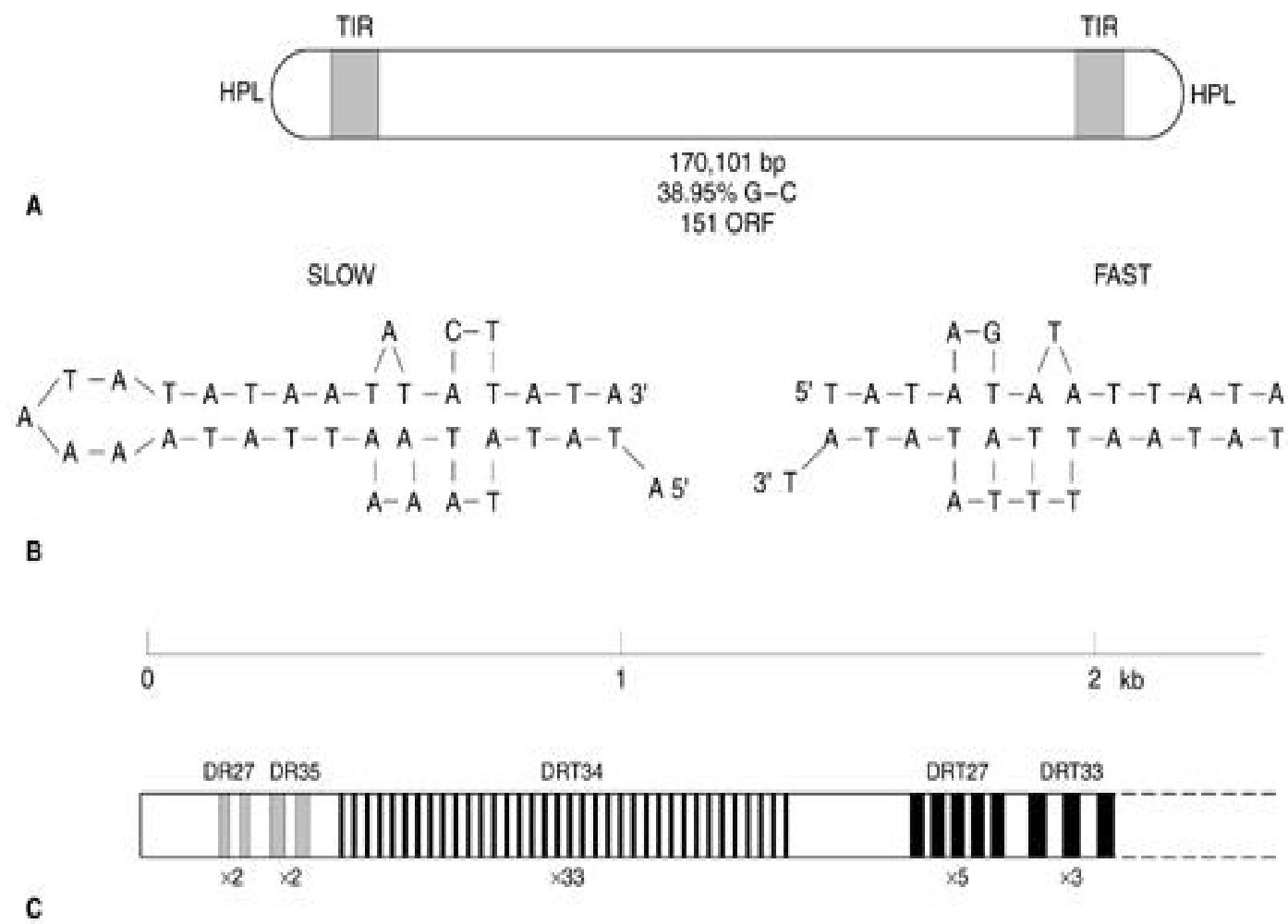

Fig 1.1 Structure of the ASFV genome. (A) ASFV DNA (BA71V strain). HPL, hairpin loop; TIR, terminal inverted repetition. (B) Predicted secondary structure of the 37 nucleotide-long fast and slow components in the HPLs. (C) Structure of the TIR. The TIR is 2134 nucleotides long and consists of unique sequences (in white) interspersed with two types of direct repeats (DR) and three sets of direct repeats in tandem (DRT). Copyright (C 1999 Academic Press (Salas, 1999).

A DNA dependent RNA polymerase and other proteins involved in activities such as polyadenylation, methylation and capping of RNA are contained in the ASFV particles (Salas, 1999; Dixon et al., 2000). A protein kinase, two nucleotide triphosphate phosphohydrolases, an acid phoshatase and a deoxyribonuclease active on singlestranded DNA, are present in the virions (Salas, 1999; Dixon et al., 2004). A further four enzymes are encoded by the genome, and these may play roles in regulating virus replication or modulating host cell function (Salas, 1999). 
A large percentage of the genome encodes multigene families (MGF), which occur at the left and right termini of the genome, and render different ASFV isolates highly variable genetically (Almendral et al., 1990; De La Vega et al., 1990; González, et al., 1990; Rodriguez et al., 1994; Yozawa et al., 1994; Zsak et al., 2001). Five MGF have been identified thus far. Proteins encoded by MGF 530 and 360 have been proven to specify macrophage host ranges and promote survival of infected cells (Tulman \& Rock, 2001; Zsak et al., 2001). These proteins also interfere with host interferon response (Afonso et al., 2004). In the tick Ornithodoros porcinus porcinus, MGF360 genes are significant tick host range determinants and they are required for efficient virus replication and generalization of infection (Burrage et al., 2004).

The early expressed 92 - 156 amino acid (aa) long UK protein with four to ten tandem repeats, determines the virulence of the strain (Zsak et al., 1996,1998). Also thought to be associated with virulence is the NL gene, which is located next to the UK gene in the right variable region of the genome (Zsak et al., 1996,1998; He et al., 1998).

The remaining genes encode proteins that play an important role in virus survival and transmission between hosts (Dixon et al., 1994; Yanez et al., 1995; Tulman and Rock, 2001). Of these, a few have been identified as role players in the evasion of the host defense mechanism. Viral protein A238L (5EL) inhibits host $\mathrm{NF}_{\mathrm{k}} \mathrm{B}$ and calcineurin (Powell et al., 1996; Miskin et al., 1998; Revilla et al., 1998). The transcriptional activation in infected macrophages of genes dependent on $\mathrm{NF}_{\mathrm{k}} \mathrm{B}$ is inhibited as a result, and so is the activation of the nuclear factor of activated T cells (NFAT) transcription factor family regulated by calcineurin. Virus protein 5EL evades and modulates or interferes with the host immune response, including suppression of immune responses in vitro (Powell et al., 1996; Miskin et al., 1998). The 8DR protein, also called CD2v, is a virus adhesion protein involved in virus spread and impairment of lymphocyte function (Borca et al., 1998; Tulman and Rock, 2001; Dixon et al., 2004). Two anti-apoptosis proteins are encoded by the ASFV genome, and these ensure progeny virus production in infected cells (Afonso et al., 1996; Revilla et al., 1997; Nogal et al., 2001). Host protein 
synthesis shut-off is inhibited by ASF114L protein that shares some sequence similarity with the Herpes simplex virus-encoded neurovirulence factor ICP34.5 (He et al., 1997, 1998; Goatley et al., 1999). Protein 4jR and the ASFV ubiquitin conjugating (UBCv) enzyme are thought to modulate host gene transcription (Bulimo et al., 2000; Goatley et al., 2002).

However, the purpose of approximately $50 \%$ of the genes that are found in the ASFV genome remains unknown (Tulman and Rock, 2001). The quest for factors and mechanisms by which the virus interacts with its hosts, especially those determining virulence and host range, nevertheless continues.

\subsubsection{Lipids and carbohydrates}

The envelope contains lipids, including the glycolipids, and carbohydrates have only been identified in the latter molecules (Dixon et al., 2000).

\subsubsection{Replication}

Entry into the host cell is by receptor-mediated endocytosis (Alcami et al., 1989; Bernades et al., 1995). Virus proteins p12, p30, p54 and p72 play important roles in the binding and entry processes (Borca et al., 1994, Gomez-Puertas et al., 1996, 1998). A mechanism involving fusion of the virus envelope and that of the endocytic pits is responsible for virus release into the cytoplasm (Valdeira et al., 1998). DNA first replicates in the nucleus of infected cells and continues in the cytoplasm at a later stage (Garcia-Beato et al., 1992; Rojo et al., 1999). Pulse chase experiments have demonstrated that these DNA fragments are precursors of the mature cross-linked viral DNA (Rojo et al., 1999). The synthesis of mRNA and its processing ensues in the cell cytoplasm, a process mediated by enzymes contained in the viral core (Dixon et al., 2004). The transcript is polyadenylated at the $3^{\prime}$ end while the $5^{\prime}$ terminal is capped, and encodes enzymes involved in mRNA transcription and DNA replication (Dixon et al., 1994, 2000). Peak DNA replication is achieved 8 hours post infection, a period within 
which the head to head concatameric forms which are presumably the replicative intermediate forms are found in the cells. Self-priming mechanisms may mediate the proceeding DNA replication process. Late genes are expressed after the onset of DNA replication and synthesis of some early genes, continues throughout the infection. Post translational modification of some virus proteins in the form of proteolytic cleavage, phosphorylation, glycosylation and myristylation, takes place (Yáñez et al., 1995). Productive infection requires the cell nucleus, while virus morphogenesis occurs in the fibrin and membrane rich perinuclear area, often surrounded by Golgi apparatus and numerous ribosomes (Garcia-Beato et al., 1992; Rojo et al., 1999). Virus is released by cell destruction or budding through the plasma membrane (Dematos and Carvalho, 1993).

\subsection{Physico-chemical properties of ASFV}

African swine fever virions have a buoyant density of $1.095 \mathrm{~g} / \mathrm{cm}^{3}$ in Percoll and 1.19 $1.24 \mathrm{~g} / \mathrm{cm}^{3}$ in $\mathrm{CsCl}$. $\mathrm{S}_{20 \mathrm{~W}}$ is approximately 3500 . The virions are sensitive to irradiation, chemicals like ether, chloroform and deoxycholate, and infectivity is destroyed by disinfectants such as $1 \%$ formaldehyde in 6 days, $2 \% \mathrm{NaOH}$ in 1 day and paraphenylphenolic substances which are very effective (Dixon et al., 2000). Heat inactivation is possible at $60^{\circ} \mathrm{C}$ within 30 minutes, but the virus may survive a number of years at $2^{0} \mathrm{C}$ or $4^{0} \mathrm{C}$. ASF viruses have been shown to be resilient to desiccation and putrefaction, and some survive at $\mathrm{pH} 4$ or 13 and high relative humidity (Plowright et al., 1967; Donaldson and Ferris, 1976; Dixon et al., 2000).

\subsection{Pathogenesis}

Following oral or respiratory infections of domestic pigs with ASFV, the virus penetrates the tonsils or the dorsal pharyngeal mucosa, proceeds to the mandibular or retropharyngeal lymphnodes, and disseminates through viraemia (Plowright et al., 1994). The virus has a predilection for antigen presenting phagocytic cells of the 
lymphoreticular system, where it causes cytolysis and hyperplastic changes in acute and subacute cases, respectively (Boulanger et al., 1966). It is also associated with $90 \%$ of the erythrocytes, and lymphopenia is observed (Plowright et al., 1968). Hemorrhage, oedema and effusions are preceded by thrombocytopaenia, impaired vascular integrity, coagulopathy and dysfibrinogenaemia (Moulton et al., 1975; Edwards and Dodds, 1985; Anderson et al., 1987). Deposition of immune complexes in kidneys, lungs and skin is observed in chronically infected pigs (Slauson and Sanchez Vizcaino, 1981). Wildlife vertebrate reservoirs display a more subtle viral course and the infection remains subclinical (Anderson et al., 1998; Oura et al., 1998). In Ornithodoros ticks, initial ASFV replication occurs in phagocytic digestive cells of the midgut epithelium, followed by undifferentiated midgut cells (Kleiboeker et al., 1998, 1999). Replication in the midgut epithelium is essential for a generalised and persistent infection following a per os infection (Kleiboeker et al., 1999). Dissemination of virus infection from midgut to other tick tissues occurs through the basal lamina of the midgut into the hemocoel. Secondary sites of virus replication include hemocytes (type I and II), connective tissue, coxal gland, salivary gland, and reproductive tissue. Significant mortalities have been observed in ticks that fed on infected blood (Endris et al., 1992 a, b; Rennie et al., 2000), while low mortalities until after the first oviposition have also been documented (Kleiboeker and Scoles, 2001).

\subsection{Pig immune response to ASFV infection}

\subsubsection{ASFV interactions with porcine macrophages}

The most crucial event of ASFV infection is the infection and lysis of the cells of the mononuclear - phagocytic system independent of isolate virulence (Wadley and Wilkinson, 1977; Martins et al., 1988). Macrophage phagocytic and chemotactic functions are substantially decreased as a result (Martins et al., 1988). Splenic swine lymphocyte antigen (SLA) expression is differentially modulated even though GonzalezJuarrero et al. (1992) could not find a clear-cut relationship between modulation of SLA 
class I and class II by isolates of different virulence. Prostaglandin $\mathrm{PGE}_{2}$, known for its immunosuppressive effect, was shown to be released from alveolar macrophages, quantities of which seemingly correlated positively with the virulence of the virus (Anderson et al., 1987). Some isolates were proven to cause the depression of lectin driven lymphocyte proliferation and $\operatorname{IgG}$ secretion, in an experiment utilizing crude supernatants of pig bone marrow cultures (PBMC) infected with the attenuated ASFV (Spain E77) and a multiple passaged Ugandan isolate (Wadley, 1982). It was however, proven that lectin driven lymphocyte proliferation and IgG secretion depression was not virulence dependent but caused by soluble inhibitors of 40 to $80 \mathrm{kDa}$ (Gonzalez et al., 1990). Clearly, basic macrophage function related to non-specific protective mechanisms and antigen presenting capacities are seriously damaged and when coupled with the production of immune mediators, the course of the host immune response during ASFV infection is strongly influenced.

\subsubsection{Functional integrity of pig lymphocytes and ASFV infection}

Many studies on the functional integrity of the swine immune system during infection with ASFV were based on measurement of peripheral blood leukocyte cultures, $\mathrm{T}$ and $\mathrm{B}$ lymphocyte quantification, and lymphoproliferative responses to mitogens and virus or viral antigens.

While some investigators noticed negligible differences in blood components of swine innoculated with different ASFV isolates (Knudsen et al., 1987 b; Genovesi et al., 1988), some observed lymphocytopenia early post infection. The latter was attributed to Blymphocytes by Wadley and Wilkinson (1980) or to a decrease in T-lymphocytes by Sanchez-Vizcaino et al. (1981).

Conflicting results have been obtained from studies of lymphocyte function of ASFV infected pigs based on proliferation responses to mitogens, concanavalin A (Con A), phytohemagglutinin (PHA) and pokeweed mitogen (PWM). Some authors recorded a correlation between lymphocytopenia and a decrease in lymphoproliferative response 
(Wadley and Wilkinson, 1980; Sanchez-Vizcaino et al., 1981), but others observed a strong decrease in lymphoproloferative response when one virus isolate was used, and a clear enhancement of response when the pigs were inoculated with different strains (Martins and Leitão, 1994).

In vitro studies of porcine lymphocyte response to the same mitogens as above also yielded contradicting results. Wadley (1982) observed a marked decrease in response to Con A and PHW after lymphocyte incubation with attenuated virus strains, and an enhanced response with virulent isolates. Knudsen et al. (1987 b) noticed an unimpaired lymphoproliferative response to PHA, Con A and PWM when inoculated with a wide dosage range of a moderately virulent strain. Gonzalez et al. (1990) have on the contrary, recorded strong inhibition of PHA responses by eleven virus isolates at low dosages independent of virulence.

Despite ASFV ability to modulate the host immune response, pigs surviving experimental inoculations often resist challenge with homologous strains irrespective of their virulence (Coggins et al., 1968; DeBoer et al., 1969; Hamdy and Dardiri, 1984).

\subsubsection{Humoral immunity}

The fact that ASFV infects, replicates in and destroys cells of the mononuclear phagocytic system irrespective of their virulence (Wardley and Wilkinson, 1977) has intrigued scientists for a number of years. Initially scientists could not demonstrate neutralizing antibodies against ASFV during infection (Wardley et al., 1983), but subsequently found that there were some protective measures taking place in the host immune system. These were antibodies which reduced virus multiplication, delayed the onset of clinical signs, and allowed better survival rates (Wadley and Wilkinson, 1985; Wadley et al., 1987).

In vitro studies have shown that anti ASFV antibodies reduce viral infectivity and viral yields from porcine macrophages (Malmquist, 1963; Knudsen et al., 1987a) and mediate 
lysis of infected fibroblast cells by neutrophils and by the classical pathway of complement activation (Norley and Wadley, 1982, 1983a). These observations assist in demonstrating the protective role of anti-ASFV antibodies in infected swine.

Neutralizing antibodies against viral proteins p72, p54, p30 and p12 have recently being confirmed (Zsak et al., 1993; Gómez-Puertas et al., 1996). However, Neilan et al. (2004) showed that neutralizing antibodies to these ASFV proteins are not sufficient for antibody-mediated protection. Previous studies have also indicated that even though there are some neutralizing antibody responses to ASFV infection, these tend to appear on days $10-12$ and 12 - 14 post infection, a time when a pig would have already died from a virulent strain of ASFV (Wardley et al., 1987).

\subsubsection{Cellular response}

Experimental models formed the basis of investigating potential cellular effector mechanisms involved in swine protection against African swine fever. Scientist found results which strongly suggested a strong correlation between activation of Natural killer (NK) cell activity and the virulence of the strain (Mendoza et al., 1991; Martins and Leitao, 1994). These cells have not been shown to kill ASFV infected macrophages but the interferon (IFN) they produce may be significant since in vitro studies have shown inhibition of ASFV replication in monocyte/macrophage and cell lines by IFN- $\gamma$ and IFN$\alpha$ (Esparza et al., 1988; Paez et al., 1990).

Cellular responses to infection have yielded controversial results which led scientist to believe that the virulence of a strain may be the determining factor in that regard, even though cytotoxic T-lymphocytes could be playing a significant role in the initial stages of infection (Wardley et al., 1987; Martins and Leitao, 1994). It is due to this poor understanding of the host - virus immune interaction that a vaccine against the disease is presently unavailable (Tulman and Rock, 2001). 


\subsection{Laboratory diagnosis of ASF}

Field diagnosis of ASF should be confirmed in the laboratory since the displayed clinicopathological signs are not pathognomonic for ASF. The recommended diagnostic techniques are focused on antigen, antibody and genomic DNA detection, and on virus isolation from clinical samples. Where possible, it is highly recommended that antigen detection tests be conducted simultaneously with antibody detection in serum or tissue fluids to avoid a delay in detecting infection by a virus of low virulence (http://www.oie.int/animalhealthcode).

\subsubsection{Virus isolation}

Malmquist and Hay (1960) described the hemadsorption and cytopathic effects of ASFV on swine bone marrow and leukocyte (buffy coat) cultures, properties distinguishing this virus from that causing Classical Swine Fever (CSF). Primary swine leucocyte and bone marrow cultures have since been used in the diagnosis of ASF. Attempts to grow the virus on continuous cell lines, especially on cells other than the reticulo-endothelial system resulted in the virus losing some of its characteristics (Malmquist, 1962). Recently, however, Weingartl et al. (2002) described a continuous cell line of swine alveolar macrophages on which ASFV was successfully grown and isolated without any adverse effects on the virus. The success of this cell line after validation trials would provide a cheaper and more convenient method of ASFV isolation.

\subsubsection{Fluorescent Antibody Test (FAT)}

A positive ASFV diagnosis can be made by virus/antigen detection in the acute stage or antibody demonstration in the latent or chronic stages of the disease. The former test could be preceded by virus growth on primary leukocyte cultures to concentrate the antigen more thus ensuring the success of the test (Botija, 1970). Impression smears or cryostat sections of tissues or leukocyte cultures of suspected ASFV infected animals are fixed on glass slides and stained with fluorescein isothiocyanate (FITC) conjugated anti- 
ASFV immunoglobulins (Bool et al., 1970). An ultraviolet microscope with barrier and exciter filters is used to view slides.

\subsubsection{Polymerase Chain Reaction (PCR)}

Polymerase chain reaction (PCR) is a rapid, highly sensitive and specific technique that employs oligonucleotide primers in a series of thermally controlled cycles to amplify a highly conserved region of the ASFV genome (Steiger et al., 1992). The test is useful where work on live viruses is undesirable or prohibited, samples have undergone putrefaction, or the virus has been chemically disinfected prior to testing. Through this technique, ASFV DNA can be detected and characterized without the need to isolate the virus (Steiger et al., 1992; Agüero et al., 2003; Bastos et al., 2003).

\subsubsection{Enzyme Linked Immunosorbent Assay (ELISA)}

An ELISA for the detection of antibodies against ASFV in convalescing swine sera using non-infectious soluble antigen was described (Hamdy and Dardiri, 1979). It combines the specificity of antibodies with the sensitivity of a simple photometric enzyme assay system by conjugating the antibodies with an enzyme. Results could be read visually or by spectrophotometer at $405 \mathrm{~nm}$ wavelength. The test was found to be extremely sensitive, and detected $5 \mathrm{ng}$ of antibodies to soluble antigen.

\subsubsection{Immunoblotting}

Immunoblotting combines the resolution of gel electrophoresis (SDS-PAGE) with the specificity of immunochemical detection. The technique is especially useful in identifying a specific ASFV antigen in a complex mixture of antigens (Oviedo et al., 1997; Barderas et al., 2000). This diagnostic method is as sensitive as ELISA but has the following additional advantages:

1. Detergents do not affect adsorption of proteins on membranes

2.Fewer samples are required 
3.Both antigenic and electrophoretic properties of the antigen are characterized simultaneously

4. Immobilized antigens of interest can be excised and used in inoculation of animals to raise monospecific antibodies

\subsubsection{Indirect Fluorescent Antibody (IFA) test}

ASFV infected cells are smeared and fixed on glass slides, test sera added onto the slide in various dilutions and a fluorescent antibody or protein A conjugate added finally to detect the reaction under an ultraviolet light microscope (Bool et al., 1970). The technique is advocated for use as a confirmatory test in sera from ASF free zones for which ELISA has yielded positive results (http://www.oie.int).

\subsubsection{Counter immunoelectrophoresis (immunoelectro-osmophoresis) test}

This test employs electrophoresis equipment with slide frames and a gel cutter, and a 500 -volt constant current power supply. It has a low sensitivity and is thus recommended for screening large groups of pigs, not individual sera (http://www.oie.int). Test antiserum and positive antigen are loaded on a glass slide in a gel on one side, while positive and negative control antisera and antigens are loaded on the other side as well. The samples are electrophoresed and the slides are examined under an indirect light source for specific precipitation lines after staining and destaining procedures (Pan et al., 1972).

\subsection{Socio-economic impact of ASF}

The catastrophic effect of this disease on pig production, both at household and commercial levels in Africa poses serious socio-economic problems and threatens food security. These are best described in a report on the Cameroonian experience by NanaNukechap and Gibbs (1985). Following the 1982 outbreak in the western Cameroonian 
province where $63 \%$ of the country's 1.1 million total pig population occurs, 3, 762 pig farmers reported pig mortalities. The 54, 432 pigs reported dead were believed to be an underestimation as farmers failed to disclose their losses. A loss of $\$ 36,000$ in accumulated stocks was declared by one farmer, while feed manufacturers estimated their losses at \$260, 000 in lost sales. Many farm workers lost their jobs as a result of the continued deaths that forced employers to reduce the labor force. Socially, pig eating at ceremonies was completely abandoned. Another West African country to suffer economically was Cote d'Ivoire, where the 1996 epizootic resulted in the death of 135,000 pigs in Abidjan (el Hicheri et al., 1998). This was equivalent to $29 \%$ of the pig population, of which $80 \%$ came from the commercial sector.

In East Africa, the 1989 outbreak in an ASF endemic Zambia involving a commercial property cost 421,238 Zambian Kwacha (ZK) in control measures. It is estimated that the cost would have been at least ZK14, 917,500 (US\$1,415,323) if the control measures had not been effected (Samui et al., 1996). The ASF outbreak in Malawi which spanned from 1989 to 1990 , claimed 31,000 pigs $(45 \%$ ) from a population of 70,000, either from mortalities or stamping out (Edelsten and Chinombo, 1995). In affected villages this accounted for $83 \%$ of the pigs present.

For countries outside the African continent, ASF control and eradication also resulted in severe economic loses. The cost of ASF eradication in Malta and the Dominican Republic was a $100 \%$ depopulation of their pigs, while 400000 pigs in Cuba were lost before elimination of the disease (Plowright et al., 1994). The Iberian Peninsula spent approximately $\$ 100$ (US) million/year to control both endemic ASF and new outbreaks (Wardley et al., 1987). In a model designed for the assessment of the economic impact an ASF outbreak would have in the U.S, Rendleman and Spinelli (1999) showed that such an incident would cost $\$ 4500$ billion both in trade embargoes and eradication. 


\subsection{Control and eradication}

Current control measures are based on rigorous prevention of contact between domestic pigs and the free living reservoirs, quarantine of affected areas, stamping out the ill and in-contact pigs, prevention of movement of pigs and pig products through the infected areas and the application of chemical disinfectants in infected swine habitats (Plowright et al., 1994). Europe successfully eradicated the disease in 1990, with the exception of Sardinia, (there was also an outbreak in Portugal in 1999) the only ASF endemic place outside Africa (Wardley et al., 1987; Dixon et al., 1999).

Identification of in-contact pigs in Spain does not only rely on the history and visual presence of ticks but a more reliable serological assay technique for antibodies (ELISA) against Ornithodorus erraticus salivary gland antigens (Canals et al., 1990) is employed. This test has been validated for use under field conditions. Although the implemented measures are effective in curbing the spread of the disease in an outbreak, a detailed epidemiological investigation remains crucial for tracing the possible origin of the disease and preventing further introductions.

\subsection{Epidemiology}

\subsubsection{Sylvatic cycle}

ASF is indigenous to the African continent where it is thought to occur in one of three possible cycles: (i) an ancient sylvatic cycle, (ii) a pig/tick cycle and (iii) a more recently described domestic pig cycle (Penrith et al., 2004). In countries south of the Sahara the sylvatic cycle seems to play an important role, with warthogs (Phaecchoerus aethiopicus), bushpigs (Potamochoerus porcus), and possibly giant forest hogs (Hylochoerus meinerzhageni) acting as natural subclinical vertebrate reservoirs of ASFV (Plowright et al., 1969; Pini and Hurter, 1975; Thomson, 1985). Argasid ticks of the Ornithodoros moubata complex are invertebrate hosts and vectors, mechanically 
transmitting the virus to domestic and wild suids during feeding (Plowright et al., 1969;

Pini and Hurter, 1975; Thomson, 1985). Efficient infection and primary replication occurs in phagocytic and undifferentiated cells of the midgut epithelium, whereas secondary replication and generalization occurs in hemocytes, coxal and salivary glands, reproductive tissues, with viral persistence occurring in all tissues. Midgut replication and escape of ASFV is extremely important for long-term maintenance of infection in ticks (Kleiboeker et al., 1999). The virus is transsexually, transovarially and transtadially transmitted in these ticks, thereby ensuring that the virus can be maintained within the tick population even in the absence of an infected blood meal (Plowright et al., 1970; Plowright et al., 1974).

\subsubsection{Pig/tick cycle}

This cycle involves domestic pigs and ticks of the Ornithodoros genus that inhabit pig pens (kholas) and crevices in huts inhabited by human beings. The West-Central Malawian situation best describes this particular cycle (Haresnape et al., 1988; Haresnape and Wilkinson, 1989).

\subsubsection{Domestic pig cycle}

The present domestic pig cycle is thought to have resulted from viruses of reduced virulence that evolved in a few domestic pigs after surviving acute forms of ASF (Plowright et al., 1994). Inapparent to subclinical infections have been recorded in this cycle (Haresnape, 1984; Costa, 1990; Plowright et al., 1994; Allaway et al., 1995; Eldelstein and Chinombo, 1995). Pigs infected with such virus can pass veterinary inspections and transmit ASFV if slaughtered and fed to their naïve counterparts (Wardley et al., 1987). 


\subsubsection{Historical trans-continental spread of ASF}

Movement of pigs and pig products between countries, and from infected to non-infected areas within countries is suspected to be responsible for transmission of the disease. The virus was introduced into countries outside the African continent via the feeding of ASF infected meat products to pigs, as is believed to have been the case with the first European ASF outbreak affecting Portugal in 1957 (Manso-Ribeiro et al., 1958). ASF spread repeatedly in Europe, from the Iberian Peninsula by illicit movements of infected pigs and pig products to invade France (1964, 1967, 1977), Madeira (1965, 1974, 1976), Italy (1967, 1980), Malta (1978), Sardinia (1978), Belgium (1985) and Holland (1986). Outside Europe, Cuba was infected, probably from Europe, in 1971. In 1977 - 1978 the disease resurfaced in the Iberian Peninsula, followed by its appearance in Brazil and the Dominican Republic in 1978, Haiti in 1979 and again in Cuba in 1980 (Plowright et al., 1994). The source of infection of the 1982 epidemic in Cameroon is suspected to have been Europe or the Americas, since the Cameroon, Dominican Republic and Haiti isolates were found to be genetically indistinguishable (Wesley and Tuthill, 1984).

In addition to Ornithodoros porcinus found in Africa, a number of African, North American, Central American, Caribbean and European ticks of the Ornithodoros genus have been shown to be potential vectors of ASFV (Groocock et al., 1980; Mellor and Wilkinson, 1985; Endris et al., 1991,1992; Hays, 1996; Kleiboeker and Scoles, 2001; Boinas et al., 2004). The fact that these ticks not only act as mechanical vectors but can support ASFV growth, maintain and transmit the infection to naïve domestic pig populations, makes ASF a threat to pigs worldwide.

\subsubsection{Current situation in sub-Saharan Africa}

\subsubsection{Epidemiology of ASF in West Africa}

Involvement of a sylvatic cycle in the epidemiology of ASF in West Africa is not evident, despite the distribution of warthogs throughout the Savanna belt from Cameroon to 
Senegal and the presence of tampans (Ornithodoros erraticus) in Senegal, north of the ASF endemic area (Penrith et al., 2000). Ticks of the Ornithodoros genus are absent in Nigeria, and attempts to isolate ASFV from the free-ranging Nigerian dwarf pigs and warthogs have failed (Scott and Hill, 1966). The western province of Cameroon and the north and south-western parts of the country, where $70 \%$ of the country's pig population is reared are the regions most frequently affected by ASF outbreaks. Ornithodoros porcinus and warthogs do not however occur in these regions (Nana - Nukechap and Gibbs, 1985; Ekue and Wilkinson, 1990). It is therefore deduced that pig-to-pig infections (pig cycle) or the feeding of contaminated pork products are the mechanism involved in the outbreaks.

\subsubsection{Epidemiology of ASF in East Africa}

Information on the history and current ASF status in the East African countries under study is incomplete. Even though the O.I.E lists the disease situation in these countries from 1990 to date in its Handistatus (that can be viewed on the website http://www.oie.int), very few publications have focused on ASF in Burundi, DRC, Mozambique, Tanzania and Uganda (Edelstein, 1989; Edelstein et al., 1991; Jere, 1991). Incidents of disease in Kenya following Montgomery's (1921) study are limited and the current situation is insufficiently articulated. In Malawi and Zambia nevertheless, extensive studies have been conducted and the course of disease from as early as 1912 to date, has been reported.

Two thirds of the entire pig population is concentrated in the central region in Malawi, and in the eastern part in Zambia, with the remaining third found in the Southern part in both countries (Sumption, 1992). Pig meat production constitutes $7 \%$ in Zambia and 30 $\%$ in Malawi (Wilkinson et al., 1988; F.A.O, 1988). ASF outbreaks have been reported on regular basis in the neighbouring districts of Zambia (Northern Rhodesia) and Malawi, in Chipata and Mchinji (Wilkinson et al., 1988; Wilkinson, 1989). The latter area was declared enzootic for ASF as early as 1933 (Turnbull, 1933). 


\subsection{Malawi}

In the 1980s, the Mchinji area experienced a considerable number of outbreaks which were confirmed in the Central Veterinary Laboratory, Lilongwe, by Haresnape and colleagues (Haresnape, 1984; Haresnape et al., 1985, 1987). Wild pigs were implicated in the first report of the disease in East Africa, and these wild suids, especially warthogs, and Ornithodoros ticks, are present, in many of the localities where ASF outbreaks occur in the region. ASFV specific antibodies and viraemias were detected, and virus was isolated from some of these reservoirs, confirming the active roles they played in outbreaks (Montgomery, 1921; Plowright, 1977; Haresnape, 1984; Thomson, 1985; Dixon and Wilkinson, 1988; Haresnape et al., 1988; Wilkinson et al., 1988). Despite the presence of sylvatic reservoirs in East Africa, the location of ASF outbreaks, distribution of warthogs and to a lesser extent bushpigs, dispersal of argasid ticks in warthog burrows and pig sties, and the isolation of ASFV from argasid ticks inhabiting these burrows seldom have a positive correlation (Plowright, 1977; Allaway et al., 1995). The latter prompted researches to suggest that there could also be a pig-to-pig cycle playing a role in some parts of the region, especially in Malawi.

To corroborate the presence of a domestic pig cycle, investigations into the extent of ASF outbreaks in Malawi were carried out and revealed a wider distribution than was previously documented. The role played by wild pigs and Ornithodoros ticks could not be established (Haresnape, 1984). ASF disease surveys in the same country also identified enzootic localities in which the sylvatic hosts were irrelevant (Haresnape et al., 1985, 1987). An ASF enzootic situation in domestic pigs was thus reported for the first time in Mchinji, and the enzootic area was later extended to include Ntcheu and Dedza with the discovery of seropositive ASF survivor pigs at least nine months after the outbreaks.

The disease spread to the southern region of Malawi decimating $86 \%$ of the entire pig population in the region, with damages estimated at $£ 500000$ (Sumption, 1992). Matson (1960) estimated that 12000 of the 19000 pigs died from the 1959 - 1960 outbreaks in the 
same area. Serological studies of pigs for antibody against ASFV in two areas of southern Malawi correspondingly suggested circulation and transmission of ASFV among domestic pigs only (Allaway et al., 1995). The disease did not persist in surviving pigs post the outbreaks.

Studies of ASFV infected Ornithodoros ticks collected from villages in the ASF enzootic area of Malawi following outbreaks of the disease in domestic pigs, deduced two important facts: 1) The circulation of virus between pigs and ticks. 2) The possibility of O. porcinus becoming an ASFV reservoir and initiating new outbreaks by transmitting the virus to susceptible pigs during feeding (Haresnape et al., 1988; Haresnape and Wilkinson, 1989). These findings thus supported the existence of a pig/tick cycle in that country.

\subsection{Zambia}

ASF has been described in the Eastern Province of Zambia since 1912 and the first confirmation of the disease was made in this country in 1953, preceding that made in Malawi in 1962 (Cox and Hess, 1962; DeTray, 1963; Wilkinson et al., 1988). The eastern Province is now considered to be enzootic for ASF. Zambia nonetheless reports fewer ASF outbreaks than Malawi, all occurring within the enzootic area. This could be a result of the $400 \mathrm{~km}$ distance between this area and the Central Veterinary Research Laboratory in Lusaka, as compared to the $90 \mathrm{~km}$ distance between the enzootic area in Malawi and the laboratory in Lilongwe, resulting in the former laboratory receiving fewer samples (Sumption, 1992). Non-commercial farmers were usually affected by repeated ASF outbreaks in the Eastern Province of Zambia, until 1989 when an outbreak occurred on a commercial property in central Zambia for the first time. The property suffered losses amounting to 421,238 Zambian Kwacha (ZK) from pig deaths and control measures in the form of depopulation and a ban on exporting pig products (Samui et al., 1996). A survey of the distribution of ASF virus in Ornithodoros ticks in Zambia was carried out by virus isolation on samples collected from animal burrows in National Parks and Game 
Management Areas in northern, eastern, central and southern Zambia. ASFV was isolated from ticks in all areas examined (Wilkinson et al., 1988).

\subsection{Regional considerations}

The prevalence and incidence of ASF in East Africa varies greatly between countries and is related to the efficacy of the veterinary measures, type of husbandry system practised and the socio - political stability within countries. Fewer pigs are intensively reared in both Malawi and Zambia than are free roaming. Although both types of pig farming have experienced outbreaks, the source of infection in the two systems seems to differ. Swill feeding and scavenging are the biggest causes of ASFV introduction in free ranging pigs, while movement of infected pig material from one place to the other is responsible for disease occurrences in intensive pig farms. Both countries have a large number of smallscale pig owners with unregistered farms. A fall in pig meat price, saturation of local markets and increased roadside and uncontrolled illegal sales of pig meat, is frequently accompanied by ASF outbreaks (Sumption, 1992). The outbreaks are perpetuated by cross border trading with common tribal groups, the presence of peri-domestic ticks of the O. moubata complex, poaching of warthogs and bushpigs, and the inadequate standards and infrastructure of veterinary services. The veterinary services often lack transport, equipment, training and a well-developed disease control policy that reflects the current ASF situation (Sumption, 1992).

Despite the limitations detailed above, it is known that all three virus cycles play an active role in ASF epidemiology in East Africa, however information on the domestic pig and pig/tick cycles is based exclusively on studies conducted in Malawi. While proof of existence of a regional domestic pig cycle is still outstanding, the ravaging effects of ASF on small scale communal and bigger commercial farmers is undisputed (Table 1.1). 
Table 1.1 Summary of ASF disease situation in East African countries for the past 10 years according to the O.I.E and Promed - mail records

\begin{tabular}{lllllllll}
\hline Country & $\mathbf{1 9 9 6}$ & $\mathbf{1 9 9 7}$ & $\mathbf{1 9 9 8}$ & $\mathbf{1 9 9 9}$ & $\mathbf{2 0 0 0}$ & $\mathbf{2 0 0 1}$ & $\mathbf{2 0 0 2}$ & $\mathbf{2 0 0 3}$ \\
\hline Burundi & & & & & & + & & \\
DRC & & & - & & & + & & $?^{*}$ \\
Eritrea & $\ldots$ & $\ldots$ & & - & - & - & & \\
Ethiopia & 1993 & 1993 & 1993 & 1993 & 1993 & 1993 & \\
Kenya & $11 / 94$ & $11 / 94$ & $11 / 94$ & $11 / 94$ & $11 / 94$ & + & \\
Madagascar & 0000 & 0000 & + & + & + & + & \\
Malawi & + & + & + & + & + & + & \\
Mozambique & +() & +() & +() & + & + & + & + & \\
Swaziland & 0000 & 0000 & 0000 & 0000 & 0000 & 0000 & \\
Tanzania & $\ldots$ & - & - & - & - & + & + \\
Uganda & + & + & + & + & + & + & $+^{*}$ & + \\
Zambia & $12 / 95$ & +() & +() & + & + & + & $?^{*}$ & \\
\hline
\end{tabular}

0000 Disease never reported; - Disease not reported (date of last outbreak not known); Date (month/year) of the last reported occurrence of the disease in previous years; ? Disease suspected but presence not confirmed; + Reported present or known to be present; +? Serological evidence and/or isolation of the causal agent, but no clinical signs of disease; ( ) Disease limited to specific zones; ... No information available; * Promed - mail records; DRC-Democratic Republic of Congo

\subsubsection{Molecular Characterisation of East African ASF viruses}

Malawi and Zambia have suffered many ASF outbreaks since their first confirmed cases of the disease in the mid 1900s. A need arose to study the epidemiology of the disease at a molecular level to determine the following: 1) The genetic relationship of the viruses causing outbreaks in domestic pigs; 2) The genetic relationship between viruses of wildlife and those of domestic pig origin; 3) The genetic diversity of ASFV from Ornithodoros ticks; 4) The potential route of spread of viruses causing outbreaks (Dixon 
and Wilkinson, 1988; Blasco et al., 1989; Sumption, 1992; Bastos et al., 2003, 2004; Lubisi et al., 2005). All these studies were aimed at acquiring a better knowledge of ASF epidemiology, with the ultimate aim of curbing future spread or re-introductions.

Molecular biological tools like the restriction fragment length polymorphism (RFLP), where the virus genome is cut into pieces of various sizes by restriction endonucleases and electorphoresed to determine the size of the resulting DNA fragments, was earlier used for viral epidemiological classification (Blasco et al., 1989; Dixon et al., 1989; Sumption, 1992).

The RFLP method when applied to ASFV isolates from Malawi and Zambia revealed eight variable regions (VR) of the genome, designated VR1 to VR8 respectively (Sumption, 1992). VR1, 2 and 3 are located approximately:

1) At a region proximal to the first $\mathrm{NeoI}$ enzyme restriction site from both the left and right genome terminal hairpin loop and about $1.2 \mathrm{~kb}$ in size. It is thought to be the terminal inverted repeat (TIR) sequence consisting of unique sequences interspersed with a total of $1650 \mathrm{bp}$ of repeat sequences, comprising 42 tandem direct repeats of $34 \mathrm{bp}$, five repeats of $24 \mathrm{bp}$ and three of $33 \mathrm{bp}$.

2) Between $7.3 \mathrm{~kb}$ and $17.6 \mathrm{~kb}$ from left terminal end.

3) Between $36 \mathrm{~kb}$ and $46 \mathrm{~kb}$ from left terminus of the Lil20/1 virus.

Within the central region of the genome, previously described as conserved (Blasco et al., 1989), lies VR4, located 90 - $92 \mathrm{~kb}$ from the left terminus. VR 5, 6 and 7 are located within the right genome terminus, approximately $22.5 \mathrm{~kb}, 12.8 \mathrm{~kb}$ to $17.7 \mathrm{~kb}$ and $10.8 \mathrm{~kb}$ to $12.2 \mathrm{~kb}$ from Lil20/1 genome's right terminus. In the right genome terminus, $7 \mathrm{~kb}$ from VR7 and $1.1 \mathrm{~kb}$ from VR1, spanning $1.2 \mathrm{~kb}$ to $3.5 \mathrm{~kb}$ from the right terminus, is the location of VR8.

Sumption (1992) preferred the BamHI restriction enzyme to other restriction enzymes in determining diverse ASFV relatedness due to the fact that the results were reproducible and yielded more fragments which could assist in determining relationships between closely related isolates. BamHI a, b (or a'b) and c were fragments from the left genome 
terminus, while BamHI t, u, v and $\mathrm{w}$ were fragments from the right terminus. All but one fragment yielded size differences of no more than $0.82 \mathrm{~kb}$ between the viruses compared. The combined fragment, BamHI a'b however, displayed significant size differences of up to $9.1 \mathrm{~kb}$ between isolates, and was thus used for comparison of the different isolates from East, West and South Africa (Sumption, 1992).

More recently, viral DNA is amplified by polymerase chain reaction (PCR) and the amplified product's nucleotide sequences are used to group viruses (Bastos et al., 2003, 2004; Lubisi et al., 2005). Of the ten major genotypes shown to occur on the African continent, five were of East African origin (Bastos et al., 2003).

\subsubsection{Phylogenetic tools and considerations in ASF molecular epidemiology}

Nucleotide sequence data of a conserved genome region, the $p 72$ gene can be used to discern ASFV phylogenetic relationships (Bastos et al., 2003). This data is amenable to both distance and character-based methods of analysis. Uniformity of results between methods is crucial for the confidence bestowed to the discerned phylogeny (Kim, 1998). Constancy of results is however not always easily attainable due to the complexity of the data which includes the number of operational taxonomic units (OTU), transition/transversion and nucleotide composition bias, unequal nucleotide substitution rates and the presence of homoplasy. A five-point criterion system, based on power, efficiency, consistency, robustness and falsifiability (Penny et al., 1992) is used to judge each method's performance given a data set. Power determines the amount of data a method needs to draw a phylogenetic tree, while efficiency measures the speed with which a tree is drawn as data is applied. Consistency assesses a method's ability to infer the correct tree with increasing data, and robustness looks into the ability to infer a correct tree even if its assumptions are violated. Falsifiability assesses the method's discriminating ability (Huelsenbeck, 1995; Penny et al., 1992).

The different methods of phylogenetic inference commonly used are neighbor-joining (NJ), minimum evolution (ME), maximum likelihood (ML) and maximum parsimony 
(MP). NJ method (Saitou and Nei, 1987) creates distance data on the basis of pairwise comparisons and is related to the cluster analysis of Sattath and Tversky (1977). Another distance method, ME, uses an optimality criterion, resulting in various optimal and suboptimal solutions, of which the tree with the shortest total sum of branch length is assumed the best estimate of the phylogeny (Edwards and Cavalli-Sforza, 1963). MP methods are cladistic in principle, and utilize character data and optimality criteria to infer phylogenies (Eck and Dayhoff, 1966; Fitch, 1971). ML methods of phylogenetic tree inference are evolutionary in principle, and utilize all the sequence data under analysis to formulate a probabilistic model of evolution with application of known statistical methods (Felsenstein, 1981).

In the quest for accurate phylogenetic construction, the methods used to prescribe the standards of performance of the tree building techniques are also of great importance. Simulation methods, on which most method comparisons are based, known phylogenies, statistical approaches and congruence studies are employed to set the standards by which methods are expected to perform given a certain data set (Huelsenbeck, 1995; Sourdis and Nei, 1988; Lin and Nei, 1991; Kuhner and Felsenstein, 1994). Many biases such as the selection of parameters that describe the simulated tree, evolutionary model, poor method implementation and the acquisition of multiple and equally good solutions (Tanaka et al., 1997; Takezaki, 1998; Oberste et al., 1999; Servant et al., 2002) occur in the quest for uncovering the true phylogenetic relationships and therefore have to be approached with caution.

All the methods discussed above have different strengths and limitations, and different requirements for input data, in order to perform maximally. Methods are only superior to others when all their assumptions are satisfied and the questions asked are within their capability and the amount of data they process is not overwhelming their search capabilities. Selection of one particular method should therefore be based on the research question asked, the number of taxa examined and the type and nature of the data (e.g amount of base pair substitutions, transition/transversion $(\mathrm{si} / \mathrm{sv})$ ratios and the number of nucleotides). Knowledge of each available method's principles and assumptions and how 
it would perform under the given circumstances is important. Care should be taken to scrutinise the models used to assess the performance of a particular method since results of such models often seem to match pre-existing preferences of the particular investigators (Hillis, 1995). The availability of computer software to perform the desired phylogenetic analysis is also a factor of consideration when choosing a method. Software such as Farris' Hennig 86, MEGA by Kumar, Tamura and Nei, Swofford's PAUP, Felsenstein's PHYLIP, and many more are available for the researcher to analyse data (Swofford et al., 1996). It should however be noted that real data hardly, if ever, fulfil any method's ideal assumptions and the investigator should be familiar with available corrective measures in order to acquire optimum results from the methods employed.

\subsection{OBJECTIVES}

The review of the literature clearly indicates that ASF is endemic in Africa and continues to cause great economic losses. The surface glycoproteins do not allow these viruses to be distinguished on a serological basis; thereby hindering serologically based epidemiological studies. It has also been seen that East Africa has all the epidemiologically significant factors for ASF, while the West African situation lacks some of these important factors. The primary objective is therefore to obtain a regional ASF epidemiological picture for utilization in the control of outbreaks.

The aim of this study is two fold:

- To genetically characterize African swine fever viruses of diverse species, geographical and temporal origins from East Africa, in order to trace the possible origins of outbreak strains.

- To genetically characterize intra-genotypic relationships within a large homogeneous domestics pig genotype so that a finer resolution of the origins of outbreak viruses can be obtained. 


\section{Chapter 2}

\section{p72 genotyping of African swine fever viruses from East Africa}

\section{SUMMARY}

African swine fever (ASF) a lethal, viral hemorrhagic disease of domestic pigs, first reported from East Africa in 1921, is still widespread in this region. In order to assess field heterogeneity at the regional level, nucleotide sequences corresponding to the $\mathrm{C}$ terminal end of the $p 72$ gene were determined for 77 ASF viruses of diverse temporal and species origin occurring in eight East African countries. The number of sites that were not completely conserved across all East African sequences characterised in this study was $15.8 \%$ and $13.4 \%$ on nucleotide and amino acid level, respectively. Phylogenetic analysis of a homologous $404 \mathrm{bp}$ region revealed the presence of thirteen East African genotypes, of which seven appear to be country specific. An East African, pig-associated, homogeneous virus lineage linked to outbreaks in Mozambique, Zambia and Malawi over a 23 year period was demonstrated. In addition, genotype I (ESACWA) viruses were identified in East African sylvatic hosts for the first time which is significant as this genotype was previously thought to be restricted to the West African region where it occurs only in domestic pigs. The presence of discrete epidemiological cycles in East Africa and recovery of multiple genotypes affirms the epidemiological complexity of ASF in this region.

Parts of the results presented here have been accepted for publication in Archives of Virology 


\subsection{INTRODUCTION}

The epidemiology of ASF in East Africa is complex. Not only is there evidence for a sylvatic cycle, but a domestic pig cycle and a pig-tick cycle have also been described for Malawi (Haresnape, 1984, Haresnape et al., 1985, 1987, 1988; Plowright et al., 1994). Despite the presence of all three cycles no extensive molecular database comprising ASFV strains from different host species is available which would assist in clarifying the epidemiology of the disease in this region.

Of the 30 plus proteins contained in ASFV particles ranging in molecular weight from 10 to $150 \mathrm{kDa}$, the major polypeptide, virus protein 72 (VP72) has a weight of $72 \mathrm{kDa}$ (Carrascosa et al., 1985). Through the availability and use of ASFV specific monoclonal antibodies, Sanz et al. (1985) discovered that other ASF viral proteins changed following passage in macrophages while the protein VP72 remained stable. Analysis of the binding properties of these monoclonal antibodies using cloned field isolates demonstrated the antigenic stability of this protein (Sanz et al., 1985). Based on these discoveries and the findings of Tabarés and co-workers (1980) that VP72 was the major immunogen in natural infections, the protein was ear-marked for use in newly improved diagnostic tests. For this purpose, the gene encoding VP72 had to be identified for expression and further characterization of this protein. Oligonucleotide probes deduced from amino acid sequences of tryptic peptides obtained from purified protein VP72 were used to map the encoding gene (López-Otîn et al., 1990). An open reading frame (ORF) coding for 646 amino acids corresponding to a protein of approximately $73 \mathrm{kDa}$ was revealed, assuring investigators of the genomic area being the correct $p 72$ gene location. Further validation of the antigenic stability of VP72 at molecular level involved $p 72$ gene comparison of one virus from the Dominican Republic (DR-2), two isolates from Spain (BA71-V and E70) and one Ugandan virus (UGA). Results revealed a 95.5 to $100 \%$ sequence homology at nucleotide, and a 97.8 to $100 \%$ identity at amino acid level (Yu et al., 1996).

In addition to VP72's potential as an efficient antigenic protein in serological assays, the p72 gene's capability to resolve phylogenetic relationships among field and outbreak 
ASFV was postulated and explored (Bastos et al., 2003). Virus clusters similar to those identified by restriction enzyme digestion analysis (Wesley and Pan, 1982; Blasco et al., 1989) were obtained when comparing different ASFV isolates on the basis of VP72 nucleotide sequences. The gene's proficiency in resolving virus relatedness was significant as its surface glycoproteins do not allow differentiation into serological types (Dixon et al., 2000).

Nucleotide and amino acid variability plots of ASFV complete gene showed the central and C-terminal regions to be rich in non-synonymous mutations (Bastos et al., 2003). The latter region was also found to be more variable than the former making it better suited to distinguishing between field strains. Furthermore, the region was surrounded by conserved nucleotide sequences, allowing the design of oligonucleotide primers complementary to these flanking sites. This lead to the C-terminal being chosen over the central region for phylogenetic studies using the $p 72$ PCR-sequencing approach (Bastos et al., 2003).

In an attempt to validate the potential of partial $p 72$ genotyping for resolving ASFV relationships, Bastos and co-workers (2003) tested isolates from Africa, the Caribbean Islands, Europe and South America, including the same isolates previously genotyped by restriction fragment length polymorphism (RFLP) (Blasco et al., 1989), or a geographical representative thereof. Ten lineages were resolved with partial $p 72$ gene sequencing, and five of these corresponded with those previously identified by RFLP analysis. Of these, genotype I comprising viruses from Europe, South America, the Caribbean and West Africa (and termed the ESACWA genotype), represents the most widespread and homogeneous genotype identified thus far.

The corroboration of $p 72$ genotyping's ability to differentiate ASFV isolates on a genetic level in a more rapid and less labor-intensive manner, and the potential to apply the method directly to clinical specimens, without first isolating the virus resulted in this approach being favored over RFLP to resolve ASFV relationships from East Africa. 


\subsection{MATERIALS AND METHODS}

\subsubsection{Study area and samples}

For the purpose of this study, East African countries are defined as those occurring east of latitude $20^{\circ} 00 \mathrm{E}$ and south of latitude $5^{\circ} 00 \mathrm{~N}$, but excluding Namibia, South Africa, Botswana and Zimbabwe. This area encompasses the following eight countries: Burundi, Democratic Republic of Congo, Kenya, Malawi, Mozambique, Tanzania, Uganda and Zambia. A total of 77 viruses of diverse species and temporal origin from these eight East African countries were sequenced and characterized in this study, with the majority of viruses being supplied by the World Reference Laboratory, Institute for Animal Health (IAH), Pirbright. Additional strains were isolated at the Onderstepoort Veterinary Institute (OVI), Agricultural Research Council (ARC) from clinical material supplied by the respective departments of veterinary services. Twenty-five ASF viruses representative of each of the ten previously identified $p 72$ genotypes (Bastos et al., 2003) were included for phylogenetic analysis purposes, bringing the total number of viruses used in this study to 102 (summarized in Table 2.1). In order to place the results of this study in context with the RFLP studies performed previously with isolates from the East African region (Sumption 1992), a summary of the viruses used in the latter study, together with the main findings, have been summarized in Table 2.2.

2.2.2 Pig primary cell culture preparation

\subsubsection{Peripheral blood leukocyte culture}

The Malmquist and Hay (1960) method of swine macrophage preparation was employed, with a few modifications. Where peripheral blood leukocyte cells were used, whole blood from a juvenile pig was collected by injecting the pig with $20 \%$ Sodium pentobarbitone intra-cardially and exsanguination by severance of the Axillary blood vessels followed shortly thereafter. A 1 litre (L) vessel containing $1 \mathrm{ml}$ of Heparin Sodium (5000i.u/ml) 
was used to collect the blood. For the prevention of microbial and fungal growth, an antimicrobial cocktail and antifungal agent consisting of Penicillin - $4 \%$ Benzylpenicillin (Sigma), Streptomycin - $6.4 \%$ streptomycin sulphate (Sigma), Neomycin - 7.5 $\%$ Neomycin-sulphate (Merck) and Fungizone - $5 \mathrm{mg}$ Amphotericin B (Bristol-Myers Squibb) in $1 \mathrm{ml}$ quantities, were added to the blood. Iron dextran - $10 \%$ (BDK) was added to the blood in a 1:10 ratio. The blood was then aliquoted in $100 \mathrm{ml}$ Erlenmeyer flasks and incubated at $37^{\circ} \mathrm{C}$ for 20 minutes until the red blood cells formed a sediment. The white blood cell rich supernatant was pipetted out and collected into a plastic centrifuge bottle, where it was diluted 1:1 with wash buffer. The wash buffer consisted of 1L phosphate buffered saline (PBS), $0.4 \%$ Penicillin, $0.64 \%$ Streptomycin, $0.75 \%$ Neomycin and $10 \%$ normal bovine serum (NBS). Centrifugation at 2000 rotations per minute (rpm) for 4 minutes ensued. This was the first wash step. At the end of centrifugation the supernatant was discarded and a second wash step followed. At the third wash step, the cell rich sediment was re-suspended in $100 \mathrm{ml}$ of $0.82 \%$ Ammonium chloride and centrifuged as above. Wash buffer was again used for the fourth and final wash step. The clear white blood cells were suspended in growth medium constituting the following: $42 \%$ distilled water, $42 \%$ Earle's medium (Appendix A), $0.4 \%$ Hepes (UniLab), $13 \%$ swine serum, $0.52 \%$ penicillin, $0.832 \%$ streptomycin and $0.975 \%$ neomycin. The cells were grown in $100 \mu 1$ volumes on 96 well plates (Nunc). The medium was changed after 48 hours (day 2 post preparation) and fresh growth medium containing $0.5 \%$ red blood cells was added. The primary cultures were stored for a minimum of 7 days, or a maximum of 11 days. Growth medium was changed for the third time on day 6 post preparation in instances where cultures were stored for the maximum period.

\subsubsection{Bone marrow cultures}

The same pig that was euthanased for primary white blood cell cultures had two long bones removed from its body and placed in a litre of wash buffer prepared as in 2.2.2.1. Forceps were used to remove the bones from the wash buffer and these were placed on a stainless steel tray. Flesh and cartilage were excised from the bones with a scalpel blade 
and the clean bones were immersed in $300 \mathrm{ml}$ of fresh wash buffer and incubated at $37^{\circ} \mathrm{C}$ for 20 minutes. After incubation, bone-cutting forceps were used to crush the bones into small fragments and these were collected in a $1 \mathrm{~L}$ conical flask containing $250 \mathrm{ml}$ of wash buffer. The conical flask was incubated at $37^{\circ} \mathrm{C}$ and gently shaken for 90 minutes. Butter muslin was placed over funnels through which the crushed bones were sieved and the cell rich filtrate collected into centrifuge containers. The filtrate was centrifuged at $1000 \mathrm{rpm}$ for fifteen minutes. After the removal of the supernatant, the sediment was washed with $0.82 \%$ ammonium chloride solution and centrifuged at $1000 \mathrm{rpm}$ for 15 minutes. This was followed by two extra washing steps with wash buffer, followed by suspension of the sediment in growth medium as detailed in section 2.2.2.1. The cell rich suspension was poured into a boat, and a multichannel pipette was used to transfer $100 \mu 1$ of the suspension into each well of a 96 well microtitre plate. The plates were stored in a carbon dioxide $\left(\mathrm{CO}_{2}\right)$ incubator at $37^{\circ} \mathrm{C}$, and growth medium was changed after 48 hours. The primary bone marrow cultures were stored for a maximum of 7 days.

\subsubsection{Virus isolation}

Inoculum containing $10 \%(\mathrm{w} / \mathrm{v})$ of sample material in PBS was processed in a series of 10 fold dilutions. Rows of wells were inoculated with the sample material at decreasing dilutions, in $50 \mu \mathrm{l}$ quantities per well. Plastic plate sealers, followed by the lids, were used to cover the plates. The cells were examined daily for cytopathogenic effect or haemadsorption. Virus from positive wells was harvested by freezing the plates at $-80^{\circ} \mathrm{C}$ for at least 30 minutes to lyse the cells. After thawing, a syringe with a sharp needle was used to pierce the plastic sealers and collect the contents from each positive well, and these were pooled in a $20 \mathrm{ml}$ bottle. Centrifugation at $15000 \mathrm{rpm}$ for 10 minutes followed. The virus rich supernatant was removed and stored at $-80^{\circ} \mathrm{C}$. 
Table 2.1 Summary of the African swine fever viruses characterized in this study and those sourced from other studies and included for comparative and phylogenetic purposes

\begin{tabular}{|c|c|c|c|c|c|}
\hline Virus name & $\begin{array}{c}\text { Country of } \\
\text { origin }\end{array}$ & Town / District & $\begin{array}{c}\text { Year } \\
\text { of } \\
\text { isolat } \\
\text { ion }\end{array}$ & Species of origin & $\begin{array}{c}\text { GenBank } \\
\text { Accession } \\
\text { number }\end{array}$ \\
\hline BAN 91/1 & Malawi & Bangula, Lower Shire & 1991 & Sus scrofa & AY351501 \\
\hline${ }^{\#}$ BRAZIL 79 & Brazil & NK & 1979 & Sus scrofa & AF302809 \\
\hline Bartlett II & Kenya & Timau & 1959 & Phaecochoerus aethiopicus & AY351532 \\
\hline${ }^{\#}$ BUR 1/84 & Burundi & Mushasagitega & 1984 & Sus scrofa & AF449463 \\
\hline${ }^{\#}$ BUR 2/84 & Burundi & Mushasagitega & 1984 & Sus scrofa & AF449464 \\
\hline${ }^{\#}$ BUR 90/1 & Burundi & Muyinga & 1990 & Sus scrofa & AF449472 \\
\hline BUR 90/3 & Burundi & Muyinga & 1990 & Sus scrofa & AY351525 \\
\hline "BOT1/99 & Botswana & Sherwood & 1999 & Sus scrofa & AF504886 \\
\hline${ }^{\#} \mathrm{CAM} / 82$ & Cameroon & Guzang North West Province & 1982 & Sus scrofa & AF301544 \\
\hline CHG 88/1 & Zambia & Chaguza, Katete, Eastern Province & 1988 & Sus scrofa & AY351552 \\
\hline CHJ 89/1 & Zambia & Chiphanje, Petauke, Eastern Province & 1989 & Sus scrofa & AY351519 \\
\hline CHK 89/2 & Zambia & Chikuwe, Chipata, Eastern Province & 1989 & Sus scrofa & AY351526 \\
\hline CHM 88/1 & Zambia & Chambula, Petauke, Eastern Province & 1988 & Sus scrofa & AY351520 \\
\hline "Dakar59 & Senegal & Dakar & 1959 & Sus scrofa & AF301538 \\
\hline Davis & Kenya & Nanyuki & 1959 & Phaecochoerus aethiopicus & AY351527 \\
\hline${ }^{6} \mathrm{DED} 89 / 1$ & Malawi & Chiphazi, Dedza District & 1989 & Sus scrofa & AY351502 \\
\hline DED 91/1 & Malawi & Mtenden Campus, Dedza & 1991 & Sus scrofa & AY351503 \\
\hline "Dedza & Malawi & Chilikum-Wera Dedza & 1986 & Sus scrofa & AF449479 \\
\hline Doig & Kenya & Kiganjo & 1957 & Phaecochoerus aethiopicus & AY351528 \\
\hline${ }^{6}$ DOWA & Malawi & Moya, Dowa & 1986 & Sus scrofa & AY351509 \\
\hline Gasson & Kenya & Nanyuki & $<1961$ & Sus scrofa & AY351529 \\
\hline GUL 88/1 & Zambia & Gulumule, Katete, Eastern Province & 1988 & Sus scrofa & AY351521 \\
\hline Hinde I & Kenya & Nanyuki & 1954 & Sus scrofa & AY351530 \\
\hline${ }^{\#}$ HINDE II & Kenya & Nanyuki & 1959 & Sus scrofa & AF449480 \\
\hline \#JON 89/13 & Zambia & Jonase Petauke & 1989 & Sus scrofa & AF449469 \\
\hline
\end{tabular}




\begin{tabular}{|c|c|c|c|c|c|}
\hline${ }^{7} \mathrm{KAB} 6 / 2$ & Zambia & Livingstone game park, south Zambia & 1983 & Tick * & AY351522 \\
\hline \multirow[t]{2}{*}{ KAC $91 / 2$} & Malawi & Kachendere Seminary, Chisengu, & 1991 & Sus scrofa & AY351504 \\
\hline & \multicolumn{3}{|c|}{ Mchinji } & & \\
\hline${ }^{\#} \mathrm{KAL} 88 / 1$ & Zambia & Kaliyoyo-Chipate & 1988 & Sus scrofa & AF449468 \\
\hline \multirow[t]{2}{*}{ KANA $89 / 1$} & Zambia & Kangwero farm 17, Katete, Eastern & 1989 & Sus scrofa & AY351523 \\
\hline & \multicolumn{4}{|c|}{ Province } & \\
\hline${ }^{\#} \mathrm{KAV} 89 / 1$ & Zambia & Kavundula Katete & 1989 & Sus scrofa & AF449470 \\
\hline Killean I & Kenya & Nanyuki & 1959 & Phaecochoerus aethiopicus & AY351550 \\
\hline Killean II & Kenya & Nanyuki & 1959 & Phaecochoerus aethiopicus & AY351551 \\
\hline Killean III & Kenya & Nanyuki & 1959 & Phaecochoerus aethiopicus & AY351531 \\
\hline Kimakia I & Kenya & UK & 1961 & Potamochoerus porcus & AY351533 \\
\hline Kimakia II & Kenya & UK & 1961 & Potamochoerus porcus & AY351534 \\
\hline KIRT $89 / 2$ & Tanzania & Kiriwira & 1989 & Tick * & AY351511 \\
\hline KIRT $89 / 3$ & Tanzania & Kiriwira & 1989 & Tick * & AY351512 \\
\hline KIRT 89/4 & Tanzania & Kiriwira & 1989 & Tick * & AY351513 \\
\hline KIRW 89/1 & Tanzania & Kiriwira & 1989 & Phaecochoerus aethiopicus & AY351514 \\
\hline KLI $88 / 2$ & Zambia & Kalinda, Petauke, Eastern Province & 1988 & Sus scrofa & AY351553 \\
\hline${ }^{\text {"KWH/12 }}$ & Tanzania & Kiriwira & 1968 & Phaecochoerus aethiopicus & AF301546 \\
\hline${ }^{6} \mathrm{LIL} 89 / 1$ & Malawi & Mlozi, Lilongwe District & 1989 & Sus scrofa & AY351505 \\
\hline LIL 90/1 & Malawi & Kafere diptank, Lilongwe & 1990 & Sus scrofa & AY351510 \\
\hline${ }^{\#}$ LISBON/57 & Portugal & Lisbon & 1957 & Sus scrofa & AF301537 \\
\hline \multirow[t]{2}{*}{${ }^{7}$ LIV 5/40 } & Zambia & Livingstone Game Park, South & 1982 & Tick * & AY351536 \\
\hline & & Zambia & & & \\
\hline \multirow[t]{2}{*}{${ }^{7}$ LIV 5/4 } & Zambia & Livingstone Game Park, South & 1983 & Tick * & AY351537 \\
\hline & & Zambia & & & \\
\hline \multirow[t]{2}{*}{ LIV $9 / 31$} & Zambia & Livingstone Game Park, South & 1983 & Tick * & AY351538 \\
\hline & & Zambia & & & \\
\hline \multirow[t]{2}{*}{ LIV 9/35 } & Zambia & Livingstone Game Park, South & 1983 & Tick * & AY351539 \\
\hline & & Zambia & & & \\
\hline
\end{tabular}




\begin{tabular}{|c|c|c|c|c|c|}
\hline${ }^{7}$ LIV 10/11 & Zambia & Livingstone Game Park, South & 1983 & Tick * & AY351535 \\
\hline${ }^{7}$ LIV 12/17 & Zambia & $\begin{array}{c}\text { Zambia } \\
\text { Livingstone Game Park, South } \\
\text { Zambia }\end{array}$ & 1983 & Tick * & AY351524 \\
\hline${ }^{7} \mathrm{LIV} 13 / 33$ & Zambia & $\begin{array}{l}\text { Livingstone Game Park, South } \\
\text { Zambia }\end{array}$ & 1983 & Tick* & AY494560 \\
\hline LUS 93/1 & Zambia & $\begin{array}{c}\text { Nawande farm, Lusaka district, } \\
\text { Lusaka Province }\end{array}$ & 1991 & Sus scrofa & AY351563 \\
\hline${ }^{\#}$ MAD 1/98 & Madagascar & NK & 1998 & Sus scrofa & AF270705 \\
\hline $\begin{array}{c}\text { Magadi w/hog } \\
1\end{array}$ & Kenya & Magadi & 1959 & Phaecochoerus aethiopicus & AY351548 \\
\hline $\begin{array}{c}\text { Magadi w/hog } \\
9\end{array}$ & Kenya & Magadi & 1959 & Phaecochoerus aethiopicus & AY351565 \\
\hline${ }^{1}$ MAL 2002/1 & Malawi & Mpemba Quarantine Camp & 2002 & Sus scrofa & AY494553 \\
\hline $\begin{array}{c}{ }^{\#} \text { MALAWI/197 } \\
8\end{array}$ & Malawi & NK & 1978 & Sus scrofa & AF270707 \\
\hline MAN 89/2 & Zambia & Mangulu, Katete, Eastern Province & 1989 & Sus scrofa & AY351562 \\
\hline${ }^{6} \mathrm{MCH} 89 / 1$ & Malawi & Kachebere Seminary, Mchinji & 1989 & Sus scrofa & AY351506 \\
\hline${ }^{6} \mathrm{MCH} 89 / 3$ & Malawi & Chisikwa diptank, Lilongwe District & 1989 & Sus scrofa & AY351507 \\
\hline${ }^{6}$ Mchinji 075 & Malawi & Mchinji & 1987 & Sus scrofa & AY351508 \\
\hline${ }^{7}$ MFUE 6/1 & Zambia & Mfue, Luangera National Park & 1982 & Tick* & AY351561 \\
\hline${ }^{\#} \mathrm{MOZ} / 94 / 1$ & Mozambique & Maputo & 1994 & Sus scrofa & AF270711 \\
\hline${ }^{5} \mathrm{MOZ} 2001 / 1$ & Mozambique & Zambezi, Quilemane & 2001 & Sus scrofa & AY351516 \\
\hline${ }^{5} \mathrm{MOZ} 2002 / 1$ & Mozambique & Northern Nampula region & 2002 & Sus scrofa & AY351517 \\
\hline${ }^{5} \mathrm{MOZ} 2002 / 2$ & Mozambique & Northern Nampula region & 2002 & Sus scrofa & AY351518 \\
\hline MPI 89/1 & Zambia & $\begin{array}{c}\text { Mpima Seminary, Kabwe, Central } \\
\text { Province }\end{array}$ & 1989 & Sus scrofa & AY351540 \\
\hline MPO 89/1 & Zambia & Mpoka, Petauke, Eastern Province & 1989 & Sus scrofa & AY351541 \\
\hline
\end{tabular}




\begin{tabular}{|c|c|c|c|c|c|}
\hline MZI 92/1 & Malawi & Euthini, Mzinda District, north & 1992 & Sus scrofa & AY351543 \\
\hline & & Malawi & & & \\
\hline${ }^{\#} \mathrm{NDA} / 1 / 90$ & Malawi & Nadula & 1990 & Sus scrofa & AF449473 \\
\hline NGE 92/1 & Malawi & Ngerenge diptank, Karonga District & 1992 & Sus scrofa & AY351544 \\
\hline \multirow[t]{2}{*}{ NKZ 88/1 } & Zambia & Nyankonzi, Petauke, Eastern & 1988 & Sus scrofa & AY351554 \\
\hline & & Province & & & \\
\hline NYA1/2 & Zambia & Kalumo & 1986 & Tick * & AY351555 \\
\hline PHW 88/1 & Zambia & Phwata, Chipata, Eastern Province & 1988 & Sus scrofa & AY351567 \\
\hline${ }^{\#} \mathrm{RSA} / 1 / 98$ & South Africa & Potgietersrus & 1988 & Sus scrofa & AF302818 \\
\hline "RSA/1/99 & South Africa & Soutpansberg & 1999 & Phaecochoerus aethiopicus & AF302818 \\
\hline SAL 92/1 & Malawi & Chiripa diptank, Salima District & 1992 & Sus scrofa & AY351546 \\
\hline SIY 91/2 & Malawi & Sinyala diptank, Lilongwe & 1991 & Sus scrofa & AY351566 \\
\hline${ }^{\#}$ SPEC 265 & Mozambique & Maputo & 1994 & Sus scrofa & AF270210 \\
\hline${ }^{7}$ SUM 14/11 & Zambia & Sumbu National Park & 1983 & Tick $*$ & AY351542 \\
\hline${ }^{2} \mathrm{TAN} / 1 / 01$ & Tanzania & Dar Es Salaam & 2001 & Sus scrofa & AY494552 \\
\hline${ }^{2}$ TAN/2003/1 & Tanzania & Arusha & 2003 & Sus scrofa & AY494550 \\
\hline${ }^{2}$ TAN $/ 2003 / 2$ & Tanzania & Arusha & 2003 & Sus scrofa & AY494551 \\
\hline TEN 89/1 & Zambia & Tenesi, Petauke, Eastern Province & 1989 & Sus scrofa & AY351556 \\
\hline "TENGANI/60 & Malawi & Tengani & 1960 & Phaecochoerus aethiopicus & AF301541 \\
\hline THY 90/1 & Malawi & Comforzi farm, Thyolo District & 1990 & Sus scrofa & AY351545 \\
\hline TMB 89/1 & Zambia & Tembo, Petauke, Eastern Province & 1989 & Sus scrofa & AY351557 \\
\hline Trench & Kenya & Mweiga & 1959 & Phaecochoerus aethiopicus & AY351547 \\
\hline${ }^{\#} \mathrm{UGA} / 1 / 95$ & Uganda & Malindue & 1995 & Sus scrofa & AF449475 \\
\hline${ }^{\#} \mathrm{UGA} / 3 / 95$ & Uganda & Simbale & 1995 & Sus scrofa & AF449476 \\
\hline${ }^{4} U G A 2003 / 1$ & Uganda & Maria Village, Masaka District & 2003 & Sus scrofa & AY351564 \\
\hline YEL88/4 & Zambia & Yelani, Petauke, Eastern Province & 1988 & Sus scrofa & AY351558 \\
\hline${ }^{3} \mathrm{ZAM} 01 / 1$ & Zambia & Lusaka & 2001 & Sus scrofa & AY494554 \\
\hline${ }^{3}$ ZAM01/2 & Zambia & Kafue & 2001 & Sus scrofa & AY494555 \\
\hline${ }^{3}$ ZAM01/3 & Zambia & Mazabuka & 2001 & Sus scrofa & AY494556 \\
\hline
\end{tabular}




\begin{tabular}{|c|c|c|c|c|c|}
\hline${ }^{3} \mathrm{ZAM} 01 / 4$ & Zambia & Namwala & 2001 & Sus scrofa & AY494557 \\
\hline${ }^{3} \mathrm{ZAM} 01 / 5$ & Zambia & Monze & 2001 & Sus scrofa & AY494558 \\
\hline${ }^{3}$ ZAM02/1 & Zambia & Kyiundi Ranch & 2002 & Sus scrofa & AY494559 \\
\hline Zaire & DRC & NK & NK & NK & AY351515 \\
\hline ZAW 88/1 & Zambia & Gulumule, Katete, Eastern Province & 1988 & Sus scrofa & AY351559 \\
\hline${ }^{\#} \mathrm{ZOM} / 2 / 84$ & Malawi & Zomba & 1984 & Sus scrofa & AF449471 \\
\hline ZON 88/1 & Zambia & Zondola, katete, Eastern Province & 1988 & Sus scrofa & AY351560 \\
\hline
\end{tabular}

Virus supplied by: ${ }^{1}$ Dr. Klauz Lorenz (Divisional Veterinary Officer, Blantyre Agricultural Development Division, Malawi; ${ }^{2}$ Dr. J.I.G Masambu, ADRI-TEMEKE, Dar-es-Salaam, Tanzania; ${ }^{3}$ Chief Research Officer, Virology Laboratory, Central Veterinary Laboratories, Lusaka, Zambia; ${ }^{4}$ Food and Agriculture Org anization (FAO), Department of Livestock, Health and Entomology, Uganda; ${ }^{5}$ The National Veterinary Institute, Mozambique. Viruses previously characterized by RFLP analysis in the studies of Sumption et al. 1990 and Dixon \& Wilkinson 1988, are denoted by the superscript numbers '6' and '7', respectively. NK: Not known, * Indicates Ornithodoros ticks collected from warthog burrows; ${ }^{\#}$ Indicates reference isolates (Bastoset al., 2003), DRC: Democratic Republic of the Congo. 
Table 2.2 ASFV isolates characterized and grouped by Sumption (1992) using Bam HI RFLP

\begin{tabular}{|c|c|c|c|c|c|c|c|}
\hline \multirow[t]{2}{*}{ Group } & \multirow[t]{2}{*}{ Virus } & \multirow[t]{2}{*}{ Country } & \multirow[t]{2}{*}{ Location } & \multirow[t]{2}{*}{ Isolation year } & \multirow[t]{2}{*}{ Origin } & \multicolumn{2}{|c|}{ Passage details } \\
\hline & & & & & & Pig & PBMC \\
\hline $\bar{I}$ & KAV89/1\# & Zambia & Kavundulo, E. Province & 1989 & Pig & NK & NK \\
\hline & KON83 & Malawi & Mchinji-Southern Province & 1983 & Tick & 1 & 0 \\
\hline & Lil20/1 & Malawi & Kamende-Mchinji & 1983 & Tick & NK & \\
\hline & MOZ60\# & Mozambique & NK & 1960 & Pig & NK & 5 \\
\hline & RHO63 & Zambia & E. Province & 1963 & Pig & NK & NK \\
\hline II & ANG70\# & Angola & NK & 1970 & Pig & 3 & NK \\
\hline & BUR84/1\# & Burundi & Mushasha-Butega & 1984 & Pig & 0 & 0 \\
\hline & CAM82\# & Cameroon & NK & 1982 & Pig & 2 & 0 \\
\hline & KAT67 & $\overline{\text { DRC }}$ & Katanga & 1967 & NK & NK & NK \\
\hline & NAM86 & Namibia & Grootfontein & 1986 & & 0 & 2 \\
\hline III & MOZ79\# & Mozambique & Beira & 1979 & Pig & 0 & 1 \\
\hline & Tengani62 & Malawi & Tengani & 1962 & Pig & 2 & 0 \\
\hline IV & HINDE54 & Kenya & Hinde Ranch & 1954 & Pig & NK & NK \\
\hline & LIV13/33* & Zambia & Livingstone Game Park & 1983 & Tick (warthog) & 0 & 1 \\
\hline $\mathrm{V}$ & TAN87 & Tanzania & Mbeya-SW Tanzania & 1987 & Pig & 2 & 0 \\
\hline VI & MFUE6/1* & Zambia & $\begin{array}{c}\text { Mfue, Luangera National } \\
\text { Park }\end{array}$ & 1982 & Tick (warthog) & 0 & 1 \\
\hline VII & SUM14/11* & Zambia & Sumbu National Park & 1983 & Tick (warthog) & 0 & 1 \\
\hline
\end{tabular}

PBMC: Pig Bone Marrow Culture $\quad$ SW: South West $\quad$ NK: Not Known $\quad$ E: East $\quad$ DRC: Democratic Republic of Congo

* Isolates common to those characterized in this study. \# Isolates common to those characterized in previous $p 72$ genotyping studies (Bastos et al., 2003, 2004) 


\subsubsection{Extraction of viral DNA}

DNA was extracted from known virus cultures or tissue sample homogenates using a silica/guanidium-based nucleic acid extraction method (Boom et al., 1990). For each virus or homogenized diagnostic specimen, a $100 \mu \mathrm{l}$ aliquot was transferred to a $1.5 \mathrm{ml}$ labeled Eppendorf tube. A milliliter of L6 (Appendix B) lysis buffer was added to $40 \mu 1$ of silica (Appendix C) and vortexed until completely dissolved. $940 \mu 1$ of the lysis buffersilica mixture was added to each specimen, vortexed and allowed to stand at room temperature for 5 minutes. At 1 minute intervals the samples were inverted. The tubes were later vortexed again and centrifuged at $15000 \mathrm{rpm}$ for 15 seconds, and the supernatant discarded in a $10 \mathrm{M} \mathrm{NaOH}$ waste bottle. The L2 wash buffer (Appendix D) was then added in quantities of $900 \mu \mathrm{l}$ per sample, vortexed, and centrifuged for a few seconds. The supernatant was pipetted off in the above-mentioned waste bottle. A wash step with $900 \mu \mathrm{l}$ of $70 \%$ ethanol was performed and finally $900 \mu \mathrm{l}$ of acetone was added as the final cleaning step. After discarding the acetone supernatant, the silica pellets were then dried by placing on a heating block pre-set at $56^{\circ} \mathrm{C}$, with the eppendorf tube lid open, for 20 minutes approximately. 1X TE (Tris-Acetate) was prepared (Appendix E), $30 \mu \mathrm{l}$ of which was added to the dry silica pellet. The tube was vortexed and incubated for 2 minutes on the heating block with lid closed. A 10 minutes centrifugation step followed, and the supernatant was finally transferred to a clean $1.5 \mathrm{ml}$ labeled eppendorf tube. The DNA was stored at $-70^{\circ} \mathrm{C}$ until further use.

\subsubsection{Genomic amplification of viral DNA}

Two separate polymerase chain reactions (PCR) were performed: -

1. Diagnostic PCR for confirmation of the presence of ASF viral nucleic acid, where a $278 \mathrm{bp}$ region corresponding to the central portion of the $p 72$ gene was amplified using ASF diagnostic primers ASF-1 (5'ATGGATACCGAGGGAATAGC3') and ASF-2 
(5'CTTACCGATGAAAATGATAC3') described in Chapter 2.1.12 of the 2000 edition of the OIE Manual of Standards for Diagnostic Tests and Vaccines.

2. A PCR for molecular epidemiological analysis, where the C-terminal region of the p72 gene was amplified using epidemiological primers P72-U

(5' GGCACAAGTTCGGACATGT3') and P72-D (5' GTACTGTAACGCAGCACAG3'), as described previously (Bastos et al., 2003).

For each of these PCRs, genomic amplification was performed in a $50 \mu$ l volume in the presence of $200 \mu \mathrm{M}$ dNTPs (Roche), $0.4 \mu \mathrm{M}$ of each primer, $2.5 \mathrm{U}$ of thermostable Taq DNA polymerase (Roche) and $3 \mu 1$ of DNA extract. The template was amplified following 40 cycles of denaturation at $96^{\circ} \mathrm{C}$ for $12 \mathrm{~s}$, annealing at $53^{\circ} \mathrm{C}$ for $20 \mathrm{~s}$ and extension at $70^{\circ} \mathrm{C}$ for $30 \mathrm{~s}$.

\subsubsection{Agarose gel electrophoresis}

Amplification products were loaded on a $1.5 \%$ agarose gel and run against a $100 \mathrm{bp}$ DNA ladder (Promega). Once sufficient electrophoretic separation was obtained, products were visualized by UV irradiation and ethidium bromide staining. The gels were photographed in order to obtain a hard copy record of the results.

\subsubsection{Purification of PCR products}

ASFV genome regions targeted by PCR for phylogenetic analysis were excised from the agarose gel and purified using either Qiagen (Qiagen) or Nucleospin (Machery-Nagel) PCR purification kits according to the manufacturer's specifications.

2.2.8 Nucleotide sequencing and alignment 
The nucleotide sequence of the purified products was determined by automated cycle sequencing with Big Dye version 3.1 by running in a 47 centimeter capillary on an ABI Prism 310 Genetic Analyzer (Applied Biosystems).

All nucleotide sequences generated by the epidemiological primers in this study were aligned using the DAPSA program (Harley, 1994).

\subsubsection{Phylogenetic analysis of the $p 72$ gene}

A homologous region of 404 nucleotides was used for phylogenetic inference. The methods employed were either distance-based where a matrix was used to cluster closely related taxa, alternatively, character data and an optimality criterion was used to infer a phylogeny. The methods included neighbor-joining (NJ), minimum evolution (ME), maximum parsimony (MP) and maximum likelihood (ML). Model Test (Posada and Crandall, 1998) was used to identify the model of substitution that best fitted the data at hand.

\subsubsection{Neighbor-joining (NJ)}

The NJ tree was drawn in MEGA v2.1 (Kumar et al., 2001). The nucleotide substitution model of Tamura and Nei (1993) was employed which takes transition/transversion (si/sv) bias within a dataset into account when calculating distances. 10000 bootstrap replications were performed to determine the level of support for each node in the resulting mid point rooted phylogenetic tree.

\subsubsection{Minimum evolution (ME)}

An ME tree was drawn in MEGA 2 (Kumar et al., 2001)) employing the Tamura and Nei model (1993) and specifying a gamma distribution shape parameter (G) of 0.8033 from the Akaike Information Criterion (AIC) in modeltest (Posada and Crandall, 1998). Mid point rooting was applied to the tree. 


\subsubsection{Maximum likelihood (ML)}

From Model Test, the $\operatorname{TrN}+\mathrm{I}+\mathrm{G}$ nucleotide substitution model selected under the Akaike Information Criterion was used for ML analysis in PAUP*. Base frequencies for A, C, G and $\mathrm{T}$ were $0.2690,0.2344,0.1929$ and 0.3037 , respectively. In addition, proportion of invariable sites (I) of 0.5647 and a gamma distribution shape parameter (G) of 0.8033 . were specified.

\subsubsection{Maximum parsimony (MP)}

Unweighted and weighted parsimony analyses were explored. For the unweighted parsimony analysis, all characters were unordered and had equal weights. 330 characters were constant and of the variable characters, 24 were parsimony uninformative and 50 were parsimony-informative. Heuristic search option was in effect. Starting trees were obtained via stepwise addition, the closest method was used for addition of sequences, and 1 tree was held at each step during stepwise addition. Branches were swapped using the tree-bisection-reconnection (TBR) algorithm. 200 bootstrap replications were performed to assess nodal support

Successive weighting using the rescaled consistency indices RC) was also performed. The weighted MP search settings were similar to those stated above with the following exceptions: 383 characters had a weight of 1 and 21 characters had a weight other than 1.

\subsection{RESULTS}

\subsubsection{Data statistics}

Preliminary exploration of the nucleotide sequence data of the 102 OTUs (Operational Taxonomic Units) in MEGA v1.0 indicated that the four nucleotides do not occur at the same frequency. An average percentage composition of $29.1 \%$ thiamine (T), $28.2 \%$ 
adenine (A), $24.1 \%$ cytosine (C) and $18.6 \%$ guanine $(\mathrm{G})$ was observed. On average, a si/sv ratio of 4.1 was detected, clearly indicating a transitional bias. From the aligned amino acid sequences, 134 codons in length, it was shown that the majority of mutations were non-synonymous and occurred at the third base position. Of the 404 nucleotides, 333 were conserved, 71 were variable, 49 were parsimony informative and 22 were singletons (Fig 2.1). On amino acid level, 114 of the 134 codons were completely conserved and 20 were variable. Among the variable sites, 6 were parsimony informative and 14 were singletons.

\subsubsection{Model Test and data statistics}

The TrN nucleotide substitution model, invariable sites and gamma distribution were the chosen parameters for use in inferring phylogeny. The log likelihood score was $\ln \mathrm{L}$ 1272.4698. The nucleotide base frequencies of the data under this model of nucleotide substitution differed from that calculated directly from the data and was as follows: $\mathrm{A}=$ $0.2690, \mathrm{C}=0.2344, \mathrm{G}=0.1929$ and $\mathrm{T}=0.3037$. The proportion of invariable sites (I) was 0.5502 and the gamma distribution shape parameter was 0.8033 .

\subsubsection{Phylogenetic analysis}

\subsubsection{Minimum Evolution (ME)}

The ME analysis with MEGA2, using the Tamura-Nei model and specifying a gamma distribution shape parameter of 0.8033 was consistent and yielded reliable results. Thirteen East African genotypes were discerned on the $1 \%$ genetic distance basis specified previously for distinguishing different $p 72$ genotypes (Bastos et al., 2003) (genotype XVI divided into 2 genotypes), and on the $55 \%$ or higher bootstrap support values. 13 East African $p 72$ genotypes, together with the three reference viruses of nonEast African genotypes (III, IV and VII), brought the total number of identified $p 72$ 
genotypes to 16 (Fig. 2.2). Similar results were obtained with the neighbor-joining method.

\subsubsection{Maximum Likelihood}

When using the Model Test parameters and a starting NJ tree in ML analysis, the resulting phylogeny had a branching pattern that corresponded well with that obtained by ME analysis (results not shown).

\subsubsection{Maximum Parsimony}

82 unweighted parsimony trees were recovered at the end of the heuristic search, where 20344797 rearrangements were tried. All trees had a length of 114, and a consistency index $(\mathrm{CI})$, retention index (RI) and re-scaled consistency index (RC) of 0.728, 0.969 and 0.706 , respectively was obtained. The sum of minimum possible lengths was 83 , while the sum of maximum possible lengths was 1086. Mean tree length was 114. A $50 \%$ majority-rule consensus tree was obtained.

Successive weighting with the RC yielded an MP tree 72.52599 in length, and resulted in 6 equally parsimonious trees (Fig 2.3). As with the ML, ME and NJ methods, 13 East African and 3 non East African genotypes were discerned with MP. No difference in topology was noted between unweighted and reweighted parsimony analyses.

\subsubsection{Interpretation of phylogenetic analysis}

As trees with comparable topology were obtained with all methods of phylogenetic inference, the ME tree (Fig. 2.2) which was obtained using an optimality criterion and which co-incides with the method used to identify the 10 major p72 genotypes (Bastos et al. 2003), will be used to discuss the phylogenetic relationships of the 102 OTUs used in this study. 
A total of sixteen $p 72$ genotypes were consistently recovered (Fig. 2.2), of which thirteen occur within the East African region (Fig. 2.4). Genotypes I - X correspond to those identified previously (Bastos et al., 2003), whilst p72 genotypes XI - XVI are reported here for the first time and are therefore regarded as novel (Table 2.3).

Genotype I (also referred to as the ESACWA genotype), initially identified in pig isolates from Europe, South America, the Caribbean islands and West Africa (Bastos et al., 2003), was found in this study to be present in East African domestic pigs and sylvatic hosts such as bushpigs and ticks. Similarly, genotype V, X and XII viruses were recovered from both domestic pigs and from wild vertebrate and invertebrate hosts, indicating that the argasid tick vector moves readily between wild and domestic vertebrates within the regions in which these genotypes occur (Fig. 2.2). These four genotypes I, V, X and XII were shown to be present in three, one, four and two East African countries, respectively (Fig. 2.4), with some of these genotypes having a field presence of more than four decades (Table 2.3).

Genotypes XI, XIII and XIV appear to be associated exclusively with a sylvatic cycle as these viruses, which were collected in Zambia between 1983 and 1986, were all of tick (from warthog burrow) origin. Genotypes II, VI, VIII, IX, XV and XVI comprised exclusively domestic pig strains. Of these, II and VIII were confined to three countries each, and circulated for between 10 and 20 years in the field, genotype IX caused two temporally unrelated outbreaks in domestic pigs in 1995 and 2003, while the remaining genotypes were restricted to one country each and were associated with a single epizootic (and sometimes a single virus).

The molecular phylogeny further revealed the presence of three distinct evolutionary groups (labelled A - C in Fig. 2.2). Viruses sharing a common evolutionary history fall within the following genotype clades:
(A) Genotypes I - VII (80 \% bootstrap support)
(B) Genotypes VIII and XI - XVI (66 \% bootstrap support)
(C) Genotypes IX and X (100\% bootstrap support) 
Levels of mean intra-genotypic variation ranged from $0 \%$ (genotypes II, VI, IX and $\mathrm{XVI}$ ) to $0.7 \%$ (genotype XII), whilst mean inter-genotypic levels of variation ranged from $0.9 \%$ (between genotypes V and VI, and XI and XII) to $8.0 \%$ (between genotypes $\mathrm{V}$ and $\mathrm{X}$ ). The maximum level of sequence divergence between any two isolates was 9.8 $\%$.

Comparison of the findings of this investigation and that of Sumption (1992) displayed both similarities and differences. In the RFLP study BamHI restriction enzyme fragment patterns were generated in order to compare and characterize isolates from Zambia, Malawi and other African countries (Sumption, 1992; Table 2.2).

The first group consisted of isolates from Malawi and Zambia mainly, and one from Mozambique, MOZ60 (Table 2.2). This group corresponds well with $p 72$ genotype VIII since it involved identical isolates to those used in this study, or country and location representatives thereof (Fig. 2.2). However, the Mozambican isolate was classified within a different $p 72$ genotype (genotype V) by Bastos and co-workers (2004). The second group consisted of isolates from West Africa, Democratic Republic of Congo and Burundi. With the exception of the Burundi isolate, this group was identical to the ESACWA genotype (genotype I) by composition. Tengani 1962 and Mozambique 1979 constituted the third group. In this study and that of Bastos et al. (2004), Tengani60 and Malawi 2002/1, and Tengani60, Moz79 and Moz60 represented genotype V. LIV13/33 and HINDE54 comprised group IV. Contrary to RFLP, $p 72$ genotyping clustered LIV13/33 with the ESACWA isolates, while available viruses from HINDE formed part of genotype X. Similar to $p 72$ genotyping, tick isolate SUM14/11 formed a unique group, while MFUE 6/1 clustered with a pig isolate, MZI92/1, on the contrary. TAN87 also resulted in a unique restriction fragment pattern. 




(1111111112222 222222222222222333333333333333333333334

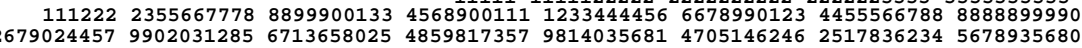

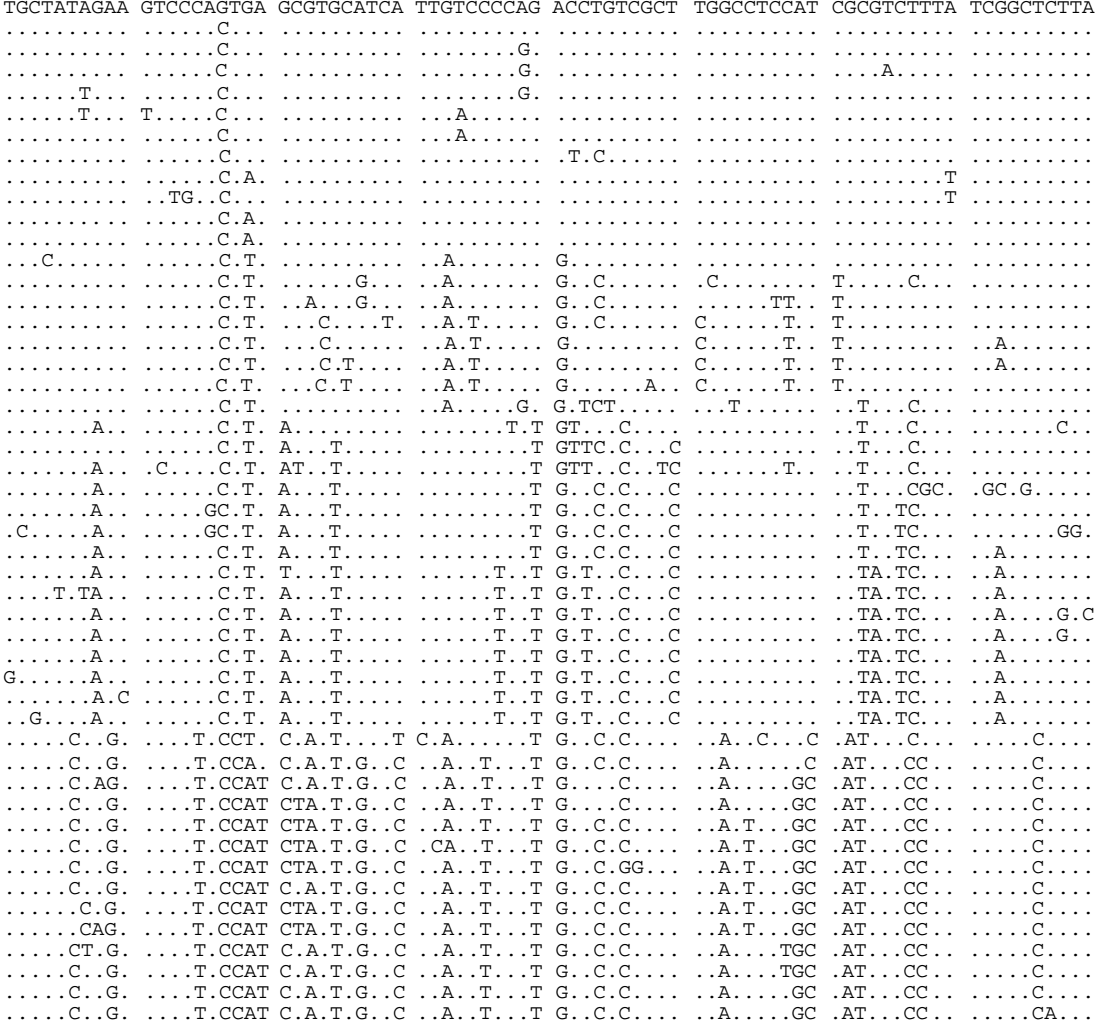

Fig. 2.1 Nucleotide sequence alignment showing the variable sites of the 49 unique sequences identified in this study and in previous studies. Dots indicate nucleotide sites identical to that of the master sequence, IC3/96. Superscript numbers 1 to 4 indicate those viruses included in the studies of Yu et al., 1996, Odemuyiwa et al., 2000, Bastos et al., 2003 and Bastos et al., 2004, respectively. 


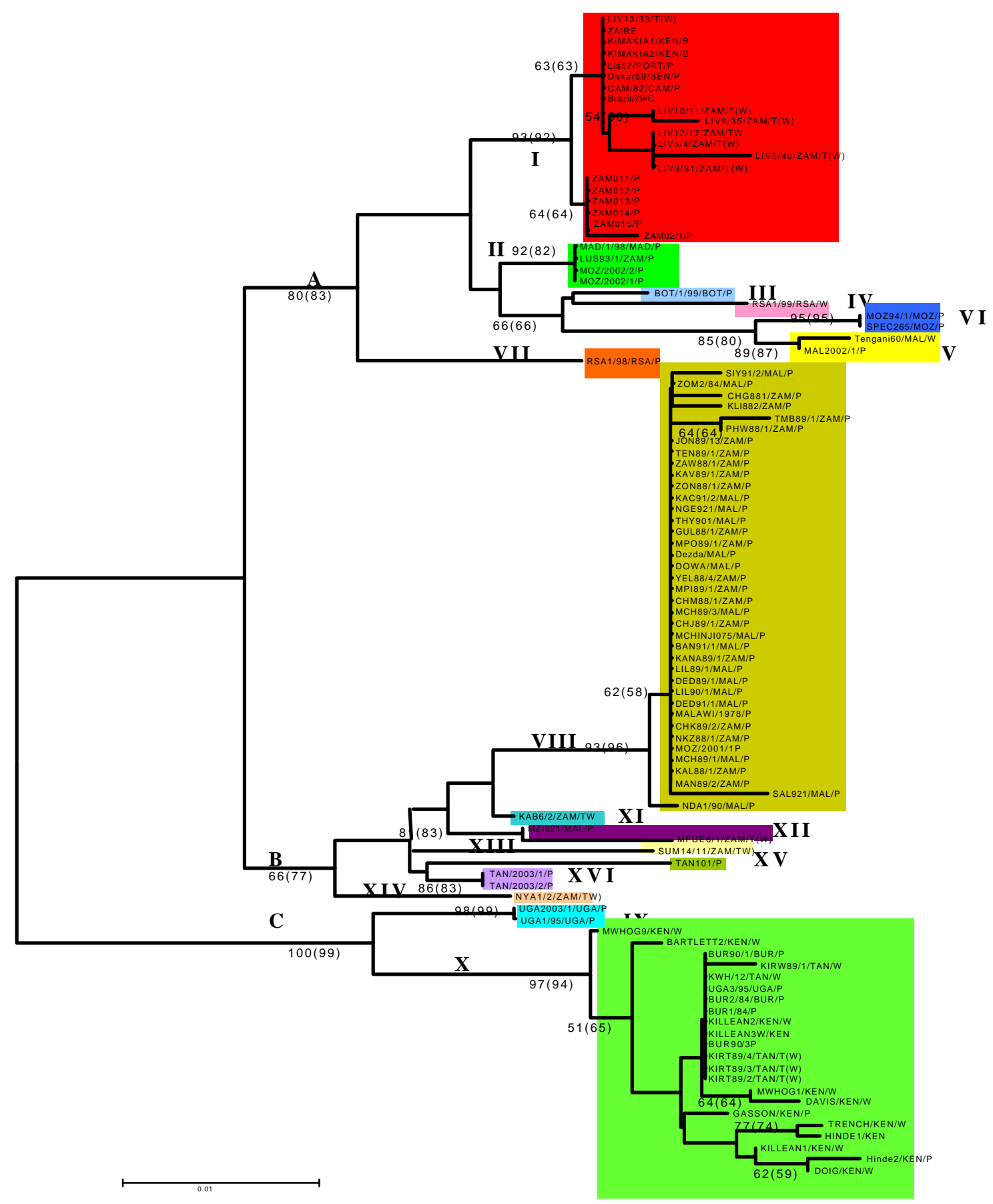

Fig. 2.2 Minimum evolution tree depicting the 16 ASFV $p 72$ genotypes (labeled I-XVI) and three main evolutionary lineages (labeled $\mathrm{A}-\mathrm{C}$ ). Bootstrap values $>50 \%$ and obtained by ME method are indicated next to the relevant node, whilst those obtained by $\mathrm{NJ}$ technique are indicated in brackets. All bootstrap values were obtained following 10000 replications. 


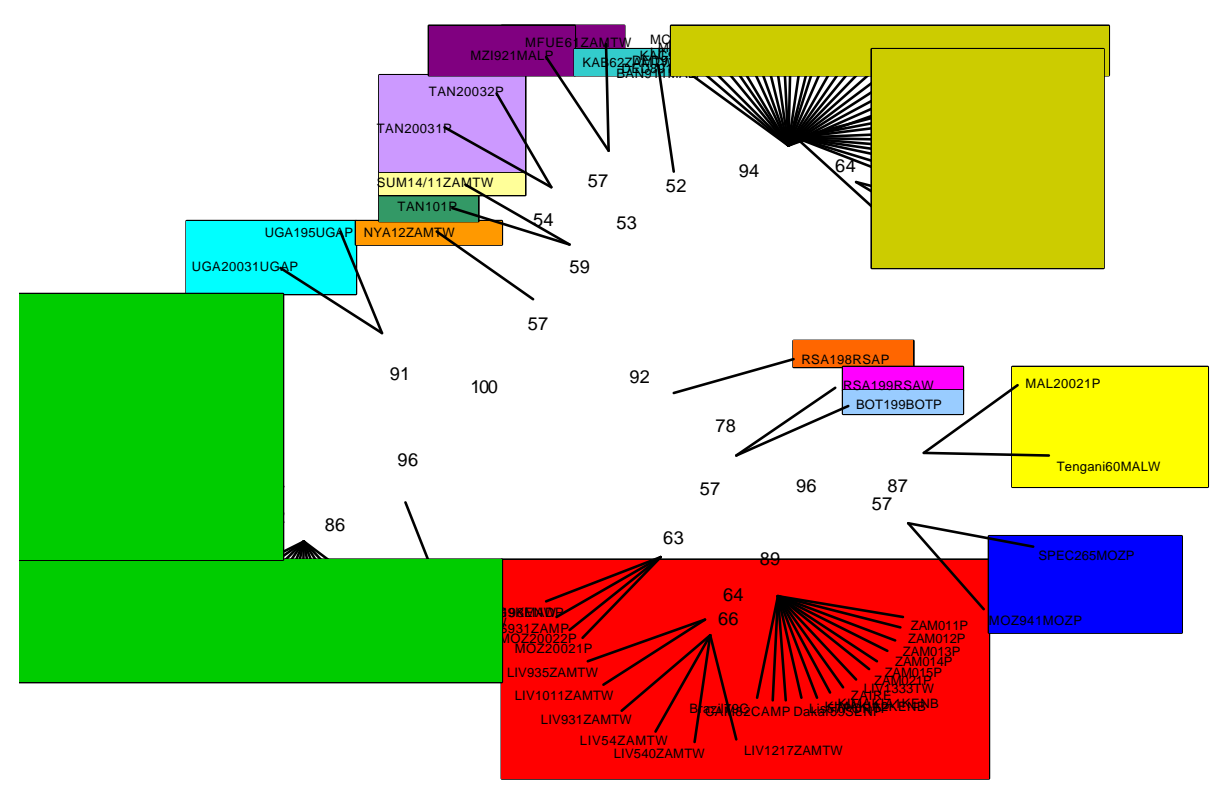

Fig. 2.3 MP tree obtained with successive weighting with the RC showing p72 phylogenetic relationships of the 102 OTU used in this study. Bootstrap support of $>50 \%$ are indicated next to the relevant nodes. 


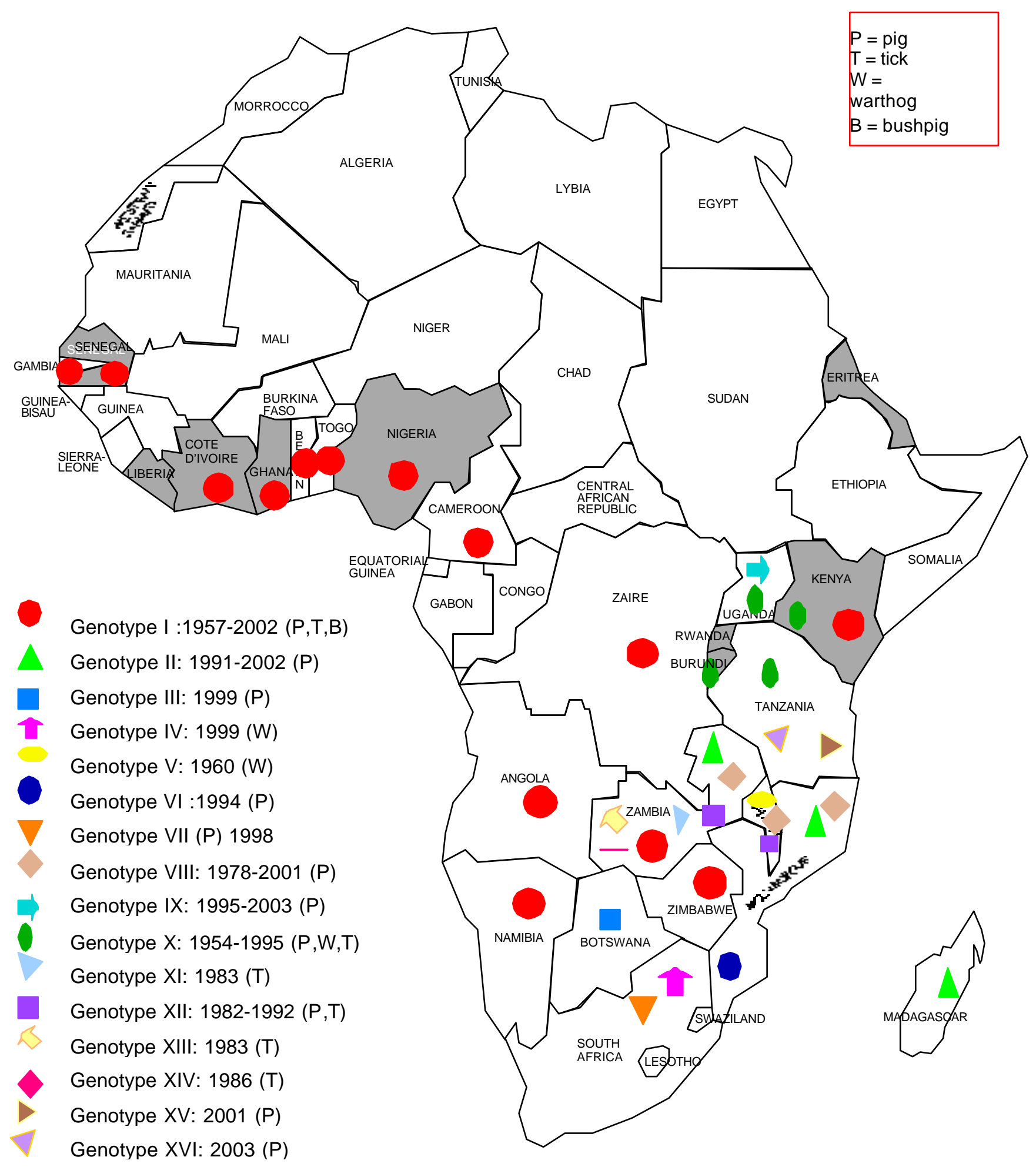

Fig. 2.4 Geographical distribution of the 16 major African Swine Fever virus genotypes identified by partial $p 72$ genotyping 
Table 2.3 Summary of the distribution, field presence and intra-genotypic variation of the major African swine fever virus $p 72$ genotypes resolved in this study using 102 viruses and comparison with 39 virus sequences from previous studies (Lopez-Otin et al., 1990; Yu et al. 1996; Odemuyiwa et al., 2000; Bastos et al., 2003, 2004). The isolates used for comparison were not included for phylogenetic analysis in this study.

\begin{tabular}{|c|c|c|c|c|c|c|}
\hline Genotype & Representative countries & $\begin{array}{l}\text { Presence in } \\
\text { the field }\end{array}$ & Species affected & $\begin{array}{l}\text { No. of } \\
\text { viruses }\end{array}$ & $\begin{array}{ll}\text { No. } & \text { of } \\
\text { countries }\end{array}$ & $\begin{array}{l}\text { Mean } \\
\text { intragenotypic } \\
\text { nucleotide } \\
\text { variation }\end{array}$ \\
\hline $\mathrm{I}$ & $\begin{array}{c}\text { Zambia, Kenya, Zaire, Cameroon, Ghana, Senegal, } \\
\text { Nigeria, Gambia, Benin, Côte d'Ivoire, Togo, } \\
\text { Angola, Zimbabwe, Namibia, Portugal, Brazil, Spain, } \\
\text { Sardinia, Malta, Holland, Belgium, Dominican } \\
\text { Republic }\end{array}$ & $1957-2002$ & $\begin{array}{c}\text { Bushpig } \\
\text { Domestic pig } \\
\text { Tick (warthog) }\end{array}$ & 57 & 22 & $0.2 \%$ \\
\hline II & Mozambique, Zambia, Madagascar & $1991-2002$ & Domestic pig & 5 & 3 & $0.0 \%$ \\
\hline III & Botswana & 1999 & Domestic pig & 1 & 1 & -- \\
\hline IV & Republic of South Africa & 1999 & Warthog & 1 & 1 & - \\
\hline $\mathrm{V}$ & Malawi & $1960-2002$ & $\begin{array}{c}\text { Domestic pig } \\
\text { Warthog }\end{array}$ & 2 & 1 & $0.4 \%$ \\
\hline$\overline{\mathrm{VI}}$ & Mozambique & 1994 & Domestic pig & 3 & 1 & $0.0 \%$ \\
\hline VII & Republic of South Africa & 1998 & Domestic pig & 1 & 1 & -- \\
\hline VIII & Zambia, Malawi and Mozambique & $1978-2001$ & Domestic pig & 39 & 3 & $0.1 \%$ \\
\hline IX & Uganda & $1995-2003$ & Domestic pig & 2 & 1 & $0.0 \%$ \\
\hline $\bar{X}$ & Uganda, Burundi, Tanzania, Kenya & $1954-1995$ & $\begin{array}{c}\text { Domestic pig } \\
\text { Tick (warthog) } \\
\text { Warthog }\end{array}$ & 22 & 4 & $0.6 \%$ \\
\hline$\overline{X I}$ & Zambia & 1983 & Tick (warthog) & 1 & 1 & - \\
\hline XII & Malawi and Zambia & $1982-1992$ & $\begin{array}{c}\text { Domestic pig } \\
\text { Tick (warthog) }\end{array}$ & 2 & 2 & $0.7 \%$ \\
\hline
\end{tabular}




\begin{tabular}{|c|c|c|c|c|c|c|}
\hline Genotype & Representative countries & $\begin{array}{l}\text { Presence in } \\
\text { the field }\end{array}$ & Species affected & $\begin{array}{l}\text { No. of } \\
\text { viruses }\end{array}$ & $\begin{array}{l}\text { No. of } \\
\text { countries }\end{array}$ & $\begin{array}{l}\text { Mean } \\
\text { intragenotypic } \\
\text { nucleotide } \\
\text { variation }\end{array}$ \\
\hline XIII & Zambia & 1983 & Tick (warthog) & 1 & 1 & - \\
\hline XIV & Zambia & 1986 & Tick (warthog) & 1 & 1 & - \\
\hline $\mathrm{XV}$ & Tanzania & 2001 & Domestic pig & 1 & 1 & -- \\
\hline XVI & Tanzania & 2003 & Domestic pig & 2 & 1 & $0.0 \%$ \\
\hline
\end{tabular}

Table 2.4 Average p-distance (in \%) between ASFV genotypes discerned by $p 72$ nucleotide sequencing

\begin{tabular}{|c|c|c|c|c|c|c|c|c|c|c|c|c|c|c|c|c|}
\hline Genotype & 1 & 2 & 3 & 4 & 5 & 6 & 7 & 8 & 9 & 10 & 11 & 12 & 13 & 14 & 15 & 16 \\
\hline 1 & & & & & & & & & & & & & & & & \\
\hline 2 & 1.1 & & & & & & & & & & & & & & & \\
\hline 3 & 2.1 & 1.5 & & & & & & & & & & & & & & \\
\hline 4 & 2.4 & 1.8 & 1.3 & & & & & & & & & & & & & \\
\hline 5 & 2.5 & 1.9 & 2.4 & 2.2 & & & & & & & & & & & & \\
\hline 6 & 2.7 & 2.1 & 2.0 & 1.8 & 0.9 & & & & & & & & & & & \\
\hline 7 & 2.6 & 2.0 & 2.0 & 2.8 & 3.5 & 3.1 & & & & & & & & & & \\
\hline 8 & 4.0 & 3.9 & 4.4 & 5.3 & $\begin{array}{l}4.9 \\
\end{array}$ & 5.6 & 3.9 & & & & & & & & & \\
\hline 9 & 5.9 & 5.2 & 5.2 & 5.5 & 6.8 & 6.4 & 5.2 & 5.8 & & & & & & & & \\
\hline 10 & 6.7 & 6.4 & 5.9 & 6.2 & 8.0 & 7.6 & 6.5 & 7.0 & 2.5 & & & & & & & \\
\hline 11 & 3.4 & 3.3 & 3.3 & 4.1 & 4.3 & 4.4 & 3.3 & 1.1 & 4.7 & 5.9 & & & & & & \\
\hline 12 & 3.8 & 3.7 & 3.7 & 4.5 & 5.2 & 4.8 & 3.7 & 1.9 & 5.0 & 6.3 & \begin{tabular}{|l|}
0.9 \\
\end{tabular} & & & & & \\
\hline 13 & 4.2 & 4.1 & 4.1 & 4.9 & 5.3 & 5.2 & 4.1 & 2.6 & 5.4 & 6.4 & 1.5 & 2.1 & & & & \\
\hline 14 & 2.9 & 2.8 & 3.3 & 4.1 & 4.3 & 4.4 & 3.3 & 2.6 & 5.2 & 6.4 & 2.0 & 2.3 & \begin{tabular}{|l|}
2.8 \\
\end{tabular} & & & \\
\hline 15 & 4.3 & 4.1 & 4.7 & 4.9 & 5.1 & 5.3 & 4.1 & 2.4 & 6.1 & 7.1 & 2.3 & 2.7 & \begin{tabular}{|l|}
3.1 \\
\end{tabular} & 2.3 & & \\
\hline 16 & 3.2 & 3.1 & 3.1 & 3.9 & 4.6 & 4.2 & 2.5 & 1.8 & 4.4 & 5.7 & 1.3 & 1.6 & \begin{tabular}{|l}
2.0 \\
\end{tabular} & 1.8 & 1.5 & \\
\hline
\end{tabular}




\subsection{DISCUSSION}

The presence of six more East African genotypes than was previously identified (Bastos et al., 2003) was revealed by the molecular phylogeny. Genotypes I, V, X, XI, XIII and XIV are examples of viruses that are present within a sylvatic cycle (occurring either within eyeless tampans or sylvatic vertebrate hosts, or both), half of which have also caused outbreaks in domestic pigs. Genotype XII which comprised two viruses isolated 10 years apart from a tick and domestic pig may be an example of a pig-tick cycle but this requires confirmation by more intensive screening of sylvatic vertebrates within Malawi and Zambia. The pig-to-pig cycle is, however, classically exemplified by genotype VIII, which has been in active circulation for at least 23 years and is represented by 39 outbreak strains from three countries. A genetic feature of a domestic pig cycle appears to be a pronounced lack of genetic variation, as both genotype I in West Africa (where it has only been isolated from domestic pigs) and genotype VIII in East Africa have extremely low levels of intratypic variation $(0.2 \%$ and $0.1 \%$, respectively), with most isolates being identical to each other. This lack of genetic variation was also found following restriction enzyme profiling of some genotype VIII viruses from Malawi (Sumption et al., 1990). Although sample sizes of the remaining genotypes are inadequate to permit speculation on the epidemiological cycles into which they may be classified, the results indicate that all three ASF epidemiological cycles appear to exist in East Africa. Wherever a sylvatic cycle is confirmed, higher levels of genetic variation are recovered (Dixon and Wilkinson, 1988; Bastos et al., 2003).

The East African region is the most genotype rich, with thirteen $p 72$ genotypes being identified. This far exceeds West Africa, which only contains one genotype in the ten countries previously screened (Bastos et al., 2003). Southern Africa is intermediate with at least eight genotypes (when Mozambique is excluded from the results) being identified thus far (Boshoff et al., 2004). While many of the East African genotypes are apparently country specific (V, VI, IX, XI, XIII, XIV, XV and XVI), others (I, II, VIII, X and XII) are not restricted by national boundaries. In addition, most countries within the East African region have more than one genotype within their borders. Zambia is particularly 
genotype rich with seven genotypes being identified, followed by Malawi, Mozambique and Tanzania with three each, and Kenya and Uganda with two each.

The ASFV introduced to Europe through illicit movement of pig products (MansoRibeiro et al., 1958) and which is widespread throughout West Africa (Bastos et al., 2003) may have its origins in East Africa as this study revealed it to be present in the natural sylvatic hosts in Kenya (Kimakia I and Kimakia II viruses) as far back as 1961. As the classical ASFV transmission mode involving a sylvatic cycle could not be proven in West Africa (Penrith et al., 2004), it is likely that the disease was originally introduced from the East of the continent before becoming established in a domestic pig cycle in West Africa. The more widespread distribution of the ESACWA genotype identified in this study makes this genotype the most successful and extensively distributed genotype, being present in 22 countries described to date.

The low levels of intratypic genetic diversity within the large and homogeneous genotype VIII necessitates an investigation into a more variable gene region in order to clarify within genotype relationships. In addition, the possibility that genotype I, which was previously believed to be confined to West Africa, originated from East Africa should be confirmed through sequencing of an alternative and more informative gene region. By focusing on typing ASFV from domestic pigs in East and Central African countries, where genotype I is present in the sylvatic hosts, it may also be possible to trace the route of entry of this virus into West Africa.

Lineage A (Fig. 2.2) has an interesting evolutionary history since it constitutes the first European isolate, Lisbon57. This group consists of seven genotypes, involves all epidemiologically important ASFV hosts, and is found on at least three continents (Africa, Europe and South America). Links between East, Central and West Africa, and Europe demonstrated by genotype I in this study, make it the most widespread lineage of all the ASFV lineages identified in Africa and elsewhere. Lineage B constitutes seven East African genotypes, contains all epidemiologically important ASFV hosts, with the exception of bushpigs, and exemplifies all three ASF epidemiological cycles mentioned 
by Penrith and co-workers (2004). Lineage C, which consists of two East African genotypes is basal to lineages $\mathrm{A}$ and $\mathrm{B}$ pointing to

East Africa being the possible geographical origin of ASF viruses.

Comparison of the RFLP genotyping results of the study conducted by Sumption (1992), to those obtained with $p 72$ genotyping, clearly showed that most of the viruses clustered in comparable groups with the exception of MOZ60, BUR84/1 and LIV13/33 (Table 2.2; Bastos et al., 2003; Lubisi et al., 2005). The dissimilarities may have arisen from the following facts:

1) The two methods (RFLP and p72 genotyping) focused on different parts of the genome, with RFLP characterizing differences in the left and right variable termini, whilst $p 72$ genotyping targets a gene coding for a major capsid protein;

2) The BamHI restriction fragments a'b spanned a region of at least $1.6 \mathrm{~kb}$, but only a fraction of this was actually characterized since the endonuclease only recognized the 5' GGATCC 3' sequence (Stryer, 1988), thus the absolute genome size examined was less than the $404 \mathrm{bp}$ region used for $p 72$ genotyping;

3) The genome area used in RFLP consisted of at least 2 variable regions as well, VR1 and VR2, while one gene of conserved length, $p 72$, was the center of focus in the other method;

4) VR2 was found to be the most variable of all 8 VR located in the ASFV genome (Sumption, 1992), with deletions and insertions causing up to 9100 bp size differences between isolates, while the $p 72$ gene shows no size variation and is unaffected by passage on Monkey cells;

5) Even though the viruses displayed similar BamHI a'b restriction fragment patterns in the RFLP study, they may have had different nucleotide sequences which could have occurred naturally over time or with serial passages into different susceptible cells (Table 2.2). The latter differences may not necessarily affect the genome size but could alter virus classification into genotypes, as could have been the case with the grouping of MOZ60, BUR84/1 and LIV13/33. 
The $9.1 \mathrm{~kb}$ size difference between BamHI a'b could also have been too large and too variable for genotyping viruses from diverse geographic locations, species of origin and temporal occurrence. On average, there is a $4.9 \%$ nucleotide difference between $p 72$ genotypes V and VIII (RFLP group I) in which MOZ60 is classified using the two methods (Table 2.4 and Bastos et al., 2004). Between p72 genotype I (RFLP group II equivalent) where LIV13/33 clusters and $\mathrm{X}$ in which BUR84/1 and most HINDE viruses are categorized, an average of $6.7 \%$ nucleotide difference exists (Table 2.4). Clearly, these differences are large and warrant classification into different genotypes as the more conserved $p 72$ gene characterization method has done. Perhaps the utilization of less variable BamHI fragments from the corresponding right terminal region could yield more agreeable results between the two methods.

Both the sylvatic and domestic pig cycles appear to play an important role in the epidemiology of ASF in East Africa. The existence of multiple genotypes within countries, trans-boundary distribution of genotypes between countries and regional genotype richness adds to the complexity of ASF epidemiology in East Africa. As genotyping in this study was based on partial characterization of the gene coding for the immunodominant protein VP72, future vaccination campaigns could utilize this information when formulating vaccine for specific countries, since immunizing pigs with antigens from viruses distantly related to those with which they are challenged offers less protection (Boinas et al., 2004; Neilan et al., 2004). These factors are important considerations that need to be taken into account for effective control of the disease in East Africa. 


\section{Chapter 3}

\section{Intra-genotypic resolution of $p 72$ genotype VIII virus relationships by Central Variable Region characterization}

\section{SUMMARY}

Thirteen $p 72$ genotypes were identified within eight East African countries, of which one, genotype VIII, constituted a domestic pig cycle that was homogenous across the $p 72$ gene studied. In order to resolve within genotype relationships, sequencing of an amino acid tetrameric repeat region located within the 9-RL Open Reading Frame (ORF), and termed the central variable region (CVR), was performed. Eight discrete genetic lineages, designated A-H were recovered by phylogenetic analysis of the aligned amino acid sequences. The largest CVR lineage (group A), comprised 25 isolates, from Zambia, Malawi and Mozambique with identical CVRs 84 amino acids (aa) in length. These group A viruses which caused outbreaks over a 23 year period indicate that the repeat region in these viruses with an extended field presence, is extremely stable. The next largest CVR cluster $(\mathrm{G})$ comprised 10 viruses causing outbreaks over a 10 year period in Zambia, Malawi and Mozambique. Taken together, these results indicate that transboundary transmission of disease between the afore-mentioned three East African countries occurs readily. The remaining six intra-genotypic clusters comprised three or less viruses from outbreaks in individual counties, with a maximum circulation period of three years being identified. Intra-genotypic resolution by CVR has clearly been beneficial for identifying epidemiological links between different outbreaks caused by genotype VIII viruses, and is therefore advocated for clarifying viral relationships within homogenous $p 72$ genotypes that are associated with the domestic pig cycles. 


\subsection{INTRODUCTION}

Virus genome characterization is increasingly being utilized in the quest for taxonomical classification, discerning evolutionary and epidemiological patterns, and differentiation on the basis of pathogenesis and virulence in the field of virology (Becker et al., 1992; Gray et al., 2001; Walker et al., 2001; Costas, 2002; Shchelkunov et al., 2002). Highly conserved genome regions, characterized by their low mutation rates, have been used successfully to group viruses into various genotypes (Vanderhallen et al., 1999; Fenaux et al., 2000; Bastos et al., 2003). These regions, however, are often too stable for finer resolution of viruses within individual genotypes.

Genome regions that are variable to hyper variable have proven useful in the endeavors of scientists to determine close relationships or further resolve within genotype or serotype relationships (Bornkamm et al., 1980; Sidagis et al., 1997; Duffy et al., 2002; Gao et al., 2003; Gonz'alez-Candelas et al., 2003; Zheng et al., 2003). A considerable number of these regions are sequence repeats, usually in the form of long terminal repeats (LTR) (Rohn et al., 1998; Chen et al., 1999; Yamashita et al., 1999) or short tandem repeats (STR) (Foster and Trimarchi, 1994; Rosenberg et al., 1994; Tautz and Schlotterer, 1994; Field and Wills 1996, 1998).

The short tandem repeats, also called microsatellites, have been identified in viruses such as Herpes simplex, Epstein - Barr, Mengovirus, Vesicular Stomatitis (VSV), Hepatitis C, Human Respiratory Syncitial and Avian Influenza (Umene et al., 1984; Duke et al., 1990; Garcia - Barreno et al., 1994; Yamada et al., 1996; Barr et al., 1997; Perdue et al., 1997). To cite a few examples, Chen et al. (1999) as well as Yamashita et al. (1999) sequenced the LTR of Human T cell Leukemia virus (HTLV) type 1 to obtain finer resolutions of relationships within the serological type, and bring new insights into the possible origins of these viruses in America and Asia. The long terminal repeats of the cDNA of HIV type 1 viruses were used for subtyping (Harris et al., 2003). To differentiate oncogenic and non-oncogenic strains of Marek's disease virus (MDV) type 1 by polymerase chain reaction DNA amplification, primers amplifying a region within the long inverted region 
(Zhu et al., 1992) and those amplifying tandem direct repeats of MDV 1 DNA were utilized (Silva, 1992).

Similar to the above viruses, ASFV from Malawi and Zambia have previously proven to be highly related phylogenetically (Sumption, 1992; Lubisi et al., 2003). An exclusive study of isolates from outbreaks which occurred in Malawi between 1982 and 1989, and Zambia from 1986 to 1989 , aimed at investigating the degree of relatedness of field virus isolates within and between the two countries using RFLP, was conducted by Sumption (1992). All BamHI restriction fragments were utilized to discern relationships of viruses within each country. Eighteen isolates from Malawi were compared and these resulted in 12 genotypes, consisting of 8 unique patterns and 4 groups of patterns formed by 10 isolates (Table 3.1). Of these genotypes, 7 comprising the Mchinji group, had 22 BamHI fragments, while the remainder had 23 fragments. The genome lengths, estimated from the summation of the fragment sizes, ranged from medium $(178 \mathrm{~kb})$ to large genomes (182 kb). Seven BamHI fragments, a,b,c,t,u,v and $\mathrm{w}$ were responsible for the variable mobility, except in seven genotypes where the fusion of fragments $a$ and $b$ into fragment $a ' b$, reduced the fragment number to six. Large mobility variation was observed for fragments $\mathrm{a}$ and $\mathrm{b}$ or $\mathrm{a}$ 'b, especially in isolate MCH87 which had a large combined a and b length of $33 \mathrm{~kb}$, and isolate TIK82 with $36 \mathrm{~kb}$. Dissimilar sizes and frequency of variation were recorded for fragments $\mathrm{u}$ which varied in size between 4.8 and $4.9 \mathrm{~kb}, \mathrm{t}$ that showed a variation in length for 7 of the 12 genotypes discerned, and $\mathrm{v}$ which had a shorter length range of 2.75 to $2.9 \mathrm{~kb}$. Apart from differences in the RFLPs of the above mentioned fragments and the loss of a BamHI site between a and b in the Mchinji viruses, loss of BamHI site between s and t fragments in the Dowa'86 isolate was another form of variation found among Malawi viruses. Fragments a - c were located within $50 \mathrm{~kb}$ from the left terminus of the genome while $\mathrm{t}$ - $\mathrm{w}$ were found within $25 \mathrm{~kb}$ from the right terminus. Fragments $\mathrm{c}$ and $\mathrm{w}$ showed similar size and frequency of variation among the isolates.

In the case of Zambia, 36 virus isolates resulted in 13 genotypes, with 6 viruses yielding unique restriction patterns while the remaining isolates formed 7 genotypes (Table 3.1). 
All isolates had $22 \mathrm{BamHI}$ fragments, and the genome size ranged from short (172 kb) to medium (178 kb). Unlike the Malawi viruses, 5 fragments, a'b, c, t, v and $w$ had variable mobility, with fragment a'b showing the largest mobility variation among the isolates. PHW88/1 and MAN89 had a'b fragment sizes of $33 \mathrm{~kb}$ and $31 \mathrm{~kb}$ respectively. Contrary to the Malawi virus BamHI restriction fragments $\mathrm{u}, \mathrm{t}$ and $\mathrm{v}$ which were responsible for dissimilar size and frequency of variation, minimal or no variation was observed in the $t$ and $v$ fragments, and the longer lengths of fragments caused the length variability among the Zambian isolates. RFLP was the sole criterion used in the comparison of Zambian viruses. Similar to the Malawian viruses, the variable regions were located in the $50 \mathrm{~kb}$ left terminal end $(\mathrm{a}-\mathrm{c})$ and the right terminal $25 \mathrm{~kb}(\mathrm{t}-\mathrm{w})$. Fragments $\mathrm{c}$ and $\mathrm{w}$ in isolates from both countries showed similar size and frequency of variation.

Table 3.1 ASFV genotypes from Malawi and Zambia discerned by BamHI restriction fragment pattern analysis (Sumption, 1992)

\begin{tabular}{|c|c|c|c|}
\hline & Malawi & Zambia & \\
\hline Genotype & Virus & Genotype & Virus \\
\hline 1 & TIK82 & 1 & CHA86; CHGT88; KAZ88; ZAW88* \\
\hline 2 & KON83 & 2 & $\begin{array}{lrr}\text { CHG88/1*; } & \text { CHG88/2; } & \text { ZON88/3; } \\
\text { KAV89/1*; } & \text { KAVT89/1; } & \text { KAVT89/2; } \\
\text { KAVT89/3; KAN/A89; KAN/B89 }\end{array}$ \\
\hline 3 & BON83 & 3 & MWE88; NKZ88* \\
\hline 4 & LIL20/1 & 4 & PHW88* \\
\hline 5 & NAD84; ZOM84* & 5 & NYA88* \\
\hline 6 & DOWA86*; LIL89/3 & 6 & CHS88; NYM88 \\
\hline 7 & DED86 & 7 & KLI88* \\
\hline 8 & MCH87; MCH87/2 & 8 & $\begin{array}{l}\text { KAL88*; KEF89/1; } \quad \text { KEF89/6A; } \\
\text { KEF89/6B; CHK89* }\end{array}$ \\
\hline 9 & LIL89/1* & 9 & GUL88* \\
\hline 10 & $\mathrm{MCH} 89 / 1^{*}$ & 10 & YEL88/5; CHM88/2; MPI89/1* \\
\hline 11 & $\begin{array}{l}\text { LIL89/2; DED89/1*; } \\
\text { DED89/2; NTC88 }\end{array}$ & 11 & MAN89* \\
\hline 12 & $\begin{array}{l}\text { MCH89/3*, } \\
\text { (Zambia) }\end{array}$ & 12 & $\begin{array}{lll}\text { TEN89/1*; } & \text { JON89/13*; } & \text { CHJ89/1*; } \\
\text { MPO89/1* } & & \\
\text { TMB89* } & \end{array}$ \\
\hline
\end{tabular}


Sumption (1992) investigated relationships between ASFV from Malawi and Zambia in a number of different ways. One method involved the grouping of isolates according to increasing BamHI a and b or a'b fragment lengths, while another focused on fragment deletion characteristics in the left terminus of the genome. The first method resulted in 6 virus groups, while the second resolved 7 virus classes (Table 3.2). Five of the 23 genotypes however failed to cluster in the same genotypes when the two methods were compared.

Table 3.2 Classes of ASFV genotypes from Malawi and Zambia obtained by comparison of restriction fragment lengths (A) and deletion characteristics in the left terminus of the genome (B) (Sumption, 1992)

\begin{tabular}{lllll}
\hline Reference & A & \multicolumn{2}{l}{ B } \\
\cline { 2 - 5 } genotype & Class & $\begin{array}{l}\text { No. of genotypes } \\
\text { within group }\end{array}$ & Class & $\begin{array}{l}\text { No. of } \\
\text { genotypes } \\
\end{array}$ \\
& & & & within group \\
CHA86 (Zambia) & I & 11 & VII & 11 \\
MAN86 (Zambia) & II & 1 & VI & 1 \\
BON83 (Malawi) & III & 4 & V & 4 \\
LIL20/1 (Malawi) & IV & 5 & IV & 1 \\
KON83 (Malawi) & V & 1 & III & 4 \\
TIK82 (Malawi) & VI & 1 & II & 1 \\
\hline
\end{tabular}

Subgrouping of the shared genotype classes was also conducted, with groups assigned according to the number of BamHI restriction fragment pattern mobility differences. Virus sets which resulted from categorizing genotypes according to differences in the mobility of single BamHI restriction fragments, and in the mobility of two or less fragments are shown in Table 3.3. 
Table 3.3 Genotype sets resolved by differences in the mobility of single BamHI restriction fragments (I), and in the mobility of two or less fragments (II) (Sumption, 1992)

\begin{tabular}{|c|c|c|}
\hline \multirow[b]{2}{*}{ Set } & \multicolumn{2}{|l|}{ Method } \\
\hline & I & II \\
\hline \multirow[t]{3}{*}{1} & TEN89; TMB89; YEL88; MWE88; & TEN89; TMB89; YEL88; \\
\hline & KAL88 & MWE88; KAL88; CHG88; \\
\hline & & GUL88 \\
\hline \multirow[t]{2}{*}{2} & MCH87; BON83; MCH89/1 & CHS88; TEN89; CHG88; \\
\hline & & KAL88 \\
\hline 3 & CHG88; GUL88 & TMB89; MAN89 \\
\hline 4 & NYA88; KLI88 & MAN89; BON83; KON83 \\
\hline 5 & PHW88; CHA86 & NYA88; KLI88; CHA86 \\
\hline 6 & LIL20/1; LIL89/1 & \\
\hline
\end{tabular}

Subgrouping within the 6 groups (I - VI) discerned by BamHI a and b / a'b fragment size differences, focusing on single differences in fragment mobility, resulted in 3 subgroups within group I designated A - C, and one subgroup each for groups III and IV designated A (Table 3.4).

Apart from the left and right ends of ASFV genome, approximately $35 \mathrm{~kb}$ and $15 \mathrm{~kb}$ in size respectively, which vary primarily on the basis of length (Wesley and Tuthill, 1984; Blasco et al., 1989 a, b), there is a central variable region (CVR) of up to $686 \mathrm{bp}$ (Phologane et al., 2005) within the $125 \mathrm{~kb}$ long central conserved region. This central variable region (CVR) occurs within a late viral gene, termed $9-R L$ (Sumption et al., 1990; Irusta et al., 1996). The molecular basis of the CVR variation is due to variation in the number and type of tandemly repeated amino acid tetramers and analysis of this region has shown a high degree of variation among different ASFV isolates as well as between parental strains and their cell culture adapted strains (Irusta et al., 1996). These 
discoveries prompted an investigation into the possibility of using this gene for within genotype resolution of ASF viruses (Bastos et al., 2004; Phologane et al., 2005).

Table 3.4 ASFV genotypes and subgenotypes from Malawi and Zambia discerned by RFLP (Sumption 1992)

\begin{tabular}{|c|c|c|c|c|}
\hline Virus & Country & Genotype & Group & Subgroup \\
\hline MCH89/3 & Malawi & $\overline{1}$ & $I$ & \\
\hline $\begin{array}{l}\text { CHA86 } \\
\text { ZAW88 } \\
\text { CHGT88 } \\
\text { KAZ88 }\end{array}$ & Zambia & 1 & I & \\
\hline CHS88 & Zambia & 6 & I & \\
\hline KEF89 & Zambia & 8 & I & \\
\hline TEN89 & Zambia & 12 & I & A \\
\hline $\begin{array}{l}\text { YEL88 } \\
\text { MPI88 }\end{array}$ & Zambia & 10 & I & $\bar{A}$ \\
\hline \multirow[t]{2}{*}{ KAL88 } & Zambia & 8 & I & A \\
\hline & Zambia & 3 & I & $\bar{A}$ \\
\hline $\begin{array}{l}\text { CHG88 } \\
\text { KAV89 } \\
\text { KAVT89/1-4 }\end{array}$ & Zambia & 2 & I & $\bar{B}$ \\
\hline KLI88 & Zambia & 7 & $\mathrm{I}$ & $\mathrm{C}$ \\
\hline NYA88 & Zambia & 5 & I & $\mathrm{C}$ \\
\hline MAN89 & Zambia & 11 & II & \\
\hline LIL89/2 & Malawi & 11 & III & \\
\hline PHW88 & Zambia & 4 & III & \\
\hline BON83 & Malawi & 3 & III & $\bar{A}$ \\
\hline$\overline{\mathrm{MCH}} 87 / 1-2$ & Malawi & 8 & III & $\mathrm{A}$ \\
\hline$\overline{\mathrm{MCH} 89 / 1}$ & Malawi & 10 & III & $\overline{\mathrm{A}}$ \\
\hline NAD84 & Malawi & 5 & IV & \\
\hline DOW86 & Malawi & 6 & $\overline{I V}$ & \\
\hline DED86 & Malawi & 7 & IV & \\
\hline Virus & Country & Genotype & Group & Subgroup \\
\hline LIL20/1 & Malawi & 4 & $\overline{I V}$ & A \\
\hline LIL89/1 & Malawi & 9 & IV & A \\
\hline KON83 & Malawi & 2 & $\mathrm{~V}$ & \\
\hline TIK82 & Malawi & 1 & $\mathrm{VI}$ & \\
\hline
\end{tabular}


Following the promising results that Bastos et al. (2004) obtained when differentiating intra-genoypic relationships of viruses of Mozambican origin, and the identification of at least four discrete CVR size classes for genotype VIII viruses (Phologane et al., 2005), this gene was targeted for characterization in this study to attempt to resolve relationships within the homogeneous $p 72$ genotype discerned previously (Chapter 2) in East Africa.

\subsection{MATERIALS AND METHODS}

\subsubsection{Viruses}

All viruses which constituted genotype VIII on $p 72$ genotyping in chapter 2 (Fig. 2.1) were selected for CVR typing. Five additional genotype VIII viruses and one isolate from a different genotype were obtained from Bastos et al. (2004) bringing the total number of viruses used in this study to 45 (Table 3.5 ).

\subsubsection{DNA extraction and CVR - PCR}

The DNA extracted for $p 72$ genotyping purposes in the previous chapter was utilized in this investigation. PCR mixtures were prepared in which the CVR and flanking regions were amplified using the following primers with a forward and reverse orientation, respectively:

CVR-FL1 (5' TCG GCC TGA AGC TCA TTA G 3') and CVR-FL2 (5' CAG GAA ACT AAT GAT GTT CC 3') (Bastos et al., 2004). All reactions were performed in a final volume of $50 \mu \mathrm{l}$ containing $200 \mu \mathrm{M}$ dNTPs (Roche), $0.4 \mu \mathrm{M}$ of each primer, $2.5 \mathrm{U}$ of thermostable Taq DNA polymerase (Roche) and $3 \mu$ l of DNA extract. The templates were amplified following 35 cycles of denaturation at $96{ }^{\circ} \mathrm{C}$ for $12 \mathrm{~s}$, annealing at $52{ }^{\circ} \mathrm{C}$ for $20 \mathrm{~s}$ and extension at $70{ }^{\circ} \mathrm{C}$ for $25 \mathrm{~s}$. These cycles were preceded by an initial incubation step of $96{ }^{\circ} \mathrm{C}$ for $20 \mathrm{~s}$, and followed by an elongation step of $70{ }^{\circ} \mathrm{C}$ for 1 minute. 
3.2.3 Agarose gel electrophoresis and molecular weight estimation

The amplified DNA products were loaded on a $1.5 \%$ agarose gel and run against a 100 bp DNA ladder (Promega). Once sufficient electrophoretic separation was obtained, products were visualized by UV irradiation and ethidium bromide staining. The gels were photographed in order to obtain a hard copy record of the results from which to measure the distance migrated by the samples. A linear graph and standard curve were plotted using the $\log$ of the molecular weight (MW) of each fragment in the $100 \mathrm{bp}$ ladder against the distance migrated $(\mathrm{mm})$. The molecular weights of the CVR-PCR products were then determined by extrapolation of the standard curve, where the log of the molecular weights corresponding to the estimated distances that each of the CVR fragments had migrated, were read using Microsoft Excel.

\subsubsection{PCR product purification and nucleotide sequencing}

CVR products were excised from the agarose gel and purified using the Nucleospin kit (Machery-Nagel) according to the manufacturer's specifications. The nucleotide sequence of the purified product was determined by automated sequencing on an ABI Prism 310 Genetic Analyzer (Applied Biosystems) using a Big Dye version 3.1 kit and a 47 centimeter capillary.

\subsubsection{Sequence alignment}

Forward and reverse sequences were aligned with the DAPSA program (Harley, 1994) to obtain a final consensus sequence for each virus sample. The sequences were translated into amino acids and grouped into tetramers. Amino acid sequences generated in this way for the diverse viruses were aligned manually and gaps were inserted for alignment purposes. 


\subsubsection{Phylogenetic analysis of the CVR}

A final dataset consisting of 124 characters/amino acids grouped according to tetrameric composition (Fig. 3.1) was used for phylogenetic inference. The gaps were treated as a $21^{\text {st }}$ character state and coded according to the simple indel coding method specified by Simmons and Ochoterena (2000).

\subsubsection{Neighbor-joining (NJ)}

Neighbor-joining analysis was carried out on the uncoded dataset employing both the amino Poisson correction and p - distance methods in MEGA 2 (Kumar et al., 2001). Pairwise deletion of gaps was specified for pairwise distance calculations and 10000 bootstrap replications were used to test the nodes of the resulting phylogeny. Mean character distances were also determined for the coded dataset in PAUP* and used to generate an alternative neighbor-joining tree. In the latter approach, information contained within the gap regions was taken into account, rather than being excluded in each pairwise comparison.

\subsubsection{Maximum parsimony analysis}

The most parsimonious tree was sought using the hheuristic search settings. Characters were weighted with gaps being down weighted by a factor of 0.25 (PAUP*), as specified previously (Bastos et al., 2004). Starting tree(s) were obtained via stepwise addition, and subsequent taxa were added by the simple method. MOZ 1960 isolate was used as an outgroup taxon (Bastos et al., 2004). One tree was held at each step during stepwise addition and branches were collapsed (creating polytomies) if maximum branch length was zero. Tree bisection-reconnection (TBR) was the branch-swapping algorithm selected and topological constraints were not enforced. The bootstrap method was employed for assessing nodal support, where 1000 replications were performed. 
A branch-and-bound search where characters were unordered and bore equal weights, was also attempted. The furthest option was chosen for addition of sequences and branches were collapsed (creating polytomies) if maximum branch length was zero. 'MulTrees' option in effect and topological constraints were not enforced.

\subsection{RESULTS}

\subsubsection{CVR size and sequence differentiation}

CVR product size differentiation on the basis of molecular weight estimates and number of amino acids are indicated in Table 3.5.

\subsubsection{Data statistics from MEGA}

Of the 124 sites utilized, 67 were constant, 57 variable, 29 parsimony informative and 28 were singletons. The dataset comprised the following 10 amino acids, arranged in descending order of percentage composition: 23.19 Asparagine, $21.18 \%$ Alanine, $19.47 \%$ Threonine, $14.57 \%$ Serine, $9.52 \%$ Aspartic acid, $5.58 \%$ Isoleucine, $3.75 \%$ Valine, $2.60 \%$ Cysteine, $0.12 \%$ Glycine and $0.02 \%$ Glutamic acid. The remaining 10 possible amino acids did not occur within the CVR tetrameric repeat region.

\subsubsection{Data and tree analysis in PAUP}

Results of lengths and fit measures of all parsimony trees are summarized in Table 3.6

\subsubsection{Maximum parsimony tree}

On completion of the heuristic search, 24123 rearrangements were tried, and 6 discrete CVR clades were resolved. 249 bootstrap replications were performed from which a 50 $\%$ majority-rule consensus tree was obtained (Fig. 3.3). 
Table 3.5 CVR product size estimates and amino acid sequence composition of $p 72$ genotype VIII viruses identified in this study and Bastos et al. (2004). The tetrameric repeats reflect tetrameric content only and do not represent the order in which the repeats occur within the CVR of each virus isolate.

\begin{tabular}{|c|c|c|c|c|c|}
\hline VIRUS & $\begin{array}{l}\text { Genotype } \\
\text { VIII CVR } \\
\text { lineage }\end{array}$ & $\begin{array}{l}\text { Estimated } \\
\text { size (bp) }\end{array}$ & $\begin{array}{l}\text { Number } \\
\text { of amino } \\
\text { acids }\end{array}$ & Tetrameric repeat composition & Reference \\
\hline LIL90/1/MAL/P & A & 535 & 84 & $(\text { cast })_{2}(\text { nadt })_{3}(\text { sast })_{2}(\text { nasi })_{2}(\text { nvdt })_{3}(\text { nast })_{4}(\text { nadi })_{2}(\text { nant })_{2}$ nani & This study \\
\hline DED91/1/MAL/P & A & 539 & 84 & $(\text { cast })_{2}(\text { nadt })_{3}(\text { sast })_{2}(\text { nasi })_{2}(\text { nvdt })_{3}(\text { nast })_{4}(\text { nadi })_{2}(\text { nant })_{2}$ nani & This study \\
\hline DED89/1/MAL/P & A & 540.5 & 84 & $(\text { cast })_{2}(\text { nadt })_{3}(\text { sast })_{2}(\text { nasi })_{2}(\text { nvdt })_{3}(\text { nast })_{4}(\text { nadi })_{2}(\text { nant })_{2}$ nani & This study \\
\hline LIL89/1MAL/P & $\mathrm{F}$ & 650 & 120 & $(\text { cast })_{3}(\text { nadt })_{2}(\text { nasi })_{4}(\text { nvdt })_{7}(\text { nast })_{9}(\text { nadi })_{2}(\text { nant })_{2}$ nani & This study \\
\hline BAN91/1/MAL/P & A & 581 & 84 & $(\text { cast })_{2}(\text { nadt })_{3}(\text { sast })_{2}(\text { nasi })_{2}(\text { nvdt })_{3}(\text { nast })_{4}(\text { nadi })_{2}(\text { nant })_{2}$ nani & This study \\
\hline CHM88/1/ZAM/P & A & 511 & 84 & $(\text { cast })_{2}(\text { nadt })_{3}(\text { sast })_{2}(\text { nasi })_{2}(\text { nvdt })_{3}(\text { nast })_{4}(\text { nadi })_{2}(\text { nant })_{2}$ nani & This study \\
\hline KANA89/1/ZAM/P & A & 542 & 84 & $(\text { cast })_{2}(\text { nadt })_{3}(\text { sast })_{2}(\text { nasi })_{2}(\text { nvdt })_{3}(\text { nast })_{4}(\text { nadi })_{2}(\text { nant })_{2}$ nani & This study \\
\hline KAC91/2/MAL/P & $\mathrm{B}$ & 603 & 92 & $(\text { cast })_{2}(\text { nadt })_{4}(\text { sast })_{3}(\text { nasi })_{2}(\text { nvdt })_{3}(\text { nast })_{4}(\text { nadi })_{2}(\text { nant })_{2}$ nani & This study \\
\hline
\end{tabular}




\begin{tabular}{|c|c|c|c|c|c|}
\hline MCH89/1/MAL/P & A & 554 & 84 & $(\text { cast })_{2}(\text { nadt })_{3}(\text { sast })_{2}(\text { nasi })_{2}(\text { nvdt })_{3}(\text { nast })_{4}(\text { nadi })_{2}(\text { nant })_{2}$ nani & This study \\
\hline MOZ/2001/P & A & 402 & 84 & $(\text { cast })_{2}(\text { nadt })_{3}(\text { sast })_{2}(\text { nasi })_{2}(\text { nvdt })_{3}(\text { nast })_{4}(\text { nadi })_{2}(\text { nant })_{2}$ nani & This study \\
\hline CHK89/2/ZAM/P & $\mathrm{B}$ & 402 & 92 & $(\text { cast })_{2}(\text { nadt })_{4}(\text { sast })_{3}(\text { nasi })_{2}(\text { nvdt })_{3}(\text { nast })_{4}(\text { nadi })_{2}(\text { nant })_{2}$ nani & This study \\
\hline YEL88/4/ZAM/P & A & 492 & 84 & $(\text { cast })_{2}(\text { nadt })_{3}(\text { sast })_{2}(\text { nasi })_{2}(\text { nvdt })_{3}(\text { nast })_{4}(\text { nadi })_{2}(\text { nant })_{2}$ nani & This study \\
\hline DOWA/MAL/P & $\mathrm{F}$ & 641 & 120 & $(\text { cast })_{3}(\text { nadt })_{2}(\text { nasi })_{4}(\text { nvdt })_{7}(\text { nast })_{9}(\text { nadi })_{2}(\text { nant })_{2}$ nani & This study \\
\hline KAV89/1/ZAM/P & $\mathrm{D}$ & N/D & 116 & $(\text { cast })_{2}(\text { nadt })_{4}(\text { sast })_{3}(\text { nasi })_{3}(\text { nvdt })_{4}(\text { nast })_{7}(\text { nadi })_{2}(\text { nant })_{2}$ nani nvgt & This study \\
\hline KAL88/1/ZAM/P & $\mathrm{B}$ & N/D & 92 & $(\text { cast })_{2}(\text { nadt })_{4}(\text { sast })_{3}(\text { nasi })_{2}(\text { nvdt })_{3}(\text { nast })_{4}(\text { nadi })_{2}(\text { nant })_{2}$ nani & Bastos et al., 2004 \\
\hline ZON88/1/ZAM/P & $\mathrm{E}$ & 641 & 124 & $(\text { cast })_{2}(\text { nadt })_{5}(\text { sast })_{4}(\text { nasi })_{3}(\text { nvdt })_{4}(\text { nast })_{7}(\text { nadi })_{2}(\text { nant })_{2}$ nani nvgt & This study \\
\hline MPI89/1/ZAM/P & A & 554 & 84 & $(\text { cast })_{2}(\text { nadt })_{3}(\text { sast })_{2}(\text { nasi })_{2}(\text { nvdt })_{3}(\text { nast })_{4}(\text { nadi })_{2}(\text { nant })_{2}$ nani & This study \\
\hline MCH89/3/MAL/P & $\mathrm{C}$ & 600 & 92 & $(\text { cast })_{2}(\text { nadt })_{4}(\text { sast })_{3}(\text { nasi })_{2}(\text { nvdt })_{3}(\text { nast })_{4}(\text { nadi })_{2}(\text { nant })_{2}$ nani & This study \\
\hline GUL88/1/ZAM/P & $\mathrm{D}$ & 621 & 116 & $(\text { cast })_{2}(\text { nadt })_{4}(\text { sast })_{3}(\text { nasi })_{3}(\text { nvdt })_{4}(\text { nast })_{7}(\text { nadi })_{2}(\text { nant })_{2}$ nani nvgt & This study \\
\hline NGE92/1/MAL/P & A & 529 & 84 & $(\text { cast })_{2}(\text { nadt })_{3}(\text { sast })_{2}(\text { nasi })_{2}(\text { nvdt })_{3}(\text { nast })_{4}(\text { nadi })_{2}(\text { nant })_{2}$ nani & This study \\
\hline NKZ88/1/ZAM/P & A & 492 & 84 & $(\text { cast })_{2}(\text { nadt })_{3}(\text { sast })_{2}(\text { nasi })_{2}(\text { nvdt })_{3}(\text { nast })_{4}(\text { nadi })_{2}(\text { nant })_{2}$ nani & This study \\
\hline ZAW88/1/ZAM/P & $\mathrm{B}$ & 512 & 92 & $(\text { cast })_{2}(\text { nadt })_{4}(\text { sast })_{3}(\text { nasi })_{2}(\text { nvdt })_{3}(\text { nast })_{4}(\text { nadi })_{2}(\text { nant })_{2}$ nani & This study \\
\hline DEDZA/MAL/P & A & $\mathrm{N} / \mathrm{D}$ & 56 & $(\text { cast })_{1}(\text { nadt })_{1}(\text { sast })_{1}(\text { nasi })_{1}(\text { nvdt })_{2}(\text { nast })_{3}(\text { nadi })_{2}$ (nant $)_{2}$ nani & Bastos et al., 2004 \\
\hline MAN89/2/ZAM/P & A & 560 & 84 & $(\text { cast })_{2}(\text { nadt })_{3}(\text { sast })_{2}(\text { nasi })_{2}(\text { nvdt })_{3}(\text { nast })_{4}(\text { nadi })_{2}(\text { nant })_{2}$ nani & This study \\
\hline JON89/13/ZAM/P & A & $\mathrm{N} / \mathrm{D}$ & 84 & $(\text { cast })_{2}(\text { nadt })_{3}(\text { sast })_{2}(\text { nasi })_{2}(\text { nvdt })_{3}(\text { nast })_{4}(\text { nadi })_{2}(\text { nant })_{2}$ nani & Bastos et al., 2004 \\
\hline TEN89/1/ZAM/P & A & 533 & 84 & $(\text { cast })_{2}(\text { nadt })_{3}(\text { sast })_{2}(\text { nasi })_{2}(\text { nvdt })_{3}(\text { nast })_{4}(\text { nadi })_{2}(\text { nant })_{2}$ nani & This study \\
\hline
\end{tabular}




\begin{tabular}{|c|c|c|c|c|c|}
\hline SAL92/1/MAL/P & A & 536 & 84 & $(\text { cast })_{2}(\text { nadt })_{3}(\text { sast })_{2}(\text { nasi })_{2}(\text { nvdt })_{3}(\text { nast })_{4}(\text { nadi })_{2}$ (nant $)_{2}$ nani & This study \\
\hline ZOM2/84/MAL/P & A & N/D & 84 & $(\text { cast })_{2}(\text { nadt })_{3}(\text { sast })_{2}(\text { nasi })_{2}(\text { nvdt })_{3}(\text { nast })_{4}(\text { nadi })_{2}$ (nant $)_{2}$ nani & Bastos et al., 2004 \\
\hline KLI88/2/ZAM/P & $\mathrm{D}$ & 702 & 116 & $(\text { cast })_{2}(\text { nadt })_{4}(\text { sast })_{3}(\text { nasi })_{3}(\text { nvdt })_{4}(\text { nast })_{7}(\text { nadi })_{2}(\text { nant })_{2}$ nani nvgt & This study \\
\hline CHG88/1/ZAM/P & $\mathrm{D}$ & 652 & 116 & $(\text { cast })_{2}(\text { nadt })_{4}(\text { sast })_{3}(\text { nasi })_{3}(\text { nvdt })_{4}(\text { nast })_{7}(\text { nadi })_{2}(\text { nant })_{2}$ nani nvgt & This study \\
\hline SIY91/2/MAL/P & $\mathrm{B}$ & 652 & 92 & $(\text { cast })_{2}(\text { nadt })_{4}(\text { sast })_{3}(\text { nasi })_{2}(\text { nvdt })_{3}(\text { nast })_{4}(\text { nadi })_{2}$ (nant $)_{2}$ nani & This study \\
\hline PHW88/1/ZAM/P & A & 569 & 84 & $(\text { cast })_{2}(\text { nadt })_{3}(\text { sast })_{2}(\text { nasi })_{2}(\text { nvdt })_{3}(\text { nast })_{4}(\text { nadi })_{2}(\text { nant })_{2}$ nani & This study \\
\hline TMB89/1/ZAM/P & A & 492 & 84 & $(\text { cast })_{2}(\text { nadt })_{3}(\text { sast })_{2}(\text { nasi })_{2}(\text { nvdt })_{3}(\text { nast })_{4}(\text { nadi })_{2}(\text { nant })_{2}$ nani & This study \\
\hline NDA1/90/MAL/P & A & N/D & 84 & $(\text { cast })_{2}(\text { nadt })_{3}(\text { sast })_{2}(\text { nasi })_{2}(\text { nvdt })_{3}(\text { nast })_{4}(\text { nadi })_{2}$ (nant $)_{2}$ nani & Bastos et al., 2004 \\
\hline MOZCA98/P & $\mathrm{B}$ & N/D & 92 & $(\text { cast })_{2}(\text { nadt })_{4}(\text { sast })_{3}(\text { nasi })_{2}(\text { nvdt })_{3}(\text { nast })_{4}(\text { nadi })_{2}(\text { nant })_{2}$ nani & Bastos et al., 2004 \\
\hline MOZB98/P & $\mathrm{B}$ & N/D & 92 & $(\text { cast })_{2}(\text { nadt })_{4}(\text { sast })_{3}(\text { nasi })_{2}(\text { nvdt })_{3}(\text { nast })_{4}(\text { nadi })_{2}(\text { nant })_{2}$ nani & Bastos et al., 2004 \\
\hline MOZC98/P & $\mathrm{B}$ & N/D & 92 & $(\text { cast })_{2}(\text { nadt })_{4}(\text { sast })_{3}(\text { nasi })_{2}(\text { nvdt })_{3}(\text { nast })_{4}(\text { nadi })_{2}$ (nant $)_{2}$ nani & Bastos et al., 2004 \\
\hline $\mathrm{MOZ34/98/P}$ & $\mathrm{B}$ & N/D & 92 & $(\text { cast })_{2}(\text { nadt })_{4}(\text { sast })_{3}(\text { nasi })_{2}(\text { nvdt })_{3}(\text { nast })_{4}(\text { nadi })_{2}(\text { nant })_{2}$ nani & Bastos et al., 2004 \\
\hline MOZ62/98/P & $\mathrm{B}$ & N/D & 92 & $(\text { cast })_{2}(\text { nadt })_{4}(\text { sast })_{3}(\text { nasi })_{2}(\text { nvdt })_{3}(\text { nast })_{4}(\text { nadi })_{2}(\text { nant })_{2}$ nani & Bastos et al., 2004 \\
\hline MOZ1960" & N/A & N/D & 88 & & Bastos et al., 2004 \\
\hline
\end{tabular}

N/D: Not done; N/A: Not applicable; \# Not belonging to genotype VIII 
\#ZON881 CAST NADT SAST NADT SAST NADT SAST NADT SAST NASI NADT NVDT CAST NAST NVDT NASI NAST NAST NVGT NAST NVDT NASI NAST NAST NVDT NAST NADI NANT NADI NANI NANT \#MCH893 CAST NADT SAST NADT SAST NADT SAST -- - - NASI NADT NVDT CAST NAST NVDT NASI NAST NAST -- --- NVDT NAST -- - - - - NADI NANT NADI NANI NANT \#LIL891 CAST NVDT NAST NASI NADT NVDT CAST NAST NVDT NASI NAST NAST NVDT NAST NASI NADT NVDT CAST --- NAST NVDT NASI NAST NAST NVDT NAST NADI NANT NADI NANI NAN CAST NVDT NAST NASI NADT NVDT CAST NAST NVDT NASI NAST NAST NVDT NAST NASI NADT NVDT CAST ---- NAST \#CHG881 CAST NADT SAST NADT SAST NADT SAST NASI NADT NVDT ---- --- CAST NAST NVDT NASI NAST NAST NVGT NAST \#KAV891 CAST NADT SAST NADT SAST NADT SAST NASI NADT NVDT ---- --- CAST NAST NVDT NASI NAST NAST NVGT NAST NVDI NAST NAST NAST NAST NVDT NAST NADT NANT NADI NANI NAMT

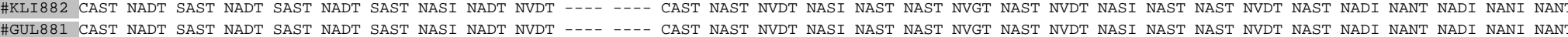

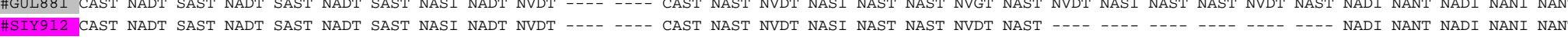

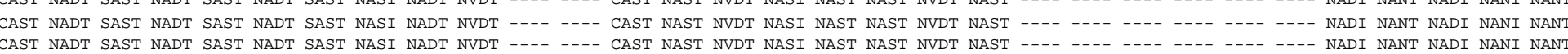

\#KAL881 CAST NADT SAST NADT SAST NADT SAST NASI NADT NVDT CAST NAST NVDT NASI NAST NAST NVDT NAST --

\#MOZ6298CAST NADT SAST NADT SAST NADT SAST NASI NADT NVDT CAST NAST NVDT NASI NAST NAST NVDT NAST --- CAST NADT SAST NADT SAST NADT SAST NASI NADT NVDT CAST NADI SAST NADT SAST NADT SAST NASI NADT NVDI WAST NADT NADT SAST NADI SAST NASI NADT NVDT SAST NADT SAST NADT SAST NAST NVD CAST NADT SAST NADT SAST NADT SAST NASI NADT NVD CAST NADT SAST NADI SAST CAST NATT SAST NADT SAST - - - - - - NASI NADT NVDT

\#NDA901 CAST NADT SAST NADT SAST ---- --- NASI NADT NVD

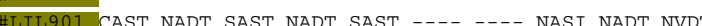

LDedza CAST NADT SAST NASI NADT NVD SAST NADT SAST ---- ---- NASI NADT NVDT CAST NADT SAST NADT SAST ---- --- NASI NADT NVDT CAST NADT SAST NADT SAST - AST NADT SAST NADT SAST -... - - NASI NADT NVD AST NADT SAST NADT SAST -- - -- NASI NADT NVDT CAST NADT SAST NADT SAST --- --- NASI NADT NVD CAST NADT SAST NADT SAST --- --- NASI NADT NVD

\#MPI891 CAST NADT SAST NADT SAST ---- --- NASI NADT NVD

FMAN892 CAST NADT SAST NADT SAST --- -- NASI NADT NVDT -

COAS NADI SAST NADI SAST ---- --- NASI NADT NVD CAST NADT SAST NADT SAST --- --- NASI NADT NVDI CAST NADT SAST NADT SAST --- --- NASI NADT NVDT CAST NADT SAST NADT SAST ---- ---- NASI NADT NVDT CAST NADT SAST NADT SAST --- --- NASI NADT NVDT CAST NADT SAST NADT SAST NASI NADT NVD NASI NADT NVD NASI NADT NVD NASI NADT NVDT NANT NADI NANI NAN CAST NAST NVDT NASI NAST NAST NVDT NAST --CAST NAST NVDT NASI NAST NAST NVDT NAST --- --CAST NAST NVDT NASI NAST NAST NVDT NAST - CAST NAST NVDT NASI NAST NAST NVDT NAST CAST NAST NVDT NASI NAST NAST NVDI NAST - - NADI NANT NADI NANI NAN CAST NAST NVDT NASI NAST NAST NVDT NAST ---- --- ---

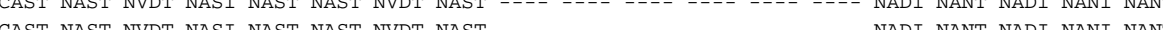

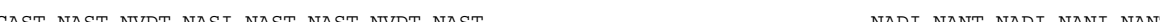
CAST NAT NASI NAST NAST NVDT NAST ---0 CAST NAST NVDT NAST NAST NAST NVDT NAST --_CAST NAST NVDT NASI NAST NAST NVDT NAST --- - CAST NAST NVDT NASI NAST NAST NVDT NAST --- - CAST NAST NVDT NASI NAST NAST NVDT NAST - CAST NAST NVDT NASI NAST NAST NVDT NAST - - CAST NAST NVDT NASI NAST NAST NVDT NAST --- - CAST NAST NVDT NASI NAST NAST NVDT NAST --CAST NAST NVDI NASI NAST NAST NVDT NAST --- - - - NAST NAST NVDT NASI NAST NAST NVDT NAST - CAST NAST NVDT NASI NAST NAST NVDT NAST --CAST NAST NUDI NASI NAST NAST NVDI NAST --CAS NAST NAD NASI NAST NAST NVDI NAST - NADI NANI NAN CAST NAST NVDI NASI NAST NAST NVDI NAST - - NADI NANI NADI NANI NAN CAST NADI NANI NADI NANI NAN CAST MAST MVDT NASI NAST NAST NVDT NAST - -




CAST NAST NVDT NASI NAST NAST NUDT NAST CAST NADT SAST NADT SAST NASI

CAST NAST NVDT NASI NAST NAST NVDT NAST

NADI NANT NADI NANI NAN

Fig. 3.1 CVR amino acid sequence alignment of genotype VIII viruses discerned in this study and that of Bastos et al., 2004).

Eight unique CVR sequences were recovered, each of which is indicated in a different background colour. 


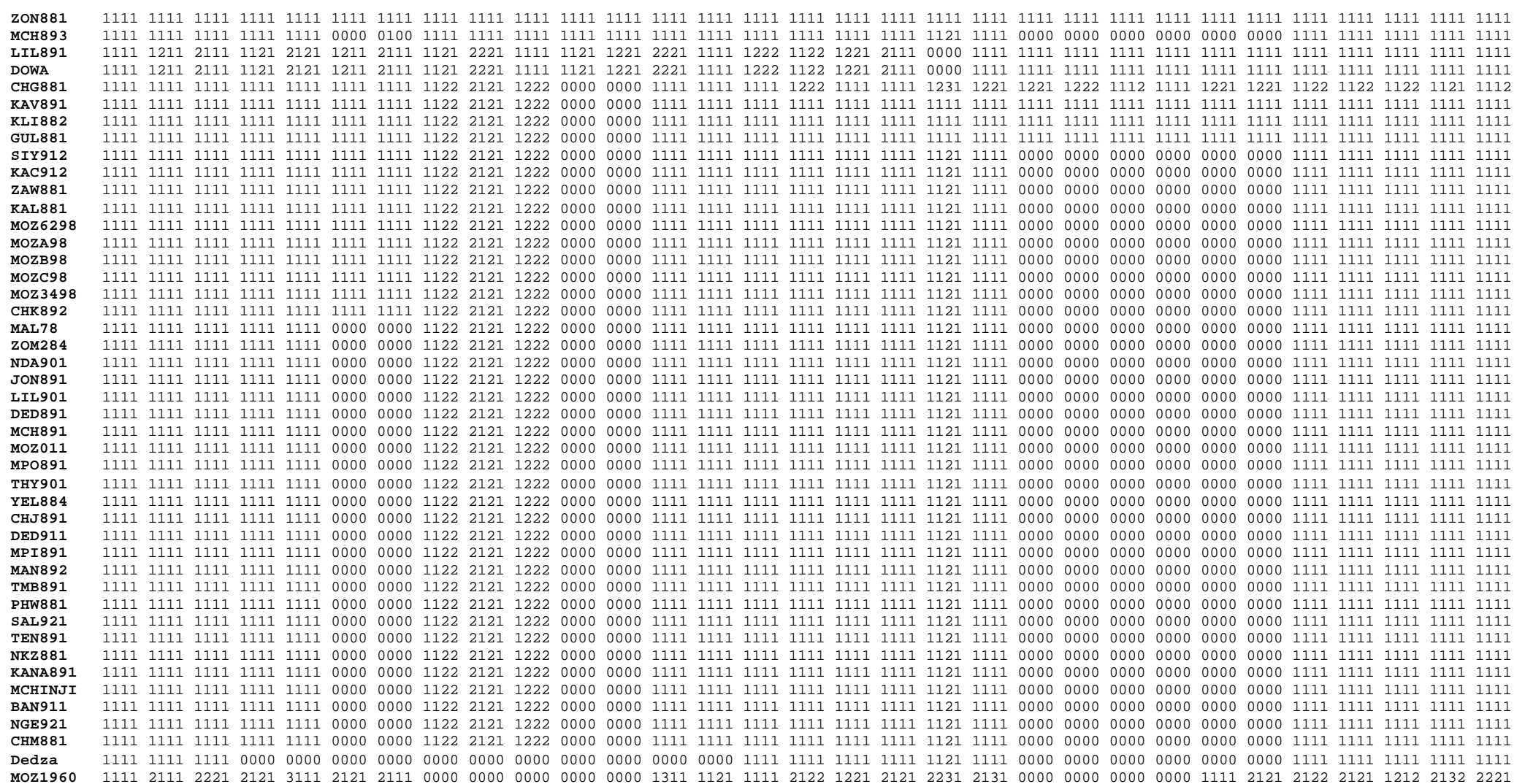

Fig. 3.2 Coded CVR amino acid dataset of genotype VIII viruses, used to determine mean character distances in order to

Infer a NJ tree that takes gap information into account 
Table 3.6 Results of lengths and fit measures of all parsimony trees in memory (PAUP) deduced from CVR sequences with gaps down weighted by a factor of 0.25 and treated as a $21^{\text {st }}$ amino acid state

\begin{tabular}{ll}
\hline Parameter & Value/Specification \\
\hline Search method & Heuristic \\
Score of best tree(s) found & 189 \\
Sum of min. possible lengths & 144 \\
Sum of max. possible lengths & 541 \\
& \\
Length & 201 \\
Consistency Index & 0.762 \\
Retention Index & 0.87 \\
Re-scaled consistency Index & 0.676 \\
\hline
\end{tabular}

\subsubsection{Neighbor-joining tree}

A phenogram was obtained indicating 6 discrete CVR clusters for the uncoded dataset, supported by bootstrap values higher than $50 \%$ on all but 2 branches. Branching patterns were similar to those identified by the parsimony method for four of the subgroups $(C, D$, $\mathrm{E}$ and F), while the remaining two (A and B) differed (Fig. 3.4). The NJ tree obtained using the coded data set (Fig. 3.2) and the distance between isolates measured as mean character differences however yielded eight well-resolved clusters (Fig. 3.5). Labeling of these clusters was done according to that used in the NJ tree obtained with the uncoded dataset. Subgroups B, C, E and F were identical, while A and D were different in terms of the number of constituent isolates, and subgroups $\mathrm{G}$ and $\mathrm{H}$ (Fig. 3.5) were unique for the coded dataset. 


\subsubsection{Interpretation of results}

Conflicting results for two of the six clades recovered from uncoded NJ and weighted MP analyses were obtained. These lesser resolved phylogenies contrast markedly with the NJ tree obtained for the coded dataset, where eight well-resolved and well-supported clusters were obtained. As the NJ tree manages to resolve the two conflicting clades and because the cluster number corresponds with the eight discrete CVR size classes that were discerned by amino acid alignment (Fig. 3.1), the coded NJ tree (Fig. 3.5) is regarded as the better phylogenetic estimate on which to base epidemiological inferences.

The eight discrete intra-genotypic lineages obtained by NJ analysis of the coded dataset were designated A to $\mathrm{H}$ (Fig. 3.5). Tetrameric repeats, NAST, NVDT, NADT and to a lesser extent SAST, were most abundant in the CVR sequences (Table 3.5 and Figure 3.1). The largest CVR lineage (group A), with a CVR length of 84 amino acids (aa), comprised isolates from three countries (Zambia, Malawi and Mozambique). These were recovered from outbreaks over a 23 year period. Group B was characterized by Dedza, a 1986 virus from Malawi with a 56 aa long CVR. MCH 89/3, a Malawian isolate with a CVR length of 92 aa, was the sole member of group C. Lineage D was solely comprised of Zambian isolates with a CVR length of 116 aa, and a two year field presence. A single Zambian virus with a length of 124 aa represented group E. Two Malawian isolates with a CVR 120 aa in length constituted group F, and had a field presence of three years. Viruses from Zambia, Malawi and Mozambique, with CVR aa length of 92 and spanning a 10 year period, formed group G. CHG 88/1, a Zambian isolate with a CVR aa size of 116, constituted group $\mathrm{H}$. 


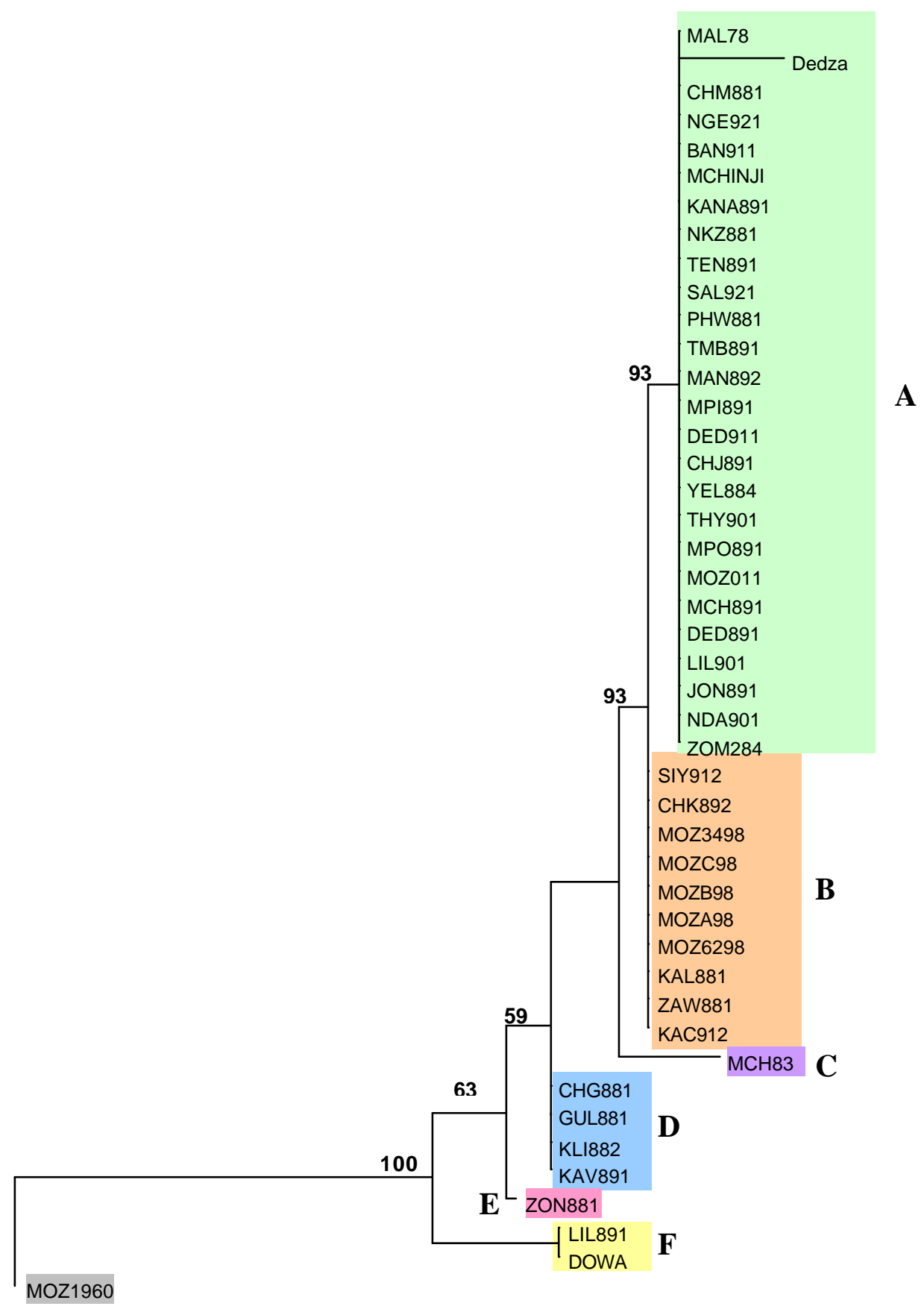

Fig. 3.3 Parsimony tree depicting 6 genotype VIII ASFV sub groups (denoted A-F) discerned by central variable region sequencing. Phylogeny was supported by 249 bootstrap replications 


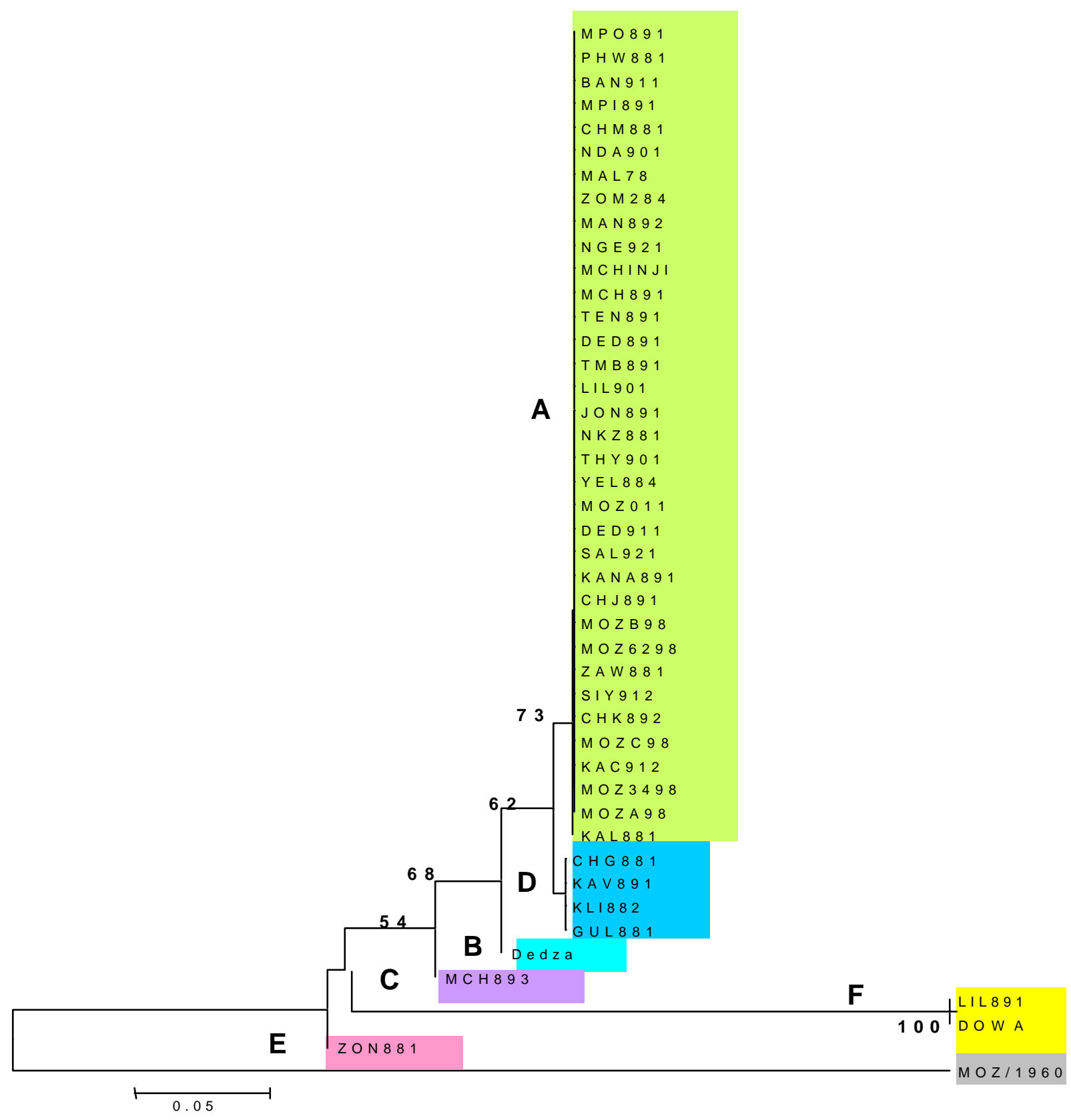

Fig. 3.4 Neighbor joining tree depicting phylogenetic relationships recovered when using uncoded CVR sequences of genotype VIII viruses from this and previous studies (Bastos et al., 2003 and 2004). Nodal support is based on 10000 bootstrap replications. 


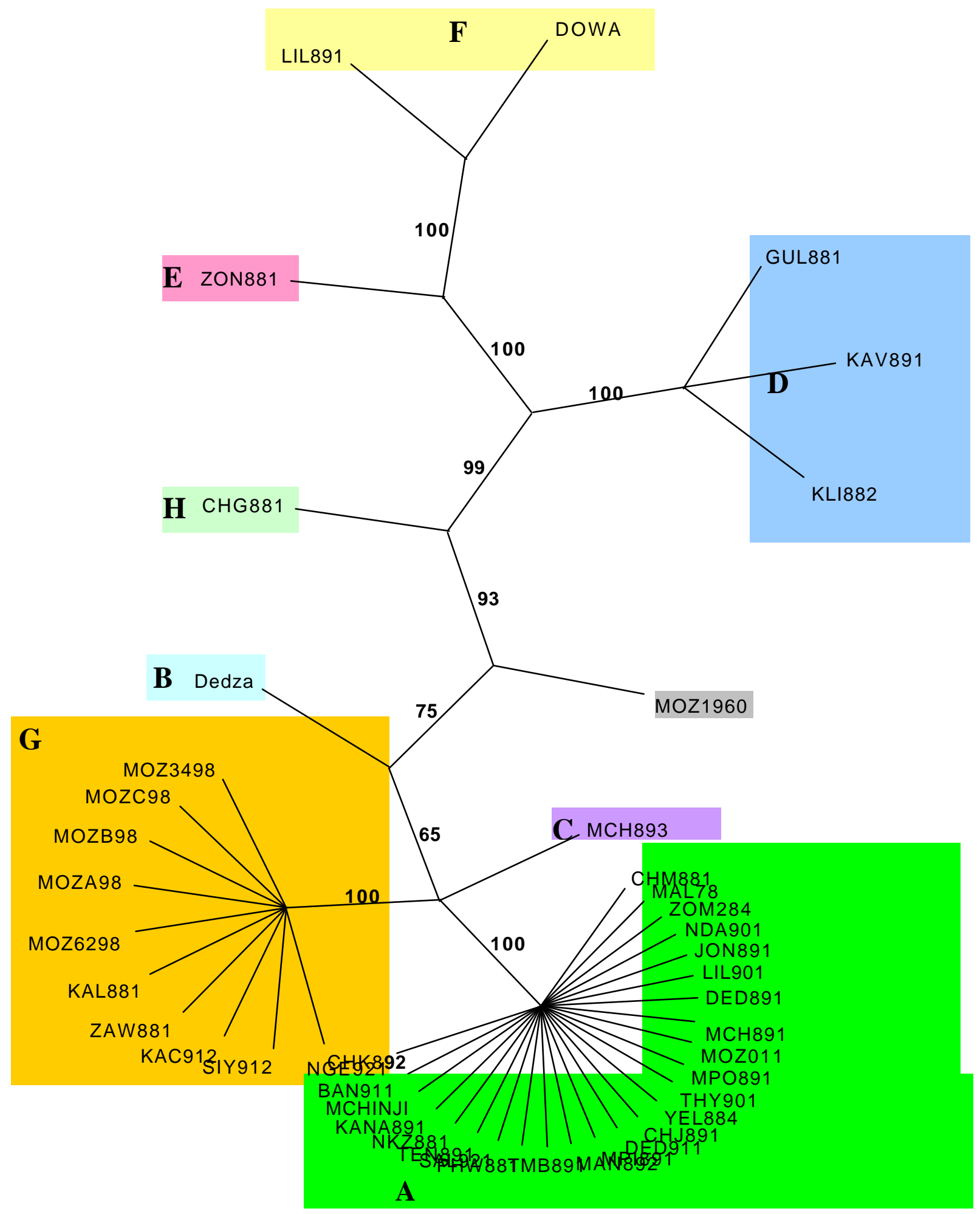

Fig 3.5 Neighbor joining tree depicting phylogenetic relationships of $p 72$ genotype VIII viruses using the coded CVR dataset. 1000 bootstrap replications were conducted. 


\subsection{DISCUSSION}

The variable nature of the CVR allowed for the isolates in genotype VIII to be classified into eight discrete lineages. Despite the hypervariable nature of the repeat region, some of the unique CVR sequences uncovered appear to have remained unchanged for at least 23 years, as seen in isolates constituting lineage A.

The huge disparity observed in the estimated molecular weights of the CVR products in each lineage/sub-genotype were probably due to the electrophoresis conditions, perturbations in the gel and the interpolation method used to calculate these values (Gough and Gough, 1984; Maina et al., 1984). This was supported by the fact that the reference strain, Malawi 1978, yielded different molecular weights when estimates were obtained from different agarose gels. Maina et al. (1984) found the following conditions to be important for DNA electrophoresis: electrophoresis apparatus must be extremely clean; care must be taken in pouring the gel so that the agarose cools evenly; all samples must be in the same buffer and of the same volume; the sample buffer must be of a salt concentration which is less than that of the running buffer; the standard lane should have at least 10 bands; and electrophoresis should be between 10 and 30 volts. Some of these conditions could however not always be met due to constrains in the laboratory such as lack of some equipment, and most importantly, performance of the electrophoresis on different days with different buffers, and the fact that a single gel could only accommodate a limited number of samples. Due to these error prone gel estimations, sizing on the basis of the number of amino acids empirically determined following sequencing was adopted (Table 3.5).

Generation of comparable sequence positions that provide the basis for the establishment of hypothesis of primary homology is dependent on alignment. With homologous sequences that differ in length (Fig. 3.1), insertion of gaps is required and unavoidable for the production of comparable positions for the entire sequences. Thus gaps, defined by Simmons and Onchoterena (2000) as single or contiguous sets of positions for which no bases are present in one or more sequences, bounded on either side by aligned nucleotides 
or amino acids, become integral to the pattern like nucleotides and amino acids. The reliability of gaps as characters in phylogenetic inferences has been debated extensively, but their importance is undeniable and they continue to be used (Lloyd and Calder, 1991; Golenberg et al., 1993; Bailey and Doyle, 1997; Lai et al., 1997; Van Dijk et al., 1999; Simmons and Onchoterena, 2000). Common complications with the use of gaps as characters in tree searches are the ambiguously aligned gaps, where these characters have more than one equally optimal alignment, as is possible with the CVR data. Gatesy et al. (1993) have however found that insertions and deletions may be unambiguous phylogenetic indicators despite the alignment ambiguity. Various investigators concluded that gap costs used in alignment may be incorporated into tree searches by coding these gaps as extra character states, a strategy which was adopted in this study in the quest for a true phylogenetic picture (Wheeler, 1994; Janies and Wheeler, 1998; Giribet and Wheeler, 1999). A decision to down weight gaps to 0.25 stemmed from the assumption that each gap, irrespective of length, was a result of a single mutational event, and also due to the ambiguity surrounding their alignment (Simmons and Onchoterena, 2000; Young and Healy, 2003). The simple indel coding proposed by Simmons and Onchoterena (2000) was applied (Fig. 3.2) because it was conservative, easy to implement and highly informative in determining a correct phylogeny.

Analysis of sequence based data matrices by different methods, especially the treatment of gaps, has been demonstrated to affect the resulting phylogenetic picture (Simons and Mayden, 1977; Eernisse and Kluge, 1993; Vogler and DeSalle, 1994). CVR phylogenetic inference using NJ (uncoded dataset) and MP methods resulted in an equal number of groups, yet two of these possessed different branching patterns (Figs. 3.3 and 3.4). In distance methods, positions containing gaps are either completely deleted across all sequences under examination, a phenomenon called complete deletion, or these sites are only deleted in two sequences under comparison, termed partial deletion (Nei and Kumar, 2000). Unless a coded dataset is used and mean distances computed in PAUP*, a large proportion of the dataset is excluded with partial or complete deletions, and phylogenetic inference is only made on those positions where gaps are absent. The differences observed between the two NJ trees (Figs. 3.4 and 3.5) thus resulted from the fact that the 
datasets analyzed for phylogenetic inference were different (unequal number of sites analyzed). Similar to NJ analysis with coded data, character-based methods completely retain data and all sites are taken into consideration (including gaps). The differences observed between the MP (Fig. 3.3) and NJ tree of the coded dataset (Fig. 3.5) is likely due to the manner in which the two methods handle data and draw trees. Due to the nature of the CVR data where gap insertion was integral to sequence alignment, the phylogeny discerned by the NJ method using the coded dataset where each character was included in the search and more clusters resolved, was adopted as the correct one (Fig. 3.5).

ME results obtained using $p 72$ genotyping indicated that Zambia was the most genotype rich East African country with seven genotypes occurring within its borders (Figs. 2.2 and 2.4). Further analysis of genotype VIII viruses by CVR sequence characterization yielded eight groups designated $\mathrm{A}-\mathrm{H}$ (Figure 3.5). The CVR phylogenetic results indicate that Malawi and Zambia had an equally high diversity of CVR lineages, having five each, followed by Mozambique with two. Group A, the largest and longest circulating lineage, consists of 25 viruses (Fig. 3.5), the most historical of which is a Malawian virus recovered from an outbreak in 1978. This could favour Malawi over Zambia as possibly being the original source of genotype VIII, from where it subsequently spread to Zambia and Mozambique. Interestingly, despite the variable nature of the CVR, this region was completely conserved across group A viruses that were recovered over a period of 23 years. Group B notably had the smallest CVR aa length of all isolates examined, and was represented by a single 1986 Malawian virus named Dedza. Groups B, C and F appear to be restricted to Malawi, whilst groups D, E and $\mathrm{H}$ seem to be confined to Zambia. It was notable that Lil89/1 forming group $\mathrm{F}$ had the tetramer SAST deleted from its CVR sequence, while group D, E and H isolates possessed a unique NVGT tetramer. More extensive sampling and sequencing of genotype VIII viruses may reveal the significance of these deletions and insertions. 
The minimum positional homology could explain why viruses possessing the same types of tetramers both in equal or unequal quantities, formed different clusters, $\mathrm{A}, \mathrm{C}$ and $\mathrm{G}$ (Figs. 3.1 and 3.5; Table 3.5).

Evidence of the existence of a domestic pig cycle in East Africa was previously presented by Haresnape and Wilkinson (1989). To corroborate this, no evidence of genetically unrelated virus isolates was found in the investigation of ASF outbreaks in Malawi and Zambia, and sylvatic hosts were trivialised in the enzootic status or as sources of ASFV in new outbreaks (Sumption, 1992). It was also shown that once a sylvatic isolate was established in the pig population, it developed low tick infectivity. Sumption (1992) speculated that the low infection rates of ticks challenged with virus from pigs by natural feeding, could have been due to lost sequences of significance in the production or functioning of viral proteins essential for tick infections. This could be the reason why domestic pig cycles like that forming $p 72$ genotype VIII are established.

RFLP using BamHI endonucleases has shown that pig viruses from Malawi and Zambia were very similar genetically, while isolates from ticks of the O. moubata complex were significantly different and showed great heterogeneity among themselves (Dixon and Wilkinson, 1988; Sumption, 1992). In contrast to these findings, in this study MFUE6/1, a tick isolate from a Zambian warthog, clustered with MZI92/1, a pig isolate from Malawi by $p 72$ genotyping. Similar to the $p 72$ gene and CVR, BamHI restriction sites were found to be highly conserved as the 1953 isolate from Zambia had 23 fragments similar in mobility to the fragment patterns of recent Malawi viruses, indicating high relatedness among viruses in these two countries (Sumption, 1992). Though conserved when compared with the left and right termini of the genome, the central region contains VR4, which, like VR5, VR8a and VR8b located towards the right termini, is characterised by the presence of tandemly repeated sequence arrays (Blasco et al., 1989; Dixon et al., 1990a, b; Sumption, 1992). The genome map location and the nature of the nucleotide sequences of VR4 corresponds to the CVR 9RL - ORF's location and composition (Sumption et al., 1990; Irusta et al., 1996). 
Resolution of relationships between viruses from Malawi and Zambia by comparison of restriction fragment lengths of $\mathrm{BamHI} a$ and $\mathrm{b} / \mathrm{a}^{\prime} \mathrm{b}$ and deletion characteristics in the left terminus of the genome resulted in 6 and 7 classes of viruses, respectively (Table 3.2). These classification methods did not correspond with $p 72$ genotyping, which clustered all the isolates common to the two studies (This study and that of Sumption, 1992) into one genotype, genotype VIII, nor did they correspond with the 8 CVR subgroups in this study (Fig. 3.5; Table 3.7).

Table 3.7 Comparison of groups/subgroups of isolates common to this study and that of Sumption (1992) resolved by $p 72$ and CVR sequence, and BamHI a and b/ a'b restriction fragment analysis

\begin{tabular}{|l|l|l|l|l|}
\hline Virus & P72 genotype & CVR subgroup & BamHI a'b class & $\begin{array}{l}\text { BamHI a'b } \\
\text { subgroup }\end{array}$ \\
\hline MCH89/3 & VIII & C & I & - \\
\hline ZAW88 & VIII & G & I & - \\
\hline TEN89 & VIII & A & I & A \\
\hline YEL88 & VIII & A & I & A \\
\hline MPI88 & VIII & A & I & A \\
\hline KAL88 & VIII & G & I & A \\
\hline NKZ88 & VIII & A & I & A \\
\hline CHG88 & VIII & H & I & B \\
\hline KAV89 & VIII & D & I & B \\
\hline KLI88 & VIII & D & I & C \\
\hline NYA88 & XIV & - & - & - \\
\hline MAN89 & VIII & A & II & - \\
\hline LIL89 & VIII & F & III & - \\
\hline PHW88 & VIII & A & III & - \\
\hline MCH89/1 & VIII & A & III & A \\
\hline DOW86 & VIII & F & IV & - \\
\hline LIL89/1 & VIII & F & IV & A \\
\hline
\end{tabular}

Similar to the differences observed in genotyping viruses from different parts of Africa employing the two methods in chapter 2 (Fig. 2.2 and Table 2.2), the different sub/grouping results of Malawi and Zambia isolates could have been due to the following reasons: 
a) Classification based on two different areas of the genome i.e. VR1 found on the left and right termini and VR2 located on the left terminal side of the genome for BamHI a and b / a'b, and 9 - RL ORF located in the central part of the genome for CVR analysis.

b) The different areas under study had different sizes, with up to $9 \mathrm{~kb}$ in BamHI a and b / a'b, and $300 \mathrm{bp} / 68$ aa in CVR size differences observed.

c) BamHI a and b / a'b fragments contain multigene families 110 and 360, while CVR contains only one gene, the $9-R L O R F$.

Comparison of the two methods would be more justified if both techniques targeted the same genomic area, and if an RFLP phylogeny was available which summarised all fragment data, rather than handling it individually as was done in Sumption (1992).

In conclusion, many ASF outbreaks occurring in Malawi and Zambia of different genotypes and CVR lineages attest to the fact that there are multiple, independent introductions from persisting virus reservoirs in these countries. CVR sequence characterisation can assist in resolving intra-genotypic relationships, thereby providing epidemiological insights into the origin and spread of outbreaks. Analysis of the CVR sequence further emphasised the complexity of the disease situation in East Africa where both sylvatic and domestic pig cycles occur and where the majority of genotypes have a trans-boundary distribution (Figs.2.2 and 2.5). 


\section{Chapter 4}

\section{General discussion}

The devastating impact of outbreaks of African Swine Fever both in and outside the African continent has been cited in chapter 1. Since ASFV surface glycoproteins do not allow differentiation into serological types, assessment of field heterogeneity at the regional level in East Africa was determined for 77 viruses from eight countries, utilizing nucleotide sequences corresponding to the $\mathrm{C}$-terminal end of the $p 72$ gene. The complex epidemiological picture in East Africa was exposed, as attested by the presence of 13 genotypes in the region (Figs. 2.2 and 2.5), multiple genotypes in many of the countries, common genotypes between and among countries, and the presence of an active sylvatic cycle. New insights into the probable origin of the domestic pig cycle in West Africa was revealed by the recovery of genotype I viruses in East Africa. Due to the conserved nature of the $p 72$ gene, intra-genotypic relationships of viruses recovered from a homogeneous domestic pig associated genotype (VIII), which appears to be confined to East Africa, could not be resolved. In order to resolve relationships within this genotype, sequencing of an amino acid tetrameric repeat region located within the 9-RL Open Reading Frame (ORF), and termed the central variable region (CVR), was performed. This resolved eight discrete CVR lineages (Fig. 3.2) and allowed for identification of epidemiological links between outbreaks caused by viruses within the homogenous genotype.

According to Geering et al. (2001), risk analysis for ASF involves risk assessment, management and communication. Assessment involves the establishment of such a danger occurring, its likelihood of occurrence and potential consequences. When determining risk presence, information on the following issues is usually required: geographic distribution and incidence of the disease in the world; status of neighboring countries and if present, the closeness of the outbreak point to the border with the 
inquiring country; dissemination of the disease and the role of various formites, biological and mechanical vectors; border and barrier security issues to prevent unlawful entry of viruses; political turmoil and civil unrests in neighboring countries; trade issues with infected countries; own ASF history, possibility of the disease laying dormant in domestic and wild hosts; unlawful livestock movement within the country and pig husbandry practices.

The molecular epidemiological database created in this study can undoubtedly assist any country trading or intending to trade in pigs and pig products with East African countries, in assessing its ASF risk. Clear presence in East African countries of infected sylvatic hosts (genotypes I, V, X, XI, XII, XIII, XIV) and domestic pigs (genotypes II, VI, VIII, IX, XV, XVI), number of recorded outbreaks involving these animal species and the socio-economic costs incurred from such occurrences in the past (Chapters 1 and 2), assist in clarifying the disease situation and incidence in the region.

The likelihood of ASF occurring and its potential socio-economic consequences are governed by factors such as: likelihood of disease establishment in a country due to presence of suitable biological hosts; wildlife management; ease of disease recognition in different parts of the country; the size, distribution and type of the pig industries; threat posed to food security and income generation from exports; possibility of control or eradication, and cost of such actions (Geering et al., 2001). In the East and South African context, the likelihood of ASF establishment and far reaching economic and social consequences is very high due to the presence of all epidemiologically important factors for disease occurrence (Chapter1).

Following the confirmation of presence of danger, hazard management has to be implemented. If a concerned country intends preventing introductions or re-introduction, strict endorsement of the guidelines of the Office International Des Epizootis (OIE)'s International Animal Health Code with regards to the safe importation of domestic and wild pigs, pig meat and meat products, pig semen, embryos and ova, and other products containing pig tissues such as pharmaceuticals, must be applied. 
Adequate quarantine services must be provided to stop food and other risk factors containing pig meat or products from being delivered into the country. These should ideally be placed at international airports, seaports and border crossing points. All risk factors seized should be destroyed and disposed off by deep burial or incineration. Swill feeding, especially feed from airplanes, ships and known ASF positive areas, should be abandoned and safer methods of feeding pigs be investigated. Containment of pigs is very important as large numbers of uncontrolled pigs constitute a high risk for ASF entry and spread. These pigs have access to carcasses and offal of other pigs that may have died from the disease. Freely roaming pigs are also more likely to have contact with wildlife reservoirs of ASFV. Epidemiological knowledge of the ASF situation of neighboring countries and those with whom business is conducted, such as the one generated in this study, can greatly influence the stringency placed on the above preventative measures. Farmers should also be informed of the dangers of careless disposal of carcasses, and of allowing pigs to range freely.

Eradication of the disease is ideal and possible, and mainly involves the following actions:

1. Zoning of the country into infected, surveillance and free zones.

2. Quarantine and movement control practices

3. Immediate slaughter of the infected and in contact animals

4. Safe carcass disposal

5. Strict and effective zoo-sanitary practices

6. Observation of safe re-stocking periods

7. Epidemiological surveillance for ASF

Zones are proclaimed geographic areas in which specific disease control actions are to be carried out. These areas are classified as infected, which immediately surround the infected premises (IP) or villages, surveillance or control, surrounding the infected zones, and ASF free zones encompassing the whole country. In infected zones, the prevention of further spread through quarantine and pig movement control, elimination of the source of infection by stamping out the infected and potentially infected pigs, safe disposal of 
carcasses, decontamination of the premises and continued disease surveillance and epidemiological investigations are crucial. The entire infected zone should be under quarantine, and a complete ban on movement of pigs and their products should be implemented. Stamping out should involve all the pigs irrespective of their clinical appearance, and deep burial of carcasses is important to eliminate the source of ASFV. Contact area decontamination with effective chemical agents, or burning of informal pigsties is essential for reducing the risk of contamination of clean environments. Strict adherence to the OIE's recommended 40 days of destocking is advisable.

Disease surveillance and other epidemiological investigations should be conducted simultaneously with the above activities. For each infected herd, tracing backwards to determine the origins of any new pigs brought $3-4$ weeks prior to the outbreak, which may have been the source of infection, and tracing forwards for destinations of pigs that may have left the IP shortly before or after the outbreak, is critical. With knowledge of the different ASFV genotypes and sub-genotypes of suspect countries of origin, it would be easier to identify the real source of the ASFV. Genotyping can also give an indication of the number of outbreak viruses the authorities are dealing with as results from previous studies have indicated that different viruses can co-circulate within what appears to be a single outbreak focus (Bastos et al., 2003, 2004).

The molecular database will also be highly applicable when communicating the risk with all relevant stakeholders. It provides scientific proof of the presence of the risk and its origin and can be used to justify the management procedures proposed or implemented.

At present, there is no vaccine against ASF. However, protection of pigs that have survived infection with ASFV of mild virulence against challenge with homologous yet virulent strains has been observed (Coggins et al., 1968; DeBoer et al., 1969; Hamdy and Dardiri, 1984; Dixon et al., 1999). Boinas et al. (2004) have also observed protection of pigs that have been infected with non pathogenic and non hemeadsorbing (HAD) viruses, against challenge with pathogenic HAD viruses isolated from the same farm. Following the discovery of neutralizing antibodies against ASFV structural proteins 30, 54 and 72, 
ideas that the pig humoral immune response against ASFV depended on these proteins, were conceived (Neilan et al., 2004). Development of neutralizing antibodies against the latter proteins was shown to be important, but not enough to protect pigs against homologous virulent isolates (Neilan et al., 2004). No matter the kind of vaccination attempt, investigators all seem to agree that less effective protection is achieved when recovered pigs are challenged with a more distantly related isolate (Boinas et al., 2004; Neilan et al., 2004). Hypothetically, if an effective vaccine against African swine fever was to be developed, areas of known presence of infection would have to be zoned and the genotypes circulating identified so that each of these areas can use vaccines with relevant strains or antigens. The data generated in this study based on characterizing the gene coding for the immunodominant protein VP72, clearly indicates the number and distribution of ASFV genotypes and may therefore be extremely useful in future vaccine campaigns for the East African region.

Molecular typing of viruses is ideally aimed at providing clinically and biologically useful information about viruses, especially on tissue specificity, virulence and epidemiological issues. The extent to which virus molecular classification techniques have approached or achieved these aims varies. Genotyping techniques based on $p 72$ phylogenetic studies however, do not achieve all the aims of virus molecular typing. This is attested by viruses of different virulence, haemadsorption ability and species of origin, clustering together (Gonzague et al., 2001; Fig. 2.2; Personal communications with diagnostic specimen suppliers).

Future studies should therefore aim at whole ASFV genome sequencing, and resolution of the functions of all the ORF identified, as is the trend in DNA virus relationship studies (Lukashov and Goudsmit, 2001). Once an extensive full genome sequence database is available, genomic regions targeted for sequence analysis will be determined by the objectives of the molecular typing exercise. Classification based on biological features like receptor usage, tissue tropism or virulence will be based on sequence information of genomic areas influencing these properties (Muir et al., 1998). 
In the near future however, the accuracy of the discerned phylogenetic relationships by a one-step method warrants investigation by full length genotyping. Although useful in determining the intra-genotype relationships, the CVR cannot currently be used independently of the $p 72$ genotyping, as it cannot resolve relationships across genotypes (Bastos et al., 2004). A more variable gene than the $p 72$, but less variable to the CVR should be identified for simultaneous genotype identification and within-genotype relationship resolution.

A future research aim is to attempt to trace the route of entry of genotype I viruses from East African into West Africa. In an attempt to address this, CVR sequences of eight of the $p 72$ genotype I viruses used in this study have been generated. A sister project where the gene coding for the structural protein p54 has been sequenced for 26 viruses from East, West and South Africa, including viruses used in this study, is also in progress. The aim of this project is to determine the potential of the p54 gene to resolve ASFV relationships in a manner that is less conservative than the $p 72$ gene, but less variable than the CVR.

Disease surveillance operations are undoubtedly crucial for prevention, control and eradication. In cases of outbreaks or virus isolation from natural hosts of ASFV, a molecular epidemiological database should be available and constantly updated in order for a country to also update its outbreak contingency plans. Molecular epidemiological studies like the ASFV $p 72$ genotyping and intra-genotypic resolution by CVR provide a powerful tool for disease control and should be updated and improved on a regular basis. 


\section{REFERENCES}

AFONSO, C.L., NEILAN, J.G., KUTISH, G.F. \& ROCK, D.L., 1996. An African swine fever virus Bcl-2 homolog, 5-HL, suppresses apoptotic cell death. Journal of Virology, 70, 4858 - 4863.

AFONSO, C.L, PICCONE, M.E, ZAFFUTO, K.M., NEILAN, J., KUTISH, G.F., LU, Z., BALINSKY, C.A., GIBB, T.R., BEAN, T.J., ZSAK, L. \& ROCK, D.L., 2004. African swine fever virus multigene family 360 and 530 genes affect host interferon response. Journal of Virology, 78, 1858 - 1864.

AGÜERO, M., FERNANDEZ, J., ROMERO, L., SANCHEZ MASCARAQUE, C., ARIAS, M. \& SANCHEZ-VIZCAINO, J.M., 2003. Highly sensitive PCR assay for routine diagnosis of African swine fever virus in clinical samples. Journal of Clinical Microbiology, 41, 4431 - 4434.

AlCAMI, A., CARrascosa, A.L. \& VINUELA, E., 1989. The entry of African swine fever virus into Vero cells. Virology, 171, 68 - 75.

Allaway, E.C., CHINOMBO, D.O., EDELSTEN, R.M., HUTCHINGS, G.H. \& SUMPTION, K.J., 1995. Serological study of pigs for antibody against African swine fever virus in two areas of southern Malawi. Revue Scietifique et Technique, 14, 667 676.

ALMENDRAL, J.M., ALMAZAN, F., BLASCO, R. \& VINUELA, E., 1990.

Multigene families in African swine fever virus: family 110. Journal of Virology, 64, 2064 - 2072.

ANDERSON, E.C., HUTCHINGS, G.H., MUKARATI, N. \& WILKINSON, P.J., 1998. African swine fever virus infection of the bushpig (Potamochoerus porcus) and its significance in the epidemiology of the disease. Veterinary Microbiology, $62,1-15$.

ANDERSON, E.C., WILLIAMS, S.M., FISHER-HOCH, S.P. \& WILKINSON, P.J., 1987. Arachidonic acid metabolites in the pathophysiology of thrombocytopenia and haemorrhage in acute African swine fever. Research in Veterinary Science, 42, 387 - 394.

ANDRES, G., GARCIA-ESCUDERO, R., VINUELA, E., SALAS, M.L. \& RODRIGUEZ, J.M., 2001. African swine fever virus structural protein pE120R is 
essential for virus transport from assembly sites to plasma membrane but not for infectivity. Journal of Virology, 75, 6758 - 6768.

BAILEY, C.D. \& DOYLE, J.J., 1997. The chloroplast $r p 12$ intron and ORF184 as phylogenetic markers in the legume tribe Desmodieae. Systematic Botany, 22, 133 - 138.

BARDERAS, M.G., WIGDOROVITZ, A., MERELO, F., BEITIA, F., AlONSO, C., BORCA, M.V. \& ESCRIBANO, J.M., 2000. Serodiagnosis of African swine fever using the recombinant protein p30 expressed in insect larvae. Journal of Virological Methods, 89, 129 - 136.

BARR, J.N., WHELAN, S.P.J. \& WERTZ, G.W., 1997. Cis-acting signals involved in termination of vesicular stomatitis mRNA synthesis include the conserved AUAC and the U7 signal for polyadenylation. Journal of Virology, 71, 8718 - 8725.

BASTOS, A.D.S., PENRITH, M-L., CRUCIÈRE, C., EDRICH, J.L., HUTCHINGS, G., ROGER, F., COUACY-HYMANN, E. \& THOMSON, G.R., 2003. Genotyping field strains of African swine fever virus by partial $p 72$ gene characterization. Archives of Virology, 148, $693-706$.

BASTOS, A.D., PENRITH, M.L., MACOME, F., PINTO, F. \& THOMSON, G.R., 2004. Co-circulation of two genetically distinct viruses in an outbreak of African swine fever in Mozambique: no evidence for individual co-infection. Veterinary Microbiology, $103,169-182$.

BECKER, Y., ASHER, Y., TABOR, E., DAVIDSON, I., MALKINSON, M. \& WEISMAN, Y., 1992. Polymerase chain reaction for differentiation between pathogenic and non-pathogenic serotype 1 Marek's disease viruses (MDV) and vaccine viruses of MDV-serotypes 2 and 3. Journal of Virological Methods, 40, 307 - 322.

BERNARDES, C., VALDEIRA, M.L., RAMALHOSANTOS, J. \& DELIMA, M.C., 1995. Study of fusion and uncoating mechanisms of African swine fever virus. Molecular Biology of the Cell, 6, 1051 - 1051.

BLASCO, R., AgUERO, M., ALMENDRAL, J.M. \& VINUELA, E., 1989 a. Variable and constant regions in African swine fever virus DNA. Virology, 168, 330 338. 
BLASCO, R., de la VEGA, I., ALMAZAN, F., AGUERO, M. \& VINUELA, E., 1989 b. Genetic variation of African swine fever virus: variable regions near the ends of the viral DNA. Virology, 173, 251- 257.

BOINAS, F.S., HUTCHINGS, G.H., DIXON, L.K. \& WILKINSON, P.J., 2004.

Characterization of pathogenic and non-pathogenic African swine fever virus isolates from Ornithodoros erraticus inhabiting pig premises in Portugal. Journal of General Virology, 85, 2177 - 2187.

BOOL, P.H., ORDAS, A. \& SANCHEZ BOTIJA, C., 1970. Le diagnostic par immunofluorescence de la peste porcine africaine. Rivista Del Patronato De Biologia Animal., 14, 115 - 132.

BOOM, R., SOL, C.J., SALIMANS, M.M.M., JANSEN, C.L., WERTHEIM-VAN DILLEN, P.M.E. \& VAN DER NOORD, A.A.J., 1990. Rapid and simple method for purification of nucleic acids. Journal of Clinical Microbiology, 28, 495 - 503.

BORCA, M.V., CARRILlO, C., ZSAK, L., LAEGREID, W.W., KUTISH, G.F., NEILAN, J.G., BURRAGE, T.G. \& ROCK, D.L., 1998. Deletion of a CD2-like gene, 8-DR, from African swine fever virus affects viral infection in domestic swine. Journal of Virology, 72, 2881 - 2889.

BORCA, M.V., IRUSTA, P., CARRILLO, C., AFONSO, C.L., BURRAGE, T. \& ROCK, D.L., 1994. African swine fever virus structural protein p72 contains a conformational neutralizing epitope. Virology, 201, 413 - 418.

BORNKAMM, G.W., DELIUS, H., ZIMBER, U., HUDEWENTZ, J. \& EPSTEIN, M.A., 1980. Comparison of Epstein-Barr virus strains of different origin by analysis of the viral DNAs. Journal of Vorology, 35, 603 - 618.

BOSHOFF, C.I., BASTOS, A.D.S., GERBER, L. \& VOSLOO, W., 2004. Determination of the origin and spread of African swine fever outbreaks in southern Africa by genetic characterization of the virus (in prep)

BOTIJA, C.S., 1970. Diagnosis of African swine fever by immunofluorescence.

Bulletin Office International des Epizootis, 73, 1025 - 1044.

BOULANGER, P., BANNISTER, G.L., GREIG, A.S., GRAY， D.P. \& RUCKERBAUER, G.M., 1966. Diagnosis of African swine fever by 
immunofluorescence and other serological methods. Bulletin Office International des Epizootis, 66, 723 - 739.

BULIMO, W.D., MISKIN, J.E. \& DIXON, L.K., 2000. An ARID family protein binds to the African swine fever virus encoded ubiquitin conjugating enzyme, UBCv1. Federation of European Biochemical Societies Letters., 471, 17 - 22.

BURRAGE, T.G., LU, Z., NEILAN, J.G., ROCK, D.L. \& ZSAK, L., 2004. African swine fever virus multigene family 360 genes affect virus replication and generalization of infection in Ornithodoros porcinus ticks. Journal of Virology, 78, 2445 - 2453.

CANAls, A., OleAGA, A., PEREZ, R., DOMingueZ, J., ENCINAS, A. \& SANCHEZ-VIZCAINO, J.M., 1990. Evaluation of an enzyme-linked immunosorbent assay to detect specific antibodies in pigs infested with the tick Ornithodoros erraticus (Argasidae). Veterinary Parasitology, 37, 145 - 153.

CARRASCOSA, A.L., DEL VAL, M., SANTAREN, J.F. \& VINUELA, E., 1985. Purification and properties of African swine fever virus. Journal of Virology, 54, $337-344$.

CHEN, Y.M., TING, S.T., LEE, C.M., LIU, W.T., PAN, W.H., CHENG, A.T. \& CHOU, P., 1999. Community-based molecular epidemiology of HTLV type I in Taiwan and Kinmen: implication of the origin of the cosmopolitan subtype in northeast Asia. AIDS Research and Humun Retroviruses, 15, 229 - 237.

COGgins, L., MOUlTON, J.E. \& COLGROVE, G.S., 1968. Studies with hinde attenuated African swine fever virus. Cornell Veterinarian, 48, 525 - 540.

COSTA, J.V., 1990. African swine fever virus. In: Darai, G., (ed). Molecular biology of iridoviruses. Norwell, Mass: Kluwer Academic Publishers.

COSTAS, J., 2002. Characterization of the intragenomic spread of the human endogenous retrovirus family HERV-W. Molecular Biology and Evolution, 19, $526-533$.

COX, B.F. \& HESS, W.R., 1962. Note on an African Swine Fever Investigation in Nyasaland. Bulletin of Epizootic Diseases of Africa, 10, 439 - 440.

DE BOER, C.J., HESS, W.R. \& DARDIRI, A.H., 1969. Studies to determine the presence of neutralizing antibody in sera and kidneys from swine recovered from African swine fever. Archiv fur die Gesamte Virusforschung, 27, 44 - 54. 
DE LA VEGA, I., VINUELA, E. \& BLASCO, R., 1990. Genetic variation and multigene families in African swine fever virus. Virology, 179, 234 - 246.

DEMATOS, A.P.A. \& CARVALHO, Z.G., 1993. African swine fever virus interaction with microtubules. Biology of the Cell, 78, 229 - 234.

DETRAY, D.E., 1963. African Swine Fever. Advances in Veterinary Science, 8, 299 333.

DIXON, L.K., ABRAMS, C.C., BOWICK, G., GOATLEY, L.C., KAY-JACKSON, P.C., CHAPMAN, D., LIVERANI, E., NIX, R., SILK, R. \& ZHANG, F., 2004. African swine fever virus proteins involved in evading host defense systems. Veterinary Immunology and Immunopathology, 100, 117 - 134.

DIXON, L.K., ABRAMS, C.C., MISKIN, J.E. \& PARKHOUSE, R.M.E., 1999. African swine fever virus: can current research lead to vaccine development? Outlook on Agriculture, 28, 187 - 194.

DIXON, L.K., BRISTOW, C., WILKINSON, P.J. \& SUMPTION, K.J., 1990 a. Identification of a variable region of the African swine fever virus genome that has undergone separate DNA rearrangements leading to expansion of minisatellite-like sequences. Journal of Molecular Biology, 216, 677 - 688.

DIXON, L.K., COSTA, J.V., ESCRIBANO, J.M., ROCK, D.L., VIÑUELA, E. \& WILKINSON, P.J., 2000. Family Asfarviridae. In: VAN REGENMORTEL, M.H.V., FAUQUET, C.M., BISHOP, D.H.L., CARESTENS, E.B., ESTES, M.K., LEMON, S.M., MANILOFF, J., MAYO, M.A., MCGEOCH, D..J., PRINGLE, C.R., WICKNER, R.B.F.A., MURPHY, C.M., FAUQUET, D.H.L., BISHOP, S.A., GHABRIAL, A.W., JAVIS, G.P. \& MARTELLI, M.D., (eds). Virus taxonomy: Seventh Report of the International Committee on Taxonomy of Viruses. San Diego: Summers Academic Press. DIXON, L.K., TWIGG, S.R., BAYLIS, S.A., VYDELINGUM, S., BRISTOW, C., HAMMOND, J.M. \& SMITH, G.L., 1994. Nucleotide sequence of a $55 \mathrm{kbp}$ region from the right end of the genome of a pathogenic African swine fever virus isolate (Malawi LIL20/1). Journal of General Virology, 75, 1655 - 1684.

DIXON, L.K. \& WILKINSON, P.J., 1988. Genetic diversity of African swine fever virus isolates from soft ticks (Ornithodoros moubata) inhabiting warthog burrows in Zambia. Journal of General Virology, 69, 2981 - 2993. 
DIXON, L.K., WILKINSON, P.J., SUMPTION, K.J. \& EKUE, F., 1990 b. Diversity of the African Swine Fever Genome. In: Darai, G. (ed). Molecular Biology of Iridoviruses. Boston, U.S.A, Boston Kluwer Academic Publications.

DONALDSON, A.I. \& FERRIS, N.P., 1976. The survival of some airborne animal viruses in relation to relative humidity. Veterinary Microbiology, 1, $413-420$.

DUFFY, M., SALEMI, M., SHEEHY, N., VANDAMME, A.M., HEGARTY, J., CURRY, M., NOLAN, N., KELLEHER, D., MCKIERNAN, S. \& HALL, W.W., 2002. Comparative rates of nucleotide sequence variation in the hypervariable region of $\mathrm{E} 1 / \mathrm{E} 2$ and the NS5b region of hepatitis C virus in patients with a spectrum of liver disease resulting from a common source of infection. Virology, 301, 354 - 364.

DUKE, G.M., OSORIO, J.E. \& PALMENBERG, A.C., 1990. Attenuation of Mengo virus through genetic engineering of the 5' noncoding poly (C) tract. Nature, 343, $474-$ 476.

ECK, R. V. \& DAYHOFF, M. O. 1966. Atlas of protein sequence and structure. National Biomedical Research Foundation, Silver Spring, MD.

EDELSTEN, R.M., 1989. Report on an Investigation into the suspected African swine fever outbreak in Karonga. Livestock disease evaluation project, Lilongwe.

EDELSTEN, R.M. \& CHINOMBO, D.O., 1995. An outbreak of African swine fever in the southern region of Malawi. Revue Scientifique et Techniquwe, 14, $655-666$.

EDELSTEN, R.M., CHINOMBO, D.O. \& SOLDAN, A.W., 1991. African Swine Fever. In: Animal Health status in Malawi 1990. Livestock Disease Evaluation report, Lilongwe.

EDWARDS, A.W.F. \& CAVALLI-SFORZA, L.L., 1963. The reconstruction of evolution. Heredity, 18, 553.

EDWARDS, J.F. \& DODDS, W.J., 1985. Platelet and fibrinogen kinetics in healthy and African swine fever-affected swine [75Se]selenomethionine-labeling study. American Journal of Veterinary Reseach, 46, 181 - 184.

EERNISSE, D.J. \& KLUGE, A.G., 1993. Taxonomic congruence versus total evidence, and Amniote phylogeny inferred from fossils, molecules, and morphology. Molecular Biology and Evolution, 10, 1170 - 1195. 
EKUE, N.F. \& WILKINSON, P.J., 1990. Absence of Ornithodoros moubata, the vector of African swine fever virus, from the main pig producing area of Cameroon. Tropical Animal Health and Production, 22, 127 - 131.

EL HICHERI, K., GOMEZ-TEJEDOR, C., PENRITH, M.L., DAVIES, G., DOUATI, A., EDOUKOU, G.J. \& WOJCIECHOWSKI, K., 1998. The 1996 epizootic of African swine fever in the Ivory Coast. Revue Scientifique et Technique, 17, $660-673$.

ENDRIS, R.G., HASLETT, T.M. \& HESS, W.R., 1991. Experimental transmission of African swine fever virus by the tick Ornithodoros (Alectorobius) puertoricensis (Acari: Argasidae). Journal of Medical Entomology, 28, 854 - 858.

ENDRIS, R.G., HASLETT, T.M. \& HESS, W.R., 1992 b. African swine fever virus infection in the soft tick, Ornithodoros (Alectorobius) puertoricensis (Acari: Argasidae). Journal of Medical Entomology, 29, 990 - 994.

ENDRIS, R.G., HESS, W.R. \& CAIADO, J.M., 1992 a. African swine fever virus infection in the Iberian soft tick, Ornithodoros (Pavlovskyella) marocanus (Acari: Argasidae). Journal of Medical Entomology, 29, 874 - 878.

ESPARZA, I., GONZALEZ, J.C. \& VINUELA, E., 1988. Effect of interferon-alpha, interferon-gamma and tumour necrosis factor on African swine fever virus replication in porcine monocytes and macrophages. Journal of General Virology, 69, 2973 - 2980.

F.A.O., 1988. Production yearbook, 42, 250 - 265. Food and Agriculture Organization of the United Nations, Rome, Italy.

FELSENSTEIN, J., 1981. Evolutionary trees from DNA sequences: A Maximum likelihood Approach. Journal of Molecular Evolution, 17, 368 - 376.

FenAUX, M., halbUR, P.G., GILL, M., TOTH, T.E. \& MENG, X.J., 2000. Genetic characterization of type 2 porcine circovirus (PCV-2) from pigs with postweaning multisystemic wasting syndrome in different geographic regions of North America and development of a differential PCR-restriction fragment length polymorphism assay to detect and differentiate between infections with PCV-1 and PCV2. Journal of Clinical Microbiology, 38, 2494 - 2503. 
FIELD, D. \& WILLS, C., 1996. Long, polymorphic microsatellites in simple organisms. Proceedings of the Royal Society of London, 263, 209 - 215.

FIELD, D. \& WILLS, C., 1998. Abundant microsatellite polymorphisms in S. cerevisiae and the different distributions of microsatellites in eight prokaryotes and $\mathrm{S}$. cerevisiae results from strong mutation pressures and a variety of selection forces. Proceedings of the National Academy of Science USA, 95, 1647 - 1652.

FITCH, W.M., 1971. Toward defining the course of evolution: Minimum change for a specific tree topology. Systematic Zoology, 20, 406 - 416.

FOSTER, P.L. \& TRIMARCHI, J.M., 1994. Adaptive reversion of a frameshift mutation in Escherichia coli by simple base deletions in homopolymeric runs. Science, $265,407-409$.

GAO, G., ALVIRA, M.R., SOMANATHAN, S., LU, Y., VANDENBERGHE, L.H., RUX, J.J., CALCEDO, R., SANMIGUEL, J., ABBAS, Z. \& WILSON, J.M., 2003. Adeno-associated viruses undergo substantial evolution in primates during natural infections. Proceedings of the National Academy of Science, 100, 6081 - 6086.

GARCIA-BARRENO，B., DELGADO，T. \& MELERO，J.A., 1994. Oligo(A) sequences of human respiratory syncytial virus $G$ protein gene: assessment of their genetic stability in frameshift mutants. Journal of Virology, 68, 5460 - 5468.

GARCIA-BEATO, R., SALAS, M.L., VINUELA, E. \& SALAS, J., 1992. Role of the host-cell nucleus in the replication of African swine fever virus-DNA. Virology, 188, 637 -649 .

GATESY，J., DESALLE，R. \& WHEELER, W., 1993. Alignment-ambiguous nucleotide sites and the exclusion of systematic data. Molecular Phylogenetics and Evolution, 2, 152 - 157.

GEERING, W.A., PENRITH, M.L. \& NYAKAHUMA, D., 2001. Risk analysis for ASF. In: Manual on the preparation of African Swine Fever contingency plans. Rome, FAO.

GENOVESI, E.V., KNUDSEN, R.C., WHYARD, T.C. \& MEBUS, C.A., 1988. Moderately virulent African swine fever virus infection: blood cell changes and infective virus distribution among blood components. American Journal of Veterinary Research, 49, 338 - 344. 
GIRIBET, G. \& WHEELER, W.C., 1999. On gaps. Molecular Phylogenetics and Evolution, 13, 132 - 143.

GOATLEY, L.C., MARRON, M.B., JACOBS, S.C., HAMMOND, J.M., MISKIN, J.E., ABRAMS, C.C., SMITH, G.L. \& DIXON, L.K., 1999. Nuclear and nucleolar localization of an African swine fever virus protein, I14L, that is similar to the herpes simplex virus-encoded virulence factor ICP34.5. Journal of General Virology, 80, 525 535.

GOATLEY, L.C., TWIGG, S.R.F., MISKIN, J.E., MONAGHAN, P., ST-ARNAUD, R., SMITH, G.L. \& DIXON, L.K., 2002. The African swine fever virus protein j4R binds to the alpha chain of nascent polypeptide-associated complex. Journal of Virology, $76,9991-9999$.

GOLENBERG, E.M., CLEGG, M.T., DURBIN, M.L., DOEBLEY, J. \& MA, D.P., 1993. Evolution of a noncoding region of the chloroplast genome. Molecular Phylogenetic Evolution, 2, 52 - 64.

GOMEZ-PUERTAS, P., RODRIGUEZ, F., OVIEDO, J.M., BRUN, A., ALONSO, C. \& ESCRIBANO, J.M.,. 1998. The African swine fever virus proteins p54 and p30 are involved in two distinct steps of virus attachment and both contribute to the antibodymediated protective immune response. Virology, 243, 461 - 471.

GÓMEZ-PUERTAS, P., RODRÍGUEZ, F., OVIEDO, J. M., RAMIRO-IBÁÑEZ, F., RUIZ-GONZALVO, F., ALONSO, C. \& ESCRIBANO, J. M., 1996. Neutralizing antibodies to different proteins of African swine fever virus inhibit both virus attachment and internalization. Journal of Virology, 70, 5689 - 5694.

GONZAGUE, M., ROGER, F., BASTOS, A., BURGER, C., RANDRIAMPARANY, T., SMONDACK, S. \& CRUCIERE, C., 2001. Isolation of a non-haemadsorbing, noncytopathic strain of African swine fever virus in Madagascar. Epidemiology and Infection, 126, 453 - 459.

GONZAlez, A., CALVO, V., AlMAZAN, F., AlMENDRAL, J.M., RAMIREZ, J.C., DE LA VEGA, I., BLASCO, R. \& VINUELA, E., 1990. Multigene families in African swine fever virus: family 360. Journal of Virology, 64, 2073 - 2081. 
GONZALEZ-CANDELAS, F., BRACHO, M.A. \& MOYA, A., 2003. Molecular epidemiology and forensic genetics: application to a hepatitis $\mathrm{C}$ virus transmission event at a hemodialysis unit. Journal of Infectious Diseases, 187, 352 - 358.

GONZALEZ-JUARRERO, M., MEBUS, C.A., PAN, R., REVILlA, Y., ALONSO, J.M. \& LUNNEY, J.K., 1992. Swine leukocyte antigen and macrophage marker expression on both African swine fever virus-infected and non-infected primary porcine macrophage cultures. Veterinary Immunology and Immunopathology, 32, 243 - 259. GONZÁlez, S., MENDOZA, C., SÁNCHEZ-VIZCAINO, J.M. \& AlONSO, F., 1990. Inhibitory effect of African swine fever virus on lectin-dependent swine lymphocyte proliferation. Veterinary Immunology and Immunopathology, 26, 71 - 80.

GONZALEZ, A., TALAVERA, A., ALMENDRAL, J.M. \& VINUELA, E., 1986. Hairpin loop structure of African swine fever virus DNA. Nucleic Acids Research, 14, $6835-6844$.

GOUGH, E.J. \& GOUGH, N.M., 1984. Direct calculation of the sizes of DNA fragments separated by gel electrophoresis using programmes written for a pocket calculator. Nucleic Acids Research, 12, 845 - 853.

GRAY, W.L., STARNES, B., WHITE, M.W. \& MAHALINGAM, R., 2001. The DNA sequence of the simian varicella virus genome. Virology. 284, 123 - 130.

GROOCOCK, C.M., HESS, W.R. \& GLADNEY, W.J., 1980. Experimental Transmission of African Swine Fever Virus by Ornithodoros coriaceus, an Argasid Tick Indigenous to the United States. American Journal of Veterinary Research, 41, 591 - 594. HAMDY, F.M. \& DARDIRI, A.H., 1979. Enzyme-linked immunosorbent assay for the diagnosis of African swine fever. Veterinary Record, 105, 445 - 446.

HAMDY, F.M. \& DARDIRI, A.H., 1984. Clinical and immunologic responses of pigs to African swine fever virus isolated from the Western Hemisphere. American Journal of Veterinary Research, 45, 711 - 714.

HARESNAPE, J.M., 1984. African swine fever in Malawi Tropical Animal Health and Production, 16, 123 - 125.

HARESNAPE, J.M., LUNGU, S.A. \& MAMU, F.D., 1985. A four-year survey of African swine fever in Malawi. Journal of Hygiene (London), 95, 309 - 323. 
HARESNAPE, J.M., LUNGU, S.A. \& MAMU, F.D., 1987. An updated survey of African swine fever in Malawi. Epidemiology and Infection, 99, 723-732.

HARESNAPE, J.M. \& WILKINSON, P.J., 1989. A study of African swine fever virus infected ticks (Ornithodoros moubata) collected from three villages in the ASF enzootic area of Malawi following an outbreak of the disease in domestic pigs. Epidemiology and Infecion, 102, 507 - 522.

HARESNAPE, J.M., WILKINSON, P.J. \& MELLOR, P.S., 1988. Isolation of African swine fever virus from ticks of the Ornithodoros moubata complex (Ixodoidea: Argasidae) collected within the African swine fever enzootic area of Malawi. Epidemiology and Infection, 101, 173 - 185.

HARLEY, E.H., 1994. DAPSA. DNA and protein sequence analysis, version 2.9. Department of Chemical Pathology, University of Cape Town, South Africa.

HARRIS, M.E., MAAYAN, S., KIM, B., ZEIRA, M., FERRARI, G., BIRX, D.L. \& MCCUTCHAN, F.E., 2003. A cluster of HIV type 1 subtype C sequences from Ethiopia, observed in full genome analysis, is not sustained in subgenomic regions. AIDS Research and Human Retroviruses, 19, 1125 - 1133.

HASEGAWA, M., KISHINO, H. \& YANO, T., 1985. Dating of the human-ape splitting by a molecular clock of mitochondrial DNA. Journal of Molecular Evolution, $22,160-174$.

HAYS, S.M., 1996. African swine fever poses risk to U.S. hogs. Agricultural Research, $14-17$.

HE, B., GROSS, M. \& ROIZMAN, B., 1997. The gamma(1)34.5 protein of herpes simplex virus I complexes with protein phosphatase 1 alpha to dephosphorylate the alpha subunit of the eukaryotic translation initiation factor 2 and preclude the shutoff of protein synthesis by double-stranded RNA-activated protein kinase. Proceedings of the National Academy of Science U.S.A, 94, 843 - 848.

HE, B., GROSS, M. \& ROIZMAN, B., 1998. The gamma134.5 protein of herpes simplex virus 1 has the structural and functional attributes of a protein phosphatase 1 regulatory subunit and is present in a high molecular weight complex with the enzyme in infected cells. Journal of Biological Chemistry, 273, 20737 - 20743. 
HILLIS, D. M. 1995. Approaches for assessing phylogenetic accuracy. Systematic Biology, 44, 3 - 16.

HUELSENBECK, J. P., 1995. The robustness of two phylogenetic methods: Four taxon simulations reveal a slight superiority of maximum likelihood over neighbor joining. Molecular Biology and Evolution, 12, 843 - 849.

HUELSENBECK, J. P., 1995. Performance of phylogenetic methods in simulation. Systematic Biology, 44, 17 - 48.

IRUSTA, P.M., BORCA, M.V., KUTISH, G.F., LU, Z., CALER, E., CARRILLO, C. \& ROCK, D.L., 1996. Amino acid tandem repeats within a late viral gene define the central variable region of African swine fever virus. Virology, 220, 20 - 27.

JANIES, D. \& WHEELER, W., 1998. MALIGN version 2.7

$\mathrm{ftp} / / / \mathrm{ftp} . \mathrm{amnh}$. org/pub/people/wheeler/malign/malign.txt

JERE, F.B.D., 1991. Epidemiology of African Swine Fever with particular reference to Malwi. MSc. Dissertation, University of Edinburgh.

KIM, J., 1998. Large scale phylogenies and measuring the performance of phylogenetic estimators. Systematic Biology, 47, 43 - 60.

KLEIBOEKER, S.B., BURRAGE, T.G., SCOLES, G.A., FISH, D. \& ROCK, D.L., 1998. African swine fever virus infection in the argasid host, Ornithodoros porcinus porcinus. Journal of Virology, 72, 1711 - 1724.

KLEIBOEKER, S.B., SCOLES, G.A, BURRAGE, T.G. \& SUR, J., 1999. African swine fever virus replication in the midgut epithelium is required for infection of Ornithodoros ticks. Journal of Virology, 73, 8587 - 8598.

KLEIBOEKER, S.B. \& SCOLES, G.A., 2001. Pathogenesis of African swine fever virus in Ornithodoros ticks. Animal Health Research Review. 2, 121 - 128.

KNUDSEN, R.C. \& GENOVESI, E.V., 1987. In vivo and in vitro effects of moderately virulent African swine fever virus on mitogenesis of pig lymphocytes. Veterinary Immunology and Immunopathology, 15, 323 - 336.

KNUDSEN, R.C., GENOVESI, E.V., WHYARD, T.C. \& WOOL, S.H., 1987. Cytopathogenic effect of African swine fever virus for pig monocytes: characterization and use in microassay. Veterinary Microbiology, 14, 15 - 24. 
KUHNER, M.K. \& FELSENSTEIN, J., 1994. A simulation comparison of phylogeny algorithms under equal and unequal evolutionary rates. Molecular Biology and Evolution, $11,459-468$.

KUMAR, S., TAMURA, K., JAKOBSEN, I.B. \& NEI, M., 2001. MEGA 2. Molecular Evolutionary Genetics Analysis software, version 2.0 Pennyslavia State University, USA.

LAI, M., SCEPPA, J., BALLENGER, J.A \& DOYLE, J.J., 1997. Polymorphism for the presence of the $\mathrm{rpL} 2$ intron in chloroplast genomes of Bauhinia (Leguminosae). Systematic Botany, 22, 519 - 528.

LIN, J. \& NEI, M., 1991. Relative efficiencies of the maximum-parsimony and distancematrix methods of phylogeny construction for restriction data. Mololecular Biology and Evolution, 8, 356 - 365.

LLOYD, D.G. \& CALDER, V.L., 1991. Multi-residue gaps, a class of molecular characters with exceptional reliability for phylogenetic analysis. Journal of Evolutionary Biology, 4, 9 - 21 .

LOPEZ-OTIN, C., FREIJE, J.M., PARRA, F., MENDEZ, E. \& VINUELA, E., 1990. Mapping and sequence of the gene coding for protein $\mathrm{p} 72$, the major capsid protein of African swine fever virus. Virology, 175, 477 - 484.

LUBISI, B.A., BASTOS, A.D.S, DWARKA, R.M. \& VOSLOO, W., 2005. The Molecular Epidemiology of African Swine Fever in East Africa. Archives of Virology (in press).

LUKASHOV, V.V. \& GOUDSMIT, J., 2001. Evolutionary Relationships among Parvoviruses: Virus-Host Coevolution Among Autonomous Primate Parvoviruses and Links between Adeno - Associated and Avian Parvoviruses. Journal of Virology., 75, $2729-2740$.

MAINA, C.V., NOLAN, G.P. \& SZALAY, A.A., 1984. Molecular weight determination program. Nucleic Acids Research, 12, 695 -702.

MALMQUIST, W.A., 1962. Propagation, modification, and hemadsorption of African swine fever virus in cell cultures. American Journal of Veterinary Research, 23, 241 247.

MALMQUIST, W.A., 1963. Serologic and immunologic studies with African swine fever virus. American Journal of Veterinary Research, 24, 450 - 459. 
MALMQUIST, W.A. \& HAY, D., 1960. Haemadsorption and cytopathic effect produced by African swine fever virus in swine bone marrow and buffy coat cultures. American Journal of Veterinary Research, 21, 104 - 108.

MANSO RIBEIRO, J., ROSA AZEVEDO, J.A., TEXEIRA, M.J.O., BRACO FORTE, M.C., RODRIGUES RIBEIRO, A.M., OLIVEIRA, E., NORONHA, F., GRAVE PERREIRA, C. \& DIAS VIAGRIO, J., 1958. An atypical strain of swine fever virus in Portugal / Peste procine africaine provoquée par une souche different (Souche L) de la souche classique. Bulletin Office International des Epizootis, 50, 516 534.

MARTINS, C.L. \& LEITAO, A.C., 1994. Porcine immune responses to African swine fever virus (ASFV) infection. Veterinary Immunology and Immunopathology, 43, 99 106.

MARTINS, C.L., SCHOLL, T., MEBUS, C.A., FISCH, H. \& LAWMAN, M.J., 1987

- 1988. Modulation of porcine peripheral blood-derived macrophage functions by in vitro infection with African swine fever virus (ASFV) isolates of different virulence. Viral Immunology. 1, 177 - 190.

MATSON, B.A., 1960. An outbreak of African Swine Fever in Nyasaland. Bulletin of Epizootic Diseases of Africa, 8, 305 - 308.

MELLOR, P.S. \& WILKINSON, P.J., 1985. Experimental transmission of African swine fever virus by Ornithodoros savignyi (Audouin). Research in Veterinary Science, $39,353-356$.

MENDOZA, C., VIDEGAIN, S.P. \& ALONSO, F., 1991. Inhibition of natural killer activity in porcine mononuclear cells by African swine fever virus. Research in Veterinary Science, 51, 317 - 321.

MISKIN, J.E., ABRAMS, C.C., GOATLEY, L.C. \& DIXON, L.K., 1998. A viral mechanism for inhibition of the cellular phosphatase calcineurin. Science, 281, 562 - 565. MONTGOMERY, R.E., 1921. On a form of swine fever occurring in British East Africa (Kenya Colony). Journal of Comparative Pathology, 34, 159 - 191.

MOUlTON, J.E., PAN, I.C., HESS, W.R., DEBOER, C.J. \& TESSLER J., 1975. Pathologic features of chronic pneumonia in pigs with experimentally induced African swine fever. American Journal of Veterinary Research, 36, 27 - 32. 
MUIR, P., KAMMERER, U., KORN, K., MULDERS, M.N., POYRY, T., WEISSBRICH, B., KANDOLF, R., CLEATOR, G.M. \& VAN LOON, A,M., 1998. Molecular typing of enteroviruses: current status and future requirements. The European Union Concerted Action on Virus Meningitis and Encephalitis. Clinical Microbiology Revиe. 1998 11, 202 - 227.

NANA-NUKECHAP, M.F. \& GIBBS, E.P., 1985. Socioeconomic effects of African swine fever in Cameroon. Tropical Animal Health and Production, 17, 183 - 184.

NEI, M. \& KUMAR, S., 2000. Molecular evolution and phylogenetics. New York: Oxford University Press.

NEILAN, J.G., ZSAK, L., LU, Z., BURRAGE, T.G., KUTISH, G.F. \& ROCK. D.L., 2004. Neutralizing antibodies to African swine fever virus proteins p30, p54, and p72 are not sufficient for antibody-mediated protection. Virology, 319, 337 - 342.

NOGAL, M.L., de BUITRAGO, G.G., RODRIGUEZ, C., CUBELOS, B., CARrascoSA, A.L., SAlAS, M.L. \& REVILLA, Y., 2001. African swine fever virus IAP homologue inhibits caspase activation and promotes cell survival in mammalian cells. Journal of Virology, 75, 2535 - 2543.

NORLEY, S.G. \& WARDLEY, R.C., 1982. Complement-mediated lysis of African swine fever virus-infected cells. Immunology, 46, 75 - 82.

NORLEY, S.G. \& WARDLEY, R.C., 1983. Effector mechanisms in the pig. Antibodydependent cellular cytolysis of African swine fever virus infected cells. Research in Veterinary Science, 35, 75 - 79.

OBERSTE, M.S., MAHER, K., KILPATRICK, D.R. \& PALlANSCH, M.A., 1999. Molecular Evolution of the Human Enteroviruses: Correlation of Serotype with VP1 Sequence and Application to Picornavirus Classification. .Journal of Virology, 73, 1941 1948.

ODEMUYIWA, S.O., ADEBAYO, I.A., AMMERLAAN, W., AJUWAPE, A.T., ALAKA, O.O., OYEDELE, O.I., SOYELU, K.O., OLALEYE, D.O., OTESILE, E.B.

\& MULLER, C.P., 2000. An outbreak of African Swine Fever in Nigeria: virus isolation and molecular characterization of the VP72 gene of a first isolate from West Africa. Virus Genes, 20, 139 - 142. 
OURA, A., POWELL, P.P., ANDERSON, E. \& PARKHOUSE, R.M., 1998. The pathogenesis of African swine fever in the resistant bushpig. Journal of General Virology, 79, 1439 - 1443.

OVIEDO, J.M., RODRIGUEZ, F., GOMEZ-PUERTAS, P., BRUN, A., GOMEZ, N., ALONSO, C. \& ESCRIBANO, J.M., 1997. High level expression of the major antigenic African swine fever virus proteins p54 and p30 in baculovirus and their potential use as diagnostic reagents. Journal of Virological Methods, 64, $27-35$.

PAEZ, E., GARCIA, F. \& GIL FERNANDEZ, C., 1990. Interferon cures cells lytically and persistently infected with African swine fever virus in vitro. Archives of Virology, 112, 115 - 127.

PAN, I.C., DE BOER, C.J. \& HESS, W.R., 1972. African swine fever: application of immunoelectroosmophoresis for the detection of antibody. Canadian Journal of Comparative Medicine, 36, 309 - 316.

PENNY, D., HENDY, M.D. \& STEEL, M., 1992. Progress with methods for constructing evolutionary trees. Trends in Ecology and Evolution, 7, 73 - 79.

PENRITH, M-L., THOMSON, G.R. \& BASTOS, A.D.S., 2004. African swine fever. In: Coetzer, J.A.W. \& Tustin, R.C. (Eds.). Infectious Diseases of livestock with special reference to southern Africa $2^{\text {nd }}$ edition. Cape Town, London, New York: Oxford University Press.

PENRITH, M.L., BASTOS, A.D.S., THOMSON, G.R. \& WILKINSON, P.J., 2000. Epidemiology of African swine fever in West Africa. Proceedings of the $16^{\text {th }}$ Biennial Congress of the International Pig Veterinary Society, Melbourne Australia, 560.

PERDUE, M.L., GARCIA, M., SENNE, D. \& FRAIRE, M., 1997. Virulenceassociated sequence duplication at the hemagglutinin cleavage site of avian influenza viruses. Virus Research, 49, 173 - 186.

PHOLOGANE, S.B., BASTOS, A.D.S. \& PENRITH, M.-L., 2005. Intra- and intergenotypic size variation in the central variable region of the $9 R L$ open reading frame of diverse African swine fever viruses. Virus Genes (in press) 
PINI, A. \& HURTER, L.R., 1975. African Swine Fever: An Epizootiological Review With Special Reference To The South African Situation. Journal of the South African Veterinary Medical Association, 46, 227 - 232.

PLOWRIGHT, W., 1977. Vector Transmission of African Swine FeverVirus. In: Agriculture and Research Seminar on Hog Cholera/Classical Swine Fever and African Swine Fever. Commission of the European Communities Luxenbourgh: Office for Official Publications of the European Communities, EEC Publication.

PLOWRIGHT, W. \& PARKER, J., 1967. The stability of African swine fever virus with particular reference to heat and $\mathrm{pH}$ inactivation. Archiv fur die Gesamte Virusforschung, 21, $383-402$.

PLOWRIGHT, W., PARKER, J. \& STAPLE, R.F., 1968. The growth of a virulent strain of African swine fever virus in domestic pigs. Journal of Hygine (Lond), 66, 117 134.

PLOWRIGHT,W., PARKER, J. \& PIERCE, M.A., 1969. The Epizootiology of African Swine Fever in Africa. Veterinary Record, 85, 668 - 674.

PLOWRIGHT, W., PERRY, C.T. \& GREIG, A., 1974. Sexual transmission of African swine fever virus in the tick, Ornithodoros moubata porcinus, Walton. Research in Veterinary Science, 17, 106 - 113.

PLOWRIGHT, W., PERRY, C.T. \& PEIRCE, M.A., 1970. Transovarial infection with African swine fever virus in the argasid tick, Ornithodoros moubata porcinus, Walton. Research in Veterinary Science, 11, 582 - 584.

PLOWRIGHT, W., THOMSON, G.R. \& NESER, J.A., 1994. African swine fever. In: Coetzer, J.A.W., Thomson, G.R., Tustin, R.C. (eds). Infectious Diseases of Livestock with special reference to Southern Africa. Southern Africa: Oxford University Press.

POSADA, D. \& CRANDALL, K.A., 1998. MODELTEST:testing the model of DNA substitution. BioInformatics, 14, 817 - 818 .

POWELL, P.P., DIXON, L.K. \& PARKHOUSE, R.M.E., 1996. An I kappa B homolog encoded by African swine fever virus provides a novel mechanism for down regulation of Proinflammatory cytokine responses in host macrophages. Journal of Virology, 70, 8527 - 8533. 
RENDLEMAN, C. M. \& SPINELLI, F. J., 1999. The costs and benefits of animal disease prevention: The case of African swine fever in the U.S. Environmental Impact Assessment Review, 19, 405 - 426.

RENNIE, L, WILKINSON, P.J. \& MELLOR, P.S., 2000. Effects of infection of the tick Ornithodoros moubata with African swine fever virus. Medical and Veterinary Entomology, 14, 355 - 360.

ReVilla, Y., CAllejo, M., ROdRIGUeZ, J.M., CUlebraS, E., NOGAL, M.L., SALAS, M.L., VINUELA, E. \& FRESNO, M., 1998. Inhibition of nuclear factor kappa B activation by a virus-encoded I kappa B-like protein. Journal of Biological Chemistry, 273, 5405 - 5411.

REVILLA, Y., CEBRIAN, A., BAIXERAS, E., MARTINEZ, C., VINUELA, E. \& SALAS, M.L., 1997. Inhibition of apoptosis by the African swine fever virus bcl-2 homologue: role of the BH1 domain. Virology, 228, 400 - 404.

RODRIGUEZ, F., ALCARAZ, C., EIRAS, A., YANEZ, R.J., RODRIGUEZ, J.M., ALONSO, C., RODRIGUEZ, J.F. \& ESCRIBANO, J.M., 1994. Characterization and molecular basis of heterogeneity of the African swine fever virus envelope protein p54. Journal of Virology, 68, 7244 - 7252.

ROHN, J.L., MOSER, M.S., GWYNN, S.R., BALDWIN, D.N. \& OVERBAUGH, J., 1998. In vivo evolution of a novel, syncytium-inducing and cytopathic feline leukemia virus variant. Journal of Virology, 72, 2686 - 2696.

ROJO, G., GARCIA-BEATO, R., VINUELA, E., SALAS, M.L. \& SALAS, J., 1999. Replication of African swine fever virus DNA in infected cells. Virology, 257, 524 - 536.

ROSENBERG, S.M., LONGERICH, S., GEE, P. \& HARRIS, R.S., 1994. Adaptive mutation by deletions in small mononucleotide repeats. Science, 265, $405-407$.

SAITOU, N. \& NEI, M., 1987. The neighbor-joining method: A new method for reconstructing phylogenetic trees. Molecular Biology and Evolution, 4, 406 - 425.

SALAS, M., 1999. African Swine Fever (Asfarviridae). In: Allan Granoff, R.G.W. (Ed.). Encyclopedia of Virology. London: Academic Press.

SAMUI, K.L., NAMBOTA, A.M., MWEENE, A.S. \& ONUMA, M., 1996. African swine fever in Zambia: potential financial and production consequences for the commercial sector. Japan Journal of Veterinary Research, 44, 119 - 124. 
SANCHEZ-VIZCAINO, J.M., SLAUSON, D.O., RUIZ-GONZALVO，F. \& VALERO, F., 1981. Lymphocyte function and cell-mediated immunity in pigs with experimentally induced African swine fever. American Journal of Veterinary Research, 42, 1335 - 1341.

SANZ, A., GARCIA-BARRENO, B., NOGAL, M.L., VINUELA, E. \& ENJUANES, L., 1985. Monoclonal antibodies specific for African swine fever virus proteins. Journal of Virology, 54, 199 - 206.

SATTATH, S. \& TVERSKY, A., 1977. Additive similarity trees. Psychometrika, 42, $319-345$.

SCOTT, G.R \& HILL, D.H., 1966. Failure to detect African swine fever virus in Nigerian dwarf pigs. Bulletin of epizootic diseases of Africa, 14, 55 - 57.

SERVANT, A., LAPERCHE, S., LALLEMAND, F., MARINHO, V., DE SAINT MAUR, G., MERITET, J.F. \& GARBARG-CHENON, A., 2002. Genetic Diversity within Human Erythroviruses: Identification of Three Genotypes. Journal of Virology, 76, 9124 - 9134.

SHCHELKUNOV, S.N., TOTMENIN, A.V., SAFRONOV, P.F., MIKHEEV, M.V., GUTOROV, V.V., RYAZANKINA, O.I., PETROV, N.A., BABKIN, I.V., UVAROVA, E.A., SANDAKHCHIEV, L.S., SISLER, J.R., ESPOSITO, J.J., DAMON, I.K., JAHRLING, P.B. \& MOSS, B., 1981. Analysis of the monkeypox virus genome. Virology, 297, 172 - 194.

SIDAGIS, J., UENO, K., TOKUNAGA, M., OHYAMA, M. \& EIZURU, Y., 1997. Molecular epidemiology of Epstein-Barr virus (EBV) in EBV-related malignancies. International Journal of Cancer, 72, 72 - 76.

SILVA, R.F., 1992. Differentiation of pathogenic and non-pathogenic serotype 1 Marek's disease viruses (MDVs) by the polymerase chain reaction amplification of the tandem direct repeats within the MDV genome. Avian Diseases, 36, 521 - 528.

SIMON-MATEO, C., ANDRES, G., ALMAZAN, F. \& VINUELA, E., 1997. Proteolytic processing in African swine fever virus: evidence for a new structural polyprotein, pp62. Journal of Virology, 71, 5799 - 5804. 
SIMON-MATEO, C., ANDRES, G. \& VINUELA, E., 1993. Polyprotein processing in African swine fever virus: a novel gene expression strategy for a DNA virus. EMBO Journal, 12, 2977 - 2987.

SIMONS, A.M. \& MAYDEN, R.L., 1977. Phylogenetic relationships of creek chubs and the spine-fins: An enigmatic group of North American cyprinid fishes (Actinopterygii: Cyprinidae). Cladistics, 13, 187 - 206.

SIMMONS, M.P. \& OCHOTERENA, H., 2000. Gaps as characters in sequence-based phylogenetic analyses. Systematic Biology, 49, 369 - 381.

SLAUSON, D,O. \& SANCHEZ-VIZCAINO, J.M., 1981. Leukocyte-dependent platelet vasoactive amine release and immune complex deposition in African swine fever. Veterinary Pathology, 18, 813 - 826.

SOURDIS, J. \& NEI, M., 1988. Relative efficiencies of the maximum parsimony and distance-matrix methods in obtaining the correct phylogenetic tree.

Molecular Biology and Evolution, 5, 298 - 311.

STEIGER, Y., ACKERMANN, M., METTRAUX, C. \& KIHM, U., 1992. Rapid and biologically safe diagnosis of African swine fever virus infection by using polymerase chain reaction. Journal of Clinical Microbiology, 30, 1 - 8.

STRYER, L., 1988. Exploring genes: Analysing, constructing and cloning DNA. In: Biochemistry. Stanford University, New York: W.H Freeman and Company

SUMPTION, K. J., 1992. Genetic comparison of African swine fever virus isolates from Zambia and Malawi. Doctor of Philosophy Thesis, University of Reading, U.K.

SUMPTION, K.J., HUTCHINGS, G.H., WILKINSON, P.J. \& DIXON, L.K., 1990. Variable regions on the genome of Malawi isolates of African swine fever virus. Journal of General Virology, 71, 2331 - 2340.

SWOFFORD, D.L., 1998. PAUP: phylogenetic analysis using parsimony (and other methods). Sinauer, Sunderland, Mass.

SWOFFORD, D. L., OLSEN, G. J., WADDELL, P. J. \& HILLIS, D. M., 1996. Phylogenetic inference. In: Hillis, D.M. \& Moritz, C., (eds). Molecular Systematics, 2nd edn. Massachusetts: Sinauer Associates Inc. 
TABARES, E., MARTINEZ, J., RUIZ GONZALVO, F. \& SANCHEZ-BOTIJA, C., 1980. Proteins specified by African swine fever virus. II. Analysis of proteins in infected cells and antigenic properties. Archives of Virology, 66, 119 - 132.

TAKEZAKI, N., 1998. Tie trees generated by distance methods of phylogenetic reconstruction. Molecular Biology and Evolution, 15, 727 - 737.

TAMURA, K. \& NEI, M., 1993. Estimation of the number of nucleotide substitutions in the control region of mitochondrial DNA in humans and chimpanzees. Molecular Biology and Evolution, 10, 512 - 526.

TANAKA, H., REN, F., OKAYAMA, T. \& GOJOBORI, T., 1997. Inference of molecular phylogenetic tree based on minimum model-based complexity method. Proceedings of the International Conference on Intell. Systematics and Molecular Biology, 5, 319 - 328.

TAUTZ, D. \& SCHLOTTERER, C., 1994. Simple sequences. Current Opinion in Genetics and Development, 4, $832-837$.

THOMSON, G.R., 1985. The Epidemiology of African Swine Fever: The role of FreeLiving Hosts in Africa. Onderstepoort Journal of Veterinary Research, 52, $201-209$.

TULMAN, E.R. \& ROCK, D.L., 2001. Novel virulence and host range genes of African swine fever virus. Current Opinion in Microbiology, 4, 456 - 461.

TURNBULL, D.O., 1933. Nyasaland Annual Report of the Veterinary Department, 1932.

UMENE, K., WATSON, R.J. \& ENQUIST, L.W., 1984. Tandem repeated DNA in an intergenic region of herpes simplex virus type 1 (Patton). Gene, 30, 33 - 39.

VALDEIRA, M.L., BERNARDES, C., CRUZ, B. \& GERALDES, A., 1998. Entry of African swine fever virus into Vero cells and uncoating. Veterinary Microbiology, 60, $131-140$.

VANDERHALLEN, H., MITTELHOLZER, C., HOFMANN, M.A., KOENEN, F. \& MITTELHOZER, C., 1999. Classical swine fever virus is genetically stable in vitro and in vivo. Archives of Virology, 144, 1669 - 1677. 
VAN DIJK, M.A., PARADIS, E., CATZEFLIS, F. \& DE JONG, W.W., 1999. The virtues of gaps: xenarthran (Edentate) monophyly supported by a unique deletion in alpha A-crystallin. Systematic Biology, 48, 94 - 106.

VOGLER, A.P. \& DESALLE, R., 1994. Evolution and phylogenetic information content of the ITS-1 region in the tiger beetle Cicindela dorsalis. Molecular Biology and Evolution, 11, 393 - 405.

WALKER, A., PETHERAM, S.J., BALLARD, L., MURPH, J.R., DEMMLER, G.J. \& BALE, J.F., 2001.Characterization of human cytomegalovirus strains by analysis of short tandem repeat polymorphisms. Journal of Clinical Microbiology, 39, 2219 - 2226.

WARDLEY, R.C., 1982. Effect of African swine fever on lymphocyte mitogenesis. Immunology, 46, 215 - 220.

WARDLEY, R.C., DE MANDRADE, C., BLACK, D.N., DE CASTRO PORTUGAL，F.L., ENJUANES, L., HESS, W.R., MEBUS, C., ORDAS, A., RUTILI, D., SANCHEZ VIZCAINO, J., VIGARIO, J.D., WILKINSON, P.J., MOURA NUNES, J.F. \& THOMSON, G., 1983. African Swine Fever virus. Brief review. Archives of Virology, 76, 73-90.

WARDLEY, R.C., NORLEY, S.G., MARTINS, C.V. \& LAWMAN, M.J., 1987. The host response to African swine fever virus. Progress in Medical Virology, 34, 180 - 192.

WARDLEY, R.C. \& WILKINSON, P.J., 1977. The association of African swine fever virus with blood components of infected pigs. Archives of Virology, 55, 327 - 334.

WARDLEY, R.C. \& WILKINSON, P.J., 1980. Lymphocyte responses to African swine fever virus infection. Research in Veterinary Science, 28, 185 - 189.

WARDLEY, R.C. \& WILKINSON, P.J., 1985. An immunological approach to vaccines against African swine fever virus. Vaccine, 3, 54 - 56.

WEINGARTL, H.M., SABARA, M., PASICK, J., VAN MOORLEHEM, E. \& BABIUK, L., 2002. Continuous porcine cell lines developed from alveolar macrophages: partial characterization and virus susceptibility. Journal of Virological Methods, 104, 203 $-216$.

WESLEY, R.D. \& PAN, I.C., 1982. African swine fever virus DNA: restriction endonuclease cleavage patterns of wild - type, Vero cell-adapted and plaque-purified virus. Journal of General Virology, 63, 383 - 391. 
WESLEY, R.D. \& TUTHILL, A.E., 1984. Genome relatedness among African swine fever virus field isolates by restriction endonuclease analysis. Preventative Veterinary Medicine, 2, 53 - 62 .

WHEELER, W.C., 1994. Sources of ambiguity in nucleic acid sequence alignment. In: Schierwater, B., Wagner, G.P. \& DeSalle, R., (eds). Molecular ecology and evolution, Basel: Birkhauser Verlag.

WILKINSON, P.J., 1989. African Swine Fever. In: Pensaert, M.B (ed). Virus Infections of Porcines, Amsterdam: Elsevier Science Publishers.

WILKINSON, P.J., PEGRAM, R.G., PERRY, B.D., LEMCHE, J. \& SCHELS, H.F., 1988. The distribution of African swine fever virus isolated from Ornithodoros moubata in Zambia. Epidemiology and Infection, 101, 547 - 564.

YAMASHITA, M., VERONESI, R., MENNA-BARRETO, M., HARRINGTON, W.J., SAMPIO, C., BRITES, C., BADARO, R., ANDRADE-FILHO, A.S., OKHURA, S., IGARASHI, T., TAKEHISA, J., MIURA, T., CHAMONE, D., BIANCHINI, O., JARDIM, C., SONODA, S. \& HAYAMI, M., 1999. Molecular epidemiology of human T-cell leukemia virus type I (HTLV-1) Brazil: the predominant HTLV-1s in South America differ from HTLV-ls of Japan and Africa, as well as those of Japanese immigrants and their relatives in Brazil. Virology, 261, 59 - 69.

YAMADA, N., TANIHARA, K., TAKADA, A., YORIHUZI, T., TSITSUMI, M., SHIMOMURA, H., TSUJI, T. \& DATE, T., 1996. Genetic organization and diversity of the 3' noncoding region of the hepatitis C virus genome. Virology, 223, 255 - 261.

YÁÑEZ, R.J., RODRIGUEZ, J.M., NOGAL, M.L., YUSTE, L., ENRIQUEZ, C., RODRIGUEZ, J.F. \& VINUELA, E., 1995. Analysis of the complete nucleotide sequence of African swine fever virus. Virology, 208, 249 - 278.

YOUNG, N.D. \& HEALY, J., 2003. GapCoder automates the use of indel characters in phylogenetic analysis. BMC Bioinformatics, 4

YOZAWA, T., KUTISH, G.F., AFONSO, C.L., LU, Z. \& ROCK, D.L., 1994.

Two novel multigene families, 530 and 300, in the terminal variable regions of African Swine Fever virus genome. Virology, 202, 997 - 1002. 
YU, M., MORRISY, C.J. \& WESTBURY, H.A., 1996. Strong sequence conservation of African swine fever virus p72 protein provides the molecular basis for its antigenic stability. Archives of Virology, 141, 1795 - 1802.

ZHENG, D.P., ZHOU, Y.M., ZHAO, K., HAN, Y.R. \& FREY, T.K., 2003. Characterization of genotype II Rubella virus strains. Archives of Virology, 148, $1835-1850$.

ZHU, G.S., OJIMA, T., HIRONAKA, T., IHARA, T., MIZUKOSHI, N., KATO, A., UEDA, S. \& HIRAI, K., 1992. Differentiation of oncogenic and nononcogenic strains of Marek's disease virus type 1 by using polymerase chain reaction DNA amplification. Avian Diseases, 36, 637 - 645.

ZSAK, L., CALER, E., LU, Z., KUTISH, G.F., NEILAN, J.G. \& ROCK, D.L., 1998. A nonessential African swine fever virus gene UK is a significant virulence determinant in domestic swine. Journal of Virology, 72, 1028 - 1035.

ZSAK, L., LU, Z., BURRAGE, T.G., NEILAN, J.G., KUTISH, G.F., MOORE, D.M. \& ROCK, D.L., 2001. African swine fever virus multigene family 360 and 530 genes are novel macrophage host range determinants. Journal of Virology, 75, 3066 - 3076.

ZSAK, L., LU, Z., KUTISH, G.F., NEILAN, J.G. \& ROCK, D.L., 1996. An African swine fever virus virulence-associated gene NL-S with similarity to the herpes simplex virus ICP34.5 gene. Journal of Virology, 70, 8865 - 8871.

ZSAK, L., ONISK, D.V., AFONSO, C.L. \& ROCK, D.L., 1993. Virulent African swine fever virus isolates are neutralized by swine immune serum and by monoclonal antibodies recognizing a 72-kDa viral protein. Virology. 196, 596 - 602. 


\section{APPENDIX}

\section{A. Dextran 10\% - PLASMA VOLUME EXPANDER}

$\mathrm{NaCl}$

Double Distilled Water

Dextran 150 (BDH Laboratory Supplies \# 38108 2M)

$\mathrm{NaCl} 0.9 \%$
$9 \mathrm{~g}$

$1000 \mathrm{ml}$

$10 \mathrm{~g}$

$100 \mathrm{ml}$

Make $0.9 \% \mathrm{NaCl}$ by adding $9 \mathrm{~g} \mathrm{NaCl}$ to $1000 \mathrm{ml}$ double distilled water. Shake well and autoclave.

Add 10 g Dextran 150 to $100 \mathrm{ml} \mathrm{NaCl}$ and mix thoroughly.

\section{B. WASH BUFFER}

Phosphate buffered saline (PBS)

$1 \mathrm{~L}$

Penicillin

Streptomycin

Neomycin

Normal bovine serum (NBS).
$0.4 \%$

$0.64 \%$

$0.75 \%$

$1 \%$

Add all ingredients to 1 L PBS and mix thoroughly.

\section{AMMONIUM CHLORIDE $(0.82 \%)$}

$\mathrm{KCl}$

$\mathrm{NH}_{4} \mathrm{Cl}$

Double distilled water

\section{$0.37 \mathrm{~g}$}

$8.2 \mathrm{~g}$

$1 \mathrm{~L}$

Mix the above constituents and add $\mathrm{NaHCO}_{3}(4.4 \%)$ to adjust $\mathrm{pH}$ to 7.4

Autoclave the solution. 


\section{HEPES}

Hepes

Distilled water

Mix, filtrate or autoclave, and store at $+4^{\circ} \mathrm{C}$.

\section{E. EARLE'S SALINE X2}

$\mathrm{NaCl}$

$13.6 \mathrm{~g}$

KCI (Merck 104936)

$0.8 \mathrm{~g}$

(UNILAB 504200)

$\mathrm{MgSO}_{4}$ (Merck 5886)

$0.4 \mathrm{~g}$

Glucose (Merck 8337)

$2.0 \mathrm{~g}$

$\mathrm{NaH}_{2} \mathrm{PO}_{4} \cdot 2 \mathrm{H}_{2} \mathrm{O}$ (UNILAB 758516)

$0.31 \mathrm{~g}$

$\mathrm{CaCl}_{2}$ $0.4 \mathrm{~g}$

$\mathrm{NaHCO}_{3}($ Merck 6329) $4.4 \mathrm{~g}$

Double Distilled Water $1 \mathrm{~L}$

1\% Phenol Red solution

Mix the above. Spin to dissolve and then filtrate with a $0.22 \mu$ filter and store at $+4^{\circ} \mathrm{C}$

\section{F. GROWTH MEDIUM}

Distilled water

Earle's medium

Hepes (UniLab)

Swine serum (Highveld Biological)

Penicillin (Sigma)
$42 \%$

$42 \%$

$0.4 \%$

$13 \%$

$0.52 \%$ 
Streptomycin (Sigma)

Neomycin (Merck)

Add all ingredients and mix.

\section{G. SILICA}

Double distilled water

$100 \mathrm{ml}$

Silicon dioxide $99 \%$ (Sigma)

$\mathrm{HCl}(32 \% \mathrm{wt} / \mathrm{vol})$ (Merck)
$6 \mathrm{~g}$

$60 \mu 1$
$0.832 \%$

$0.975 \%$

- Perform all steps in treated glass and wear gloves.

- Suspend $6 \mathrm{~g}$ of silicon dioxide $99 \%$ (Sigma) in a $50 \mathrm{ml}$ volume of sterile $\mathrm{ddH}_{2} \mathrm{O}$ in a $50 \mathrm{ml}$ glass cylinder and allow to sediment for 24 hours at room temperature.

- Remove $43 \mathrm{ml}$ of the supernatant portion by suction with a pipette-aid.

- Add sterile $\mathrm{ddH}_{2} \mathrm{O}$ to the measuring cylinder so that a final volume of $50 \mathrm{ml}$ is obtained.

- Resuspend the silica pellet by vigorous shaking.

- Allow a second sedimentation for 5 hours at room temperature.

- Remove $44 \mathrm{ml}$ of the supernatant and add $60 \mu \mathrm{l}$ of $\mathrm{HCl}$ (32\% wt/vol) (Merck) in order to adjust to $\mathrm{pH} 2$.

\section{H. L6 LYSIS BUFFER}

Guanidine Thiocyanate (GuSCN- Promega)

$60 \mathrm{~g}$

Tris-HCL $(0.1 \mathrm{M})$

EDTA $(0.2 \mathrm{M})$

$50 \mathrm{ml}$

Triton X-100 (Roche)

$11 \mathrm{ml}$

$1.3 \mathrm{~g}$

- Dissolve $60 \mathrm{~g}$ of Guanidine Thiocyanate (GuSCN- Promega) in $50 \mathrm{ml}$ of $0.1 \mathrm{M}$ TrisHCL (pH 6.4).

- Add $11 \mathrm{ml}$ of 0.2 M EDTA solution and $1.3 \mathrm{~g}$ of Triton X-100 (Roche) 
- Place at $50^{\circ} \mathrm{C}$ until completely in solution.

- Wrap in foil and store at room temperature.

\section{L2 WASH BUFFER}

Guanidine Thiocyanate (GuSCN- Promega)

$60 \mathrm{~g}$

Tris-HCL $(0.1 \mathrm{M})$

$50 \mathrm{ml}$

Dissolve $60 \mathrm{~g} \mathrm{GuSCN}$ (Promega) in $50 \mathrm{ml}$ of $0.1 \mathrm{M}$ Tris-HCL (pH 6.4) by placing at $50^{\circ} \mathrm{C}$.

Wrap in foil and store at room temperature.

\section{J. 1 x TE}

Double distilled water $\left(\mathrm{ddH}_{2} \mathrm{O}\right)$

Tris- $\mathrm{HCl}(1 \mathrm{M})$

EDTA (1M)

$$
\begin{aligned}
& 100 \mathrm{ml} \\
& 1 \mathrm{ml} \\
& 1 \mathrm{ml}
\end{aligned}
$$

Add the $1 \mathrm{M}$ Tris- $\mathrm{HCl}(\mathrm{pH} 7.4)$ and $1 \mathrm{M}$ EDTA $(\mathrm{pH} 8.0)$ to the $\mathrm{ddH}_{2} \mathrm{O}$ and mix, then autoclave. 